\title{
Multi-Application Small Light Water Reactor Final Report
}

S. M. Modro

J. E. Fisher

K. D. Weaver

J. N. Reyes, Jr.

J. T. Groome

P. Babka

T. M. Carlson

December 2003

Idaho National Engineering and Environmental Laboratory Bechtel BWXT Idaho, LLC 


\title{
Multi-Application Small Light Water Reactor Final Report
}

\author{
S. Michael Modro \\ James E. Fisher \\ Kevan D. Weaver \\ Jose N. Reyes, Jr. (OSU) \\ John T. Groome (OSU) \\ Pierre Babka (NEXANT) \\ Thomas M. Carlson (NEXANT)
}

December 2003

Idaho National Engineering and Environmental Laboratory Idaho Falls, Idaho 83415

Prepared for the

U.S. Department of Energy

Office of Nuclear Energy, Science \& Technology

Under DOE Idaho Operations Office

Contract DE-AC07-99ID13727 


\section{Final Report \\ Multi-Application Small Light Water Reactor \\ DOE Nuclear Energy Research Initiative Program}

\section{Executive Summary}

The Multi-Application Small Light Water Reactor (MASLWR) project was conducted under the auspices of the Nuclear Energy Research Initiative (NERI) of the U.S. Department of Energy (DOE). The primary project objectives were to develop the conceptual design for a safe and economic small, natural circulation light water reactor, to address the economic and safety attributes of the concept, and to demonstrate the technical feasibility by testing in an integral test facility. This report presents the results of the project.

After an initial exploratory and evolutionary process, as documented in the October 2000 report, the project focused on developing a modular reactor design that consists of a self-contained assembly with a reactor vessel, steam generators, and containment. These modular units would be manufactured at a single centralized facility, transported by rail, road, and/or ship, and installed as a series of self-contained units. This approach also allows for staged construction of an NPP and "pull and replace" refueling and maintenance during each five-year refueling cycle.

Development of the baseline design concept has been sufficiently completed to determine that it complies with the safety requirements and criteria, and satisfies the major goals already noted. The more significant features of the baseline single-unit design concept include:

- Thermal Power

- Net Electrical Output

- Steam Generator Type

- Fuel $\mathrm{UO}_{2}, 8 \%$ enriched

- Refueling Intervals

- Life-Cycle
$150 \mathrm{MWt}$

$35 \mathrm{MWe}$

Vertical, helical tubes

5 years

60 years

The economic performance was assessed by designing a power plant with an electric generation capacity in the range of current and advanced evolutionary systems. This approach allows for direct comparison of economic performance and forms a basis for further evaluation, economic and technical, of the proposed design and for the design evolution towards a more cost competitive concept. Applications such as cogeneration, water desalination or district heating were not addressed directly in the economic analyses since these depend more on local conditions, demand and economy and can not be easily generalized. Current economic performance experience and available cost data were used. The preliminary cost estimate, based on a concept that could be deployed in less than a decade, is shown below.

- Net Electrical Output

- Net Station Efficiency

- Number of Power Units

- Nominal Plant Capacity Factor

- Total capital cost

- Total busbar cost
$1050 \mathrm{MWe}$

$23 \%$

30

$95 \%$

$\$ 1241 / \mathrm{kWe}$

3.4 cents/kWh 
A diagram depicting the MASLWR concept is shown in Figure 1. The unique features of the concept are:

- The reactor core and the steam generator tube bundles are located in a common primary vessel; as a result, there is no piping connecting the steam generator with the reactor.

- Buoyancy forces provide the driving head for primary coolant flow and there is no rotating equipment in the primary system.

- The primary vessel is located in a steel containment vessel which in turn is submersed in water, thus providing an effective passive ultimate heat sink..

- The entire module is removed every 5 years for refueling and maintenance and immediately replaced with a refurbished module. The removed module is moved under water to the adjacent refueling and maintenance facility.

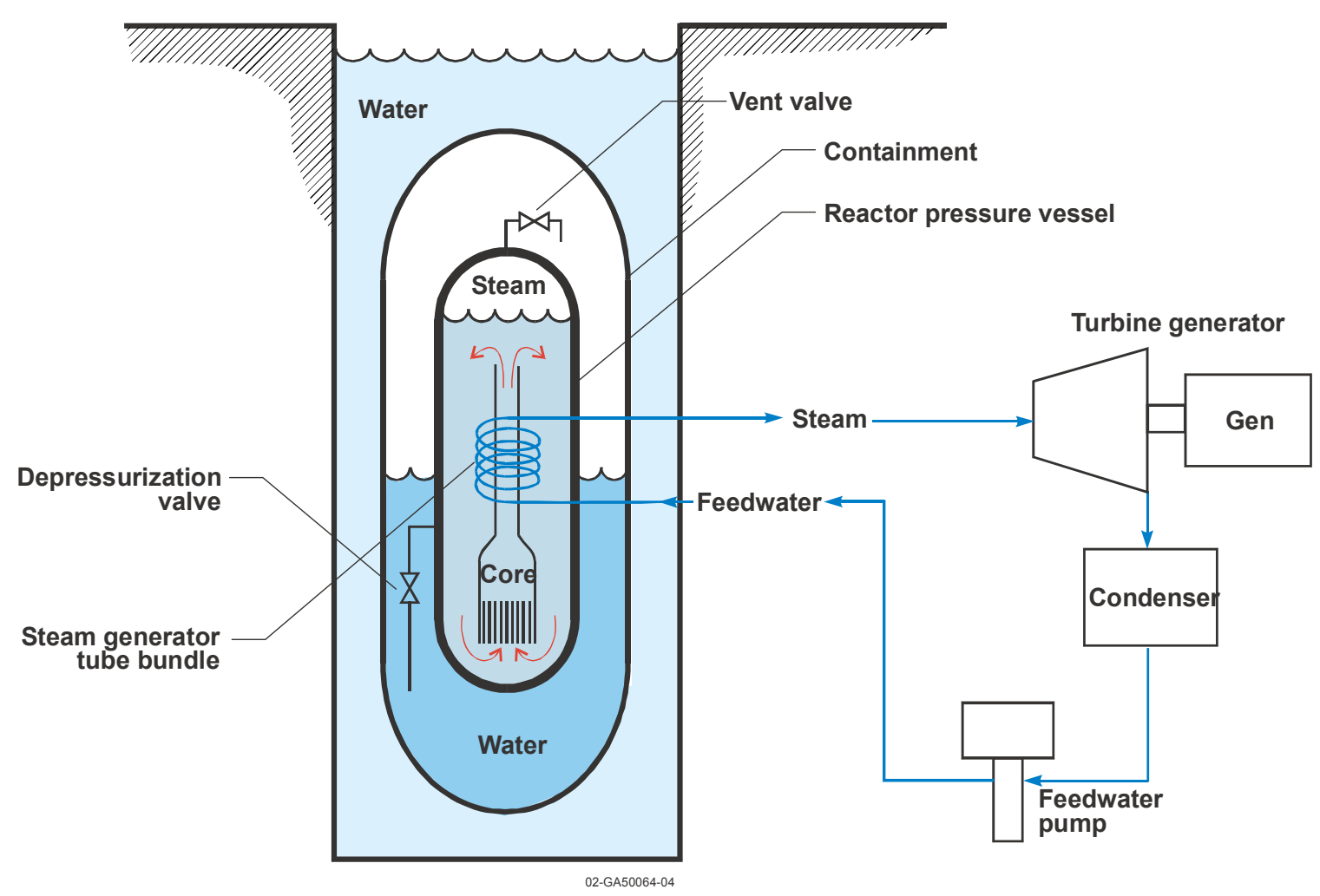

Figure 1. MASLWR Baseline Design Concept.

A three-dimensional view of a single power generation unit is shown in Figure 2. The unit consists of three basic modules: the reactor module, which includes the primary vessel with the reactor and the steam generator, and the containment vessel, the turbine generator module and

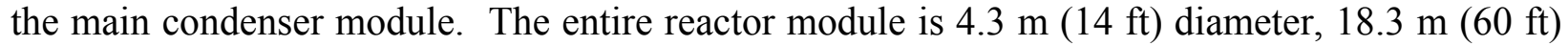
long and weighs 275 mtons (303 tons), which allows it to be entirely shop fabricated and transported to site on most railways or roads. A general view of the MASLWR baseline plant is shown in Figure 3. The baseline plant consists of 30 power generation units. However, smaller plants with as few as a single power generation unit can be built if desired. 


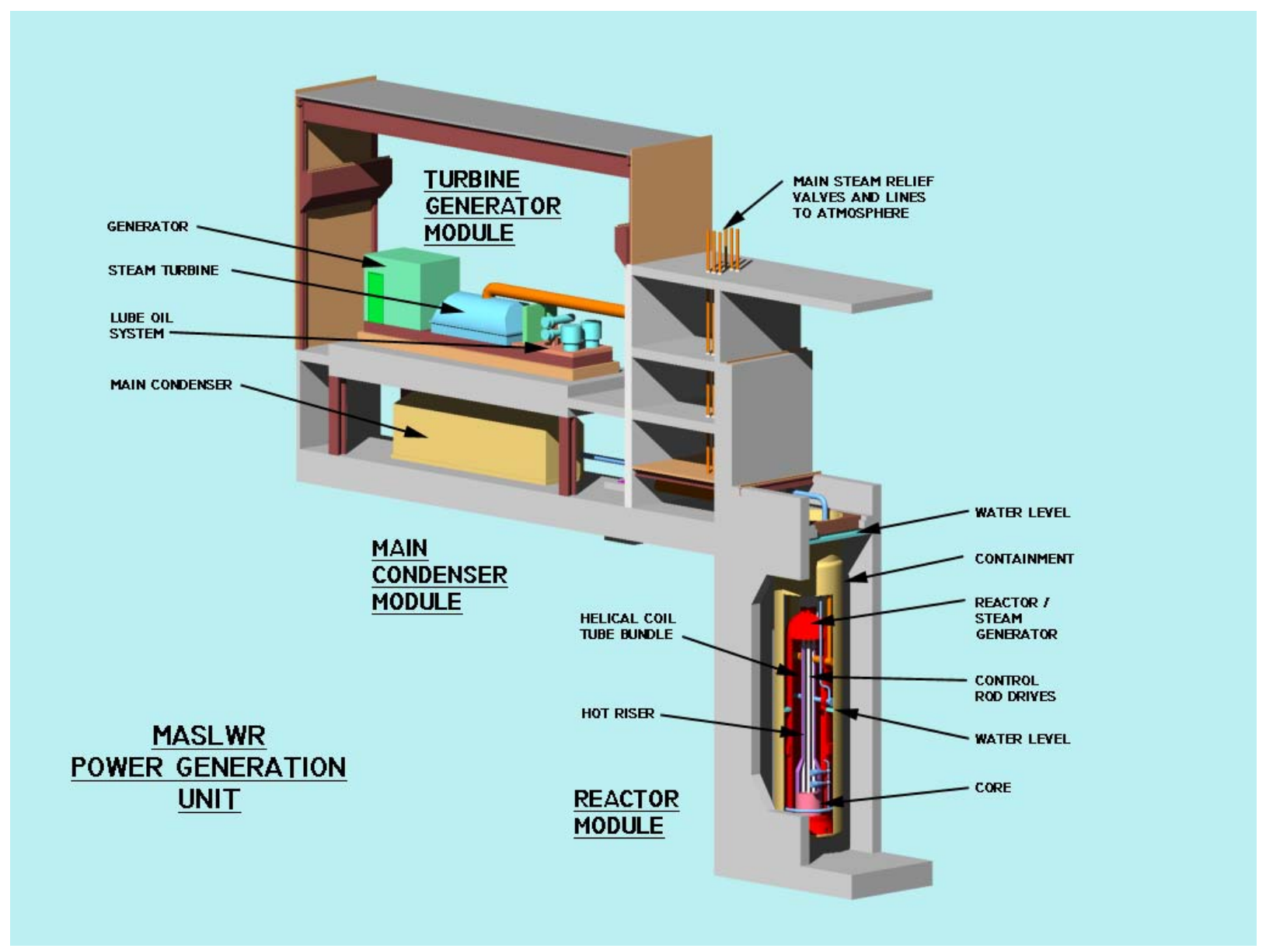

Figure 2. Power Generation Unit

The project includes a testing program that has been conducted at Oregon State University (OSU). The test facility is a $1 / 3$-height and $1 / 254.7$ volume scaled design that will operate at full system pressure and temperature, and will be capable of operation at $600 \mathrm{~kW}$. The design and construction of the facility have been completed. Testing is scheduled to begin in October 2002.

The MASLWR conceptual design is simple, safe, and economical. It operates at NSSS parameters much lower than for a typical PWR plant, and has a much simplified power generation system. The individual reactor modules can be operated as on/off units, thereby limiting operational transients to startup and shutdown. In addition, a plant can be built in increments that match demand increases. The "pull and replace" concept offers automation of refueling and maintenance activities. Performing refueling in a single location improves proliferation resistance and eliminates the threat of diversion. Design certification based on testing is simplified because of the relatively low cost of a full-scale prototype facility. The overall conclusion is that while the efficiency of the power generation unit is much lower $(23 \%$ versus $30 \%$ ), the reduction in capital cost due to simplification of design more than makes up for the increased cost of nuclear fuel. 
The design concept complies with the safety requirements and criteria. It also satisfies the goals for modularity, standard plant design, certification before construction, construction schedule, refueling schedule, operation and maintenance, long plant life-cycle, and economics.

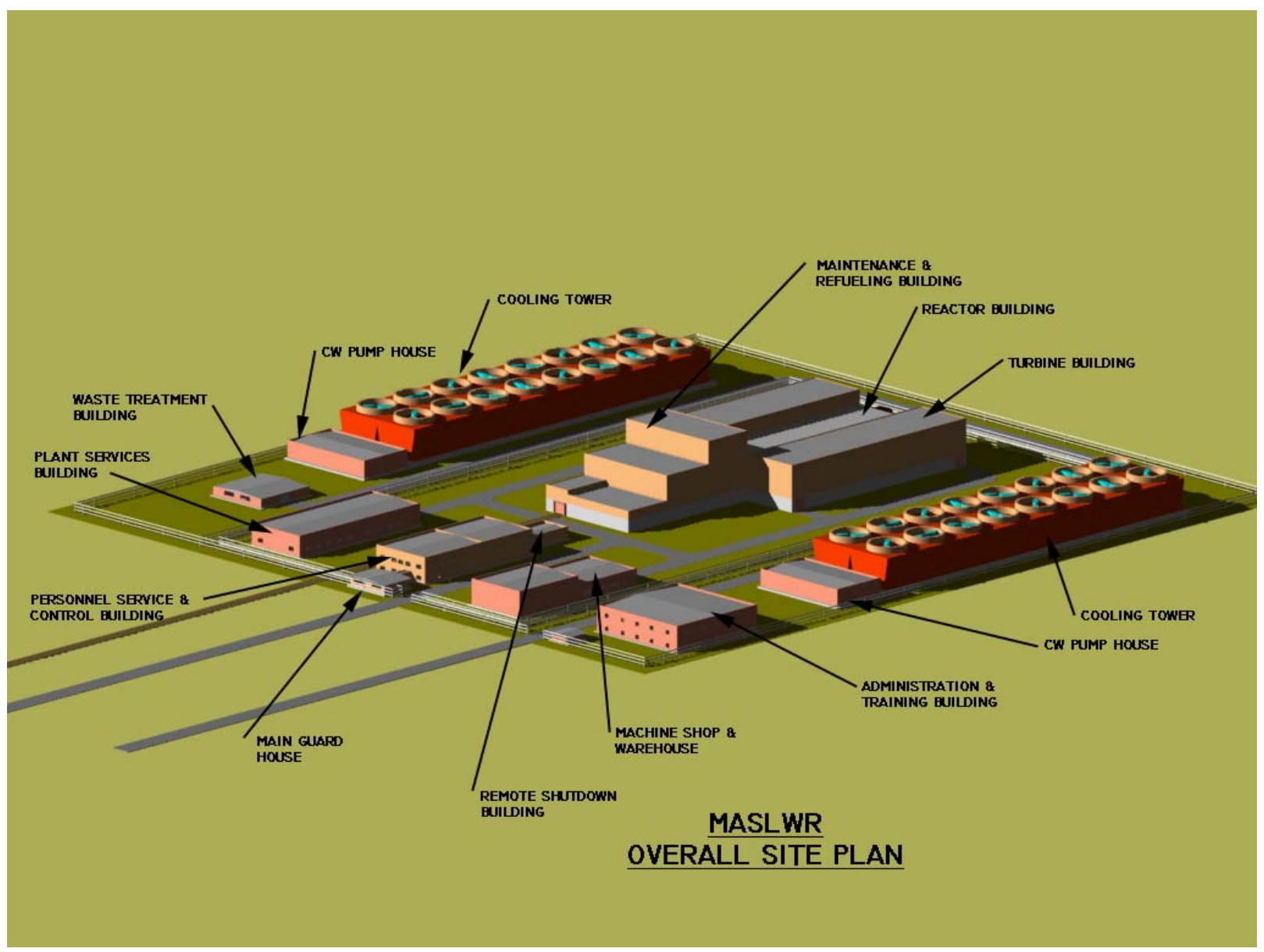

Figure 3. MASLWR Power Plant View 


\section{Acknowledgments}

The MASLWR project was conducted by three principal organizations: INEEL, OSU and NEXANT. Contributors to this project and their organizational affiliations are:

NEXANT, Inc.; San Francisco, CA

Mr. Pierre Babka

Mr. Thomas Carlson

Mr. Lody Glasmacher

Mr. Sherman May

Mr. Robert Nicaise (Framatome)

Mr. Eugene Onopko

Mr. William Schneider (B\&W)

Mr. James Waugh

Mr. Jean-Claude Yazidjian (Framatome)
Oregon State University; Corvallis, OR Prof. Jose N. Reyes, Jr.

Mr. John Groome

Dr. Abd Lafi

Mr. Chal Davidson

Mr. Brandon Haugh

Mr. Eric Young

Mr. Yeon-Jung Yoo

Mr. You Yao

Mr. Aleksy Resvi

Idaho National Engineering and Environmental Laboratory; Idaho Falls, ID

Mr. James Fisher

Mr. S. Michael Modro

Dr. Kevan Weaver 


\begin{tabular}{|c|c|}
\hline & \\
\hline BOL & Beginning- of Life \\
\hline CS & Control System \\
\hline CFR & Code of Federal Regulations \\
\hline DAS & Data Acquisition System \\
\hline DI & Demineralization System \\
\hline DOE & Department of Energy \\
\hline DP & Differential Pressure \\
\hline EEDB & Energy Economic Data Base \\
\hline EPRI & Electrical Power Research Institute \\
\hline FMM & Magnetic Flow meter \\
\hline FM & Flow meter \\
\hline FW & Feed Water \\
\hline FWP & Feed Water pump \\
\hline FW ST & Feed Water Storage Tank \\
\hline HTR & Heater \\
\hline INEEL & Idaho National Engineering and Environmental Laboratory \\
\hline LDP & Differential pressure level \\
\hline LOCA & Loss of coolant accident \\
\hline $\mathbf{L P}$ & Lower Plenum \\
\hline LWR & Light water reactor \\
\hline MASLWR & Multi-Application Small Light Water Reactor \\
\hline MCNP & Monte Carlo N-Particle Transport Code \\
\hline MOCUP & MCNP ORIGEN2 Coupled Utility Program \\
\hline MOS & Main operating screen \\
\hline MOV & Motor operating valve \\
\hline NC & Natural Circulation \\
\hline NERI & Nuclear Energy Research Initiative \\
\hline NI & Nuclear Island \\
\hline NRC & Nuclear Regulatory Commission \\
\hline NSA & Non-Safety Area \\
\hline NSSS & Nuclear Steam Supply System \\
\hline ORIGEN & Oak Ridge Isotope Generation and Depletion Code \\
\hline OSU & Oregon State University \\
\hline PCT & Peak cladding temperature \\
\hline PLC & Programmable Logic Controller \\
\hline PRZ & Pressurizer \\
\hline PT & Pressure transducer \\
\hline P steam & Steam pressure \\
\hline PWR & Pressurized water reactor \\
\hline P 1C & Pressure in the primary circuit (in the PRV) \\
\hline $\mathbf{R V}$ & Relief Valve \\
\hline RCS & Reactor coolant system \\
\hline RELAP5 & Reactor Leak Analysis Program Version 5 \\
\hline
\end{tabular}




$\begin{array}{ll}\text { RPV } & \text { Reactor Pressure Vessel } \\ \text { SG } & \text { Steam Generator } \\ \text { SOL } & \text { Solenoid operating valve } \\ \text { SS } & \text { Stainless Steel } \\ \text { TF } & \text { Fluid temperature } \\ \text { TH } & \text { Heater temperature } \\ \text { UP } & \text { Upper plenum } \\ & \\ \text { 1C or PC } & \text { Primary circuit } \quad \text { Subscripts } \\ \text { Out } & \text { Outlet parameter } \\ \text { In } & \text { Inlet parameter } \\ \text { Sat } & \text { Pressure or Temperature on saturated line }\end{array}$




\section{Table of Contents}

Executive Summary ..........................................................................................................................

Acknowledgments.......................................................................................................................................... vi

Acronyms.................................................................................................................... vii

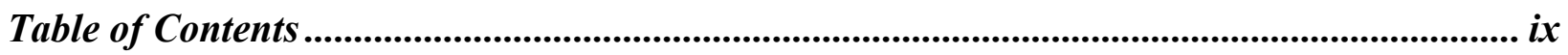

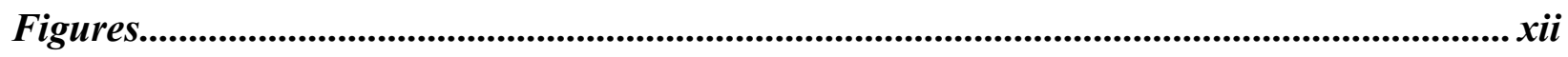

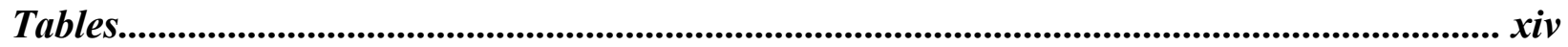

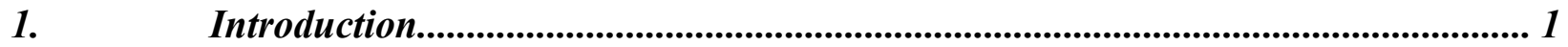

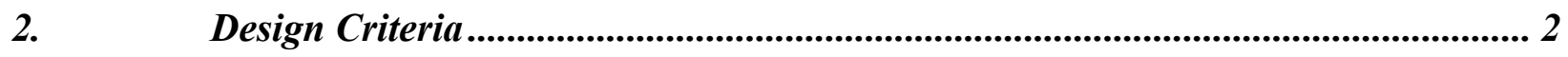

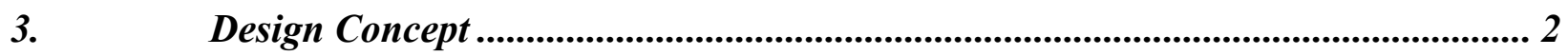

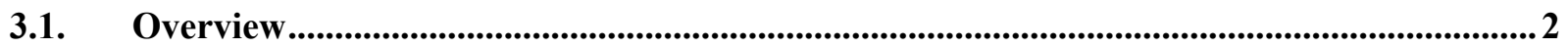

3.2. Nuclear Steam Supply System ......................................................................................................

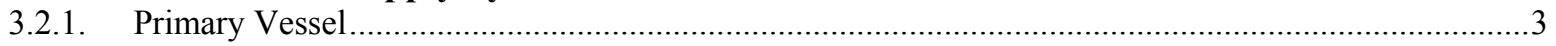

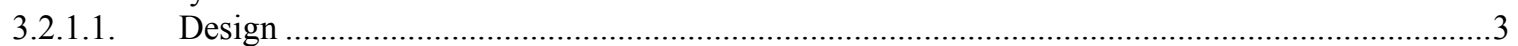

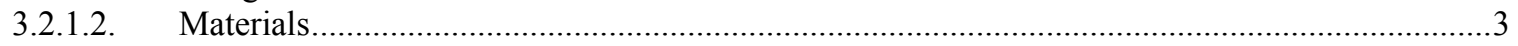

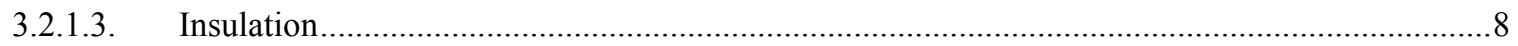

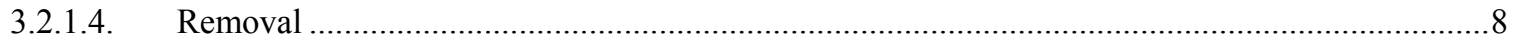

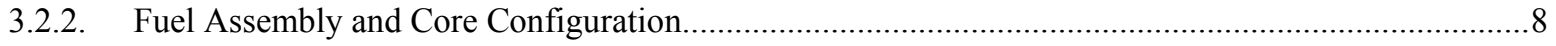

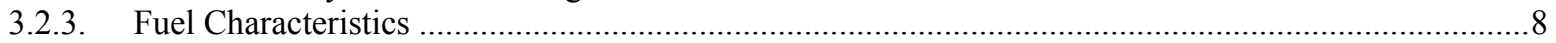

3.2.4. Control Rod Configuration ...............................................................................................................

3.2.5. Fuel Physics Performance............................................................................................................. 10

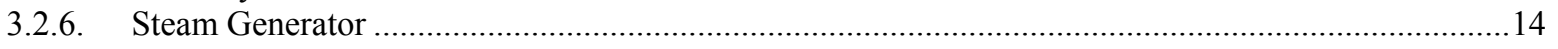

3.2.7. Reactor Module Support.....................................................................................................

3.3. Containment ............................................................................................................................. 15

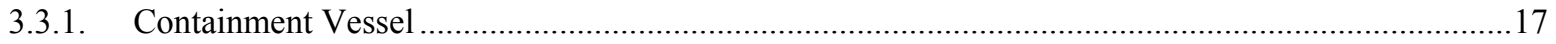

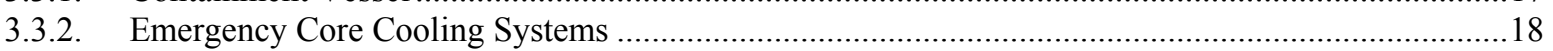

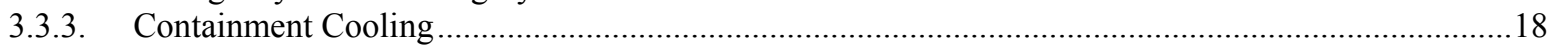

3.4. Plant Description ................................................................................................................. 18

3.4.1. Power Generation Concept .......................................................................................................

3.4.2. Overall Plant Arrangement ………………………………………………………………..22

3.4.3. Power Generation Complex.................................................................................................2

3.4.3.1. Reactor Building ..........................................................................................................24

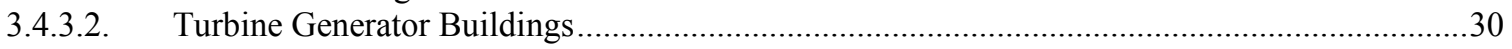

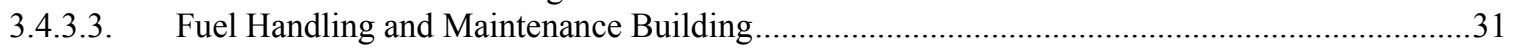

3.4.4. Remaining Facilities ……………………………………………………………………31

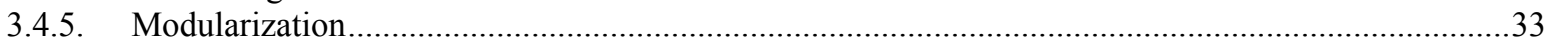

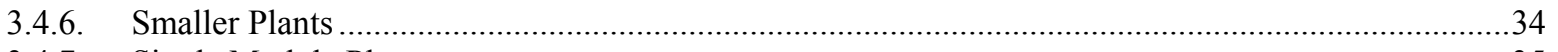

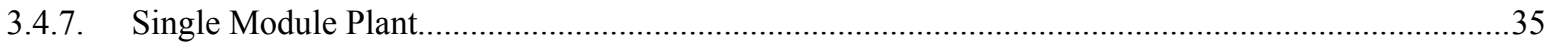

3.5. Reactor Refueling and Maintenance............................................................................37

3.6. Operation, In-Service-Inspection and Maintenance …………………………..........................37

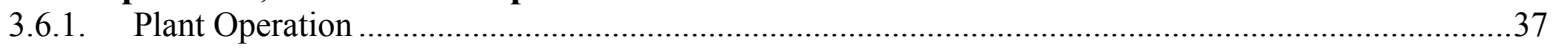

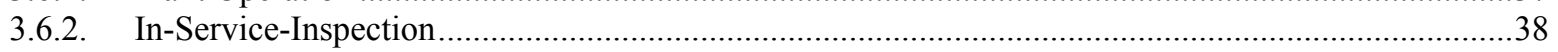

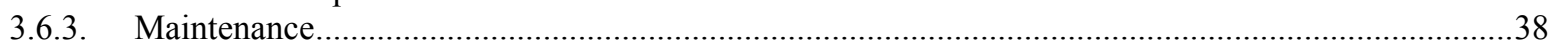

3.7. Seawater Desalination .................................................................................................... 40 


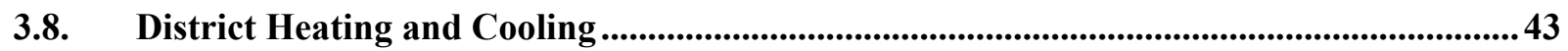

4. Performance and Safety Analyses................................................................... 44

4.1. RELAP5 Model............................................................................................................................. 44

4.2. Accident Categories and Acceptance Criteria ............................................................................... 46

4.3. Normal Operation ................................................................................................................................ 46

4.4. Incidents of Moderate Frequency .................................................................................................. 47

4.5. Infrequent Faults .............................................................................................................................5 50

4.6. Beyond Design Basis Accidents ........................................................................................................51

4.7. Summary of Results..................................................................................................................5 52

4.8. Novel Passive Safety Systems For The MASLWR. ..................................................................5 52

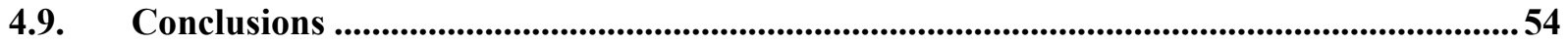

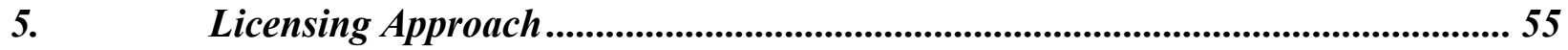

6. Plant Construction and Schedule...................................................................55

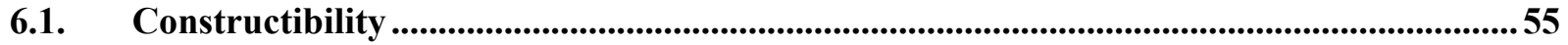

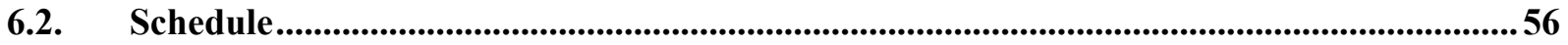

7. Capital and Busbar Cost Estimates..................................................................5

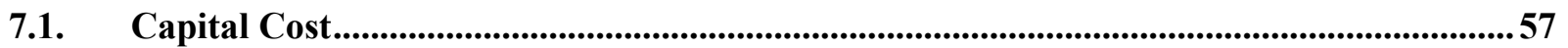

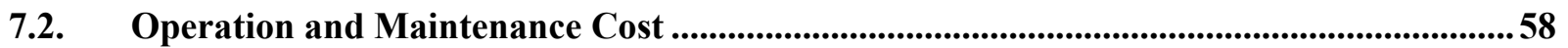

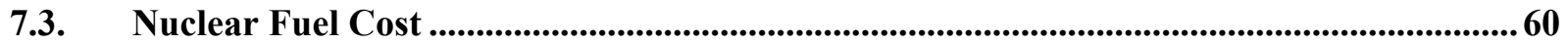

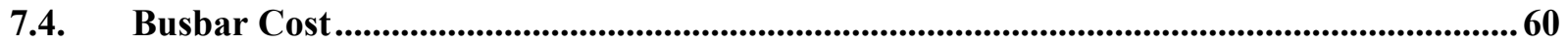

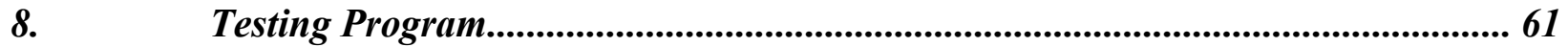

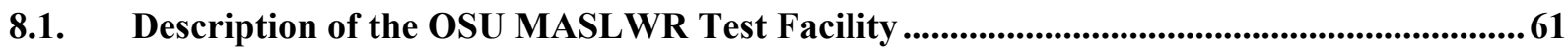

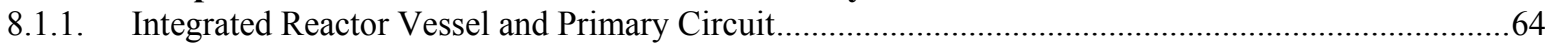

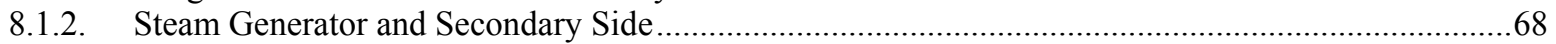

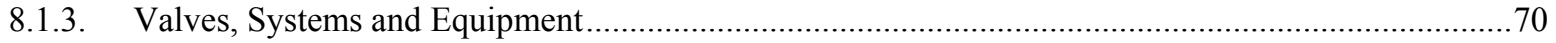

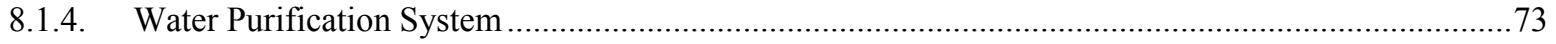

8.1.5. Data Acquisition System, Instrumentation and Controls ..................................................................

8.1.5.1. Data Acquisition and Control Hardware Description...............................................................

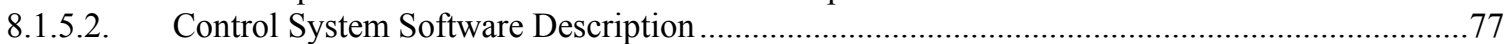

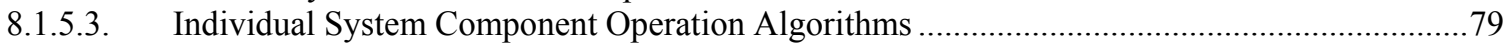

8.1.6. Containment and Exterior Cooling Pool Models .............................................................................83

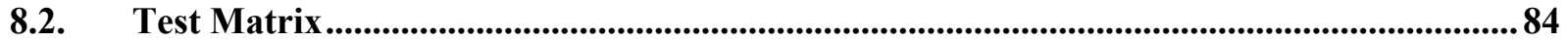

8.2.1. OSU-MASLWR-001, Inadvertent Actuation of 1 Submerged ADS Valve .......................................85

8.2.2. OSU-MASLWR-002 \& OSU-MASLWR-003A, Natural Circulation with Core Power up to $210 \mathrm{~kW}$ 89

8.2.3. OSU-MASLWR-003B, Inadvertent High Containment ADS Vent Line Actuation............................94

9. Summary, Conclusions and Recommendations ............................................... 99

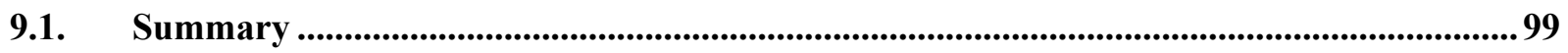

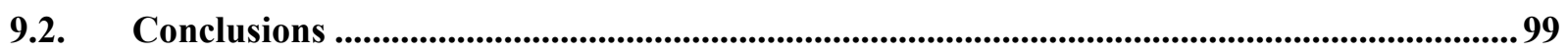




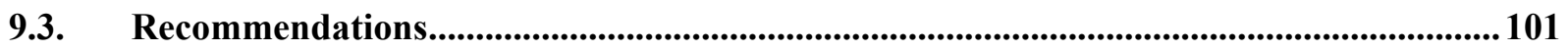


Figure 1. MASLWR Baseline Design Concept............................................................................ iii

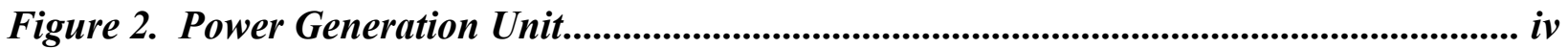

Figure 3-1 Containment and Internals. ........................................................................ 4

Figure 3-2 Modular Primary System Vessel................................................................. 5

Figure 3-4 Reactor Module Arrangement ..................................................................................... 7

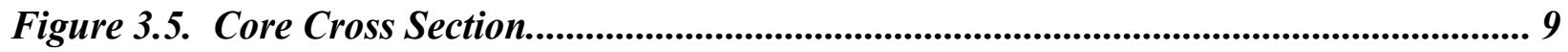

Figure 3-6 Cross sectional view of the pin cell model............................................................. 10

Figure 3-7. Comparison of reactivity versus burnup of uranium and thorium-uranium fuel. 11

Figure 3-8. Comparison of reactivity versus burnup of uranium and thorium-uranium fuel. 11

Figure 3-9 Axial neutron flux profile ................................................................................................ 14

Figure 3-10 Reactor Module Support Concepts ........................................................................ 16

Figure 3-11 Containment with Internal components............................................................ 17

Figure 3-12 Simplified Heat Cycle Piping Diagram. .................................................................... 20

Figure 3-13 Power Generation Unit ............................................................................. 21

Figure 3-14 Overall Plant Arrangement.............................................................................. 23

Figure 3-15 Power Generation Complex - Plan View Above Grade......................................... 25

Figure 3-16 Power Generation Complex - Plan View Below Grade...................................... 26

Figure 3-19 Fuel Handling and Maintenance Building - Elevation ..................................... 29

Figure 3-20 Six Reactor Module Plant - Plan View .......................................................... 34

Figure 3-21 Single Module Power Generation Complex......................................................... 35

Figure 3-22 Single Module Plant Reactor/Turbine Building Plan View ............................... 36

Figure 3-23 Single Module Plant Reactor/Turbine Building Elevation .................................... 36

Figure 3-24 Reactor Module Disassembly................................................................................ 39

Figure 3-25 RO Flow Schematic.................................................................................................. 42

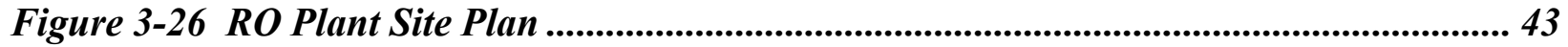

Figure 3-27 District Heating/Cooling …...................................................................................... 43

Figure 4-1. RELAP5 model....................................................................................................... 45

Figure 4-2. Results of ADS blowdown line nozzle break transient........................................ 48

Figure 4-3. Results of steam vent line nozzle break transient.................................................. 49

Figure 4-4. Results of feedwater flow increase transient. ................................................... 50

Figure 4-5. Inadvertent opening of steam vent valve with failure of reactor to scram............ 51 
Figure 8-1 P\&ID Drawing for the MASLWR Facility............................................................... 62

Figure 8-2 Schematic of the OSU MASLWR Primary Side Components................................. 63

Figure 8-3 Photograph of the MASLWR Test Facility at OSU ........................................... 64

Figure 8-4 Electrically Heated Core Bundle in OSU MASL WR........................................ 65

Figure 8-5 Electrical Connections for the OSU MASLWR Core Bundle (RPV Bottom Plate).

Figure 8-6 Three Sections of the Helical Tube Steam Generator .......................................... 68

Figure 8-7 Feed Water Pump and Electric Motor............................................................. 69

Figure 8-8 Control System Schematic.............................................................................. 76

Figure 8-9 Computer Screen Image of Control System Software GUI ................................. 79

Figure 8-10 Containment Heater Control Algorithm Flow Chart ........................................ 80

Figure 8-11 Containment and Exterior Pool Vessels of the MASLWR Test Facility............... 84

Figure 8-12 Primary and Containment Pressure for MASLWR-OSU-001 ........................... 86

Figure 8-13 Relative values of the Location of the Reactor Vessel Penetrations, and the coolant level in MASLWR-OSU-001...................................................................................8 87

Figure 8-14 Hot Leg Flow Rate in MASLWR-OSU-001 ............................................... 87

Figure 8-15 Reactor Vessel Temperatures in MASLWR-OSU-001.................................... 88

Figure 8-16 Core Temperatures for MASL WR-OSU-002 ...................................................... 90

Figure 8-17 Core Temperatures for MASL WR-OSU-003A................................................. 91

Figure 8-18 Differential Temperatures Across the Core for MASLWR-OSU-002................. 91

Figure 8-19 Differential Temperature Across the Core for MASLWR-OSU-003A................. 92

Figure 8-20 Steam Generator FW Flow Rate for MASL WR-OSU-002 ................................... 92

Figure 8-21 Steam Generator FW Flow Rate for MASL WR-OSU-003A ............................ 93

Figure 8-22 Core Volumetric Flow Rate for MASLWR-OSU-002 ......................................... 93

Figure 8-23 Core Volumetric Flow Rate for MASLWR-OSU-003A ..................................... 94

Figure 8-24 Containment "Non-Condensation" Wall Surface Temperatures for MASLWR-

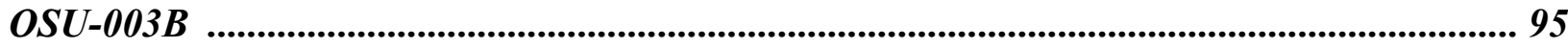

Figure 8-25 Containment "Non-Condensation” Wall Surface Temperatures Percent Difference with Containment Saturation Temperature for MASL WR-OSU-003B ................. 96

Figure 8-26 Containment Pressure for MASLWR-OSU-003B........................................... 96

Figure 8-27 Containment Condensation Plate Wall Fluid Temperatures for MASLWR-OSU$003 B$

Figure 8-28 Containment Liquid Level for MASLWR-OSU-003B ...................................... 98 
Tables

Table 3-1 Parameters of the fuel pin at hot full power........................................................9

Table 3.2. Plutonium isotopics at 11MWd/kg burnup..................................................... 12

Table 3.3. Plutonium isotopics at discharge burn up. ........................................................ 12

Table 3-4 Reactivity comparison of different coolant densities. ............................................ 14

Table 3-3 Plant Performance Characteristics........................................................................ 19

Table 3-4 Desalination Processes Comparison...................................................................... 41

Table 4-1. Steady-state operating conditions. ................................................................. 47

Table 4-2. Scenarios categorized by frequency of occurrence. .......................................... 52

Table 7-1 Capital Cost Estimate (in Millions of January 2002 Dollars)................................... 59

Table 7-2 Busbar Cost Estimate (in Cents/kWh)..........................................................6 60

Table 8-1 Primary Loop Data .............................................................................................6 67

Table 8-2 Motor Operated Valves................................................................................70

Table 8-3 Manual Operated Valves....................................................................................... 71

Table 8-4 Pressure Measurement Device Root Valves......................................................... 72

Table 8-5 Balance of Plant Information ......................................................................... 73

Table 8-6 MASL WR Instrumentation List........................................................................ 75

Table 8-7 Logic Chart Descriptions ............................................................................................... 78

Table 8-8 Listing of the System Safety Limits............................................................................... 82

Table 8-9 Containment Geometrical Data ...................................................................... 83

Table 8-10 Summary of the OSU MASLWR Testing Program to Date.................................. 85

Table 8-11 Core Power and FW Flow Rates for MASLWR-OSU-002, MASLWR-OSU-003A 89 Table 8-12 Inlet and Outlet Temperatures in the Primary and Secondary for MASLWR-OSU-

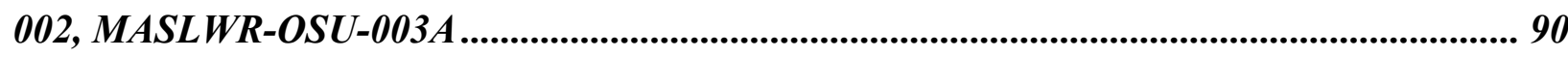




\section{Multi-Application Small Light Water Reactor Final Report}

\section{Introduction}

In recognition of increasing world energy needs and emphasis on a clean environment, the U. S. Department of Energy (DOE) has implemented the Nuclear Energy Research Initiative (NERI) program. This program has sponsored research for the Multi-Application Small Light Water Reactor (MASLWR) project. The primary project objectives were to develop the conceptual design for a safe and economic plant and to test the design feasibility. A small, natural circulation light water reactor concept was developed with the primary goal of producing electric power, but including the flexibility to be used in process heat applications with deployment in a variety of locations. Economic and engineering analyses were used to address the design and safety attributes of the concept. These analyses are coupled with testing in an integral test facility to demonstrate the concept's technical feasibility.

The initial concept, explored during Year 1 activities, was a natural circulation design to be operated at approximately $1000 \mathrm{MWt}$ and $5.4 \mathrm{MPa}$ steam pressure. This design included 4 horizontal U-tube type steam generators located at a height of $36 \mathrm{~m}$ above the thermal center of the reactor core. A cylindrical containment, $30 \mathrm{~m}$ in diameter, housed the reactor and primary system and the required support systems and equipment. The preliminary estimates for this design indicated that the busbar cost would be about 5.7 cents $/ \mathrm{kWh}$, which is far above the goal of 4 cents $/ \mathrm{kWh}$. It was concluded that if the basic concept principles identified at the outset of the project were maintained, i.e. a pressurized water system with natural circulation, cost reduction could be achieved only by using smaller, simpler, factory-assembled units. Therefore, the focus of the project was redirected to a modular reactor design that consists of a selfcontained assembly of reactor vessel, steam generators, and containment. These modular units would be manufactured at a single centralized facility, transported by rail, road, and/or ship, and installed as a series of self-contained units. This modular design, which has been developed by the MASLWR project is documented in this report. 


\section{Design Criteria}

The major design criteria and goals initially set for the MASLWR project are as follows:

- Electricity busbar cost 4.0 cents/kWh or less

- Construction schedule of maximum 2 years for a single unit plant

- Simple design with maximum use of passive systems

- Maximizing shop fabrication through extensive use of modularization

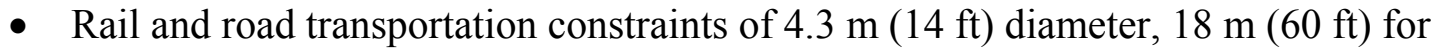
unrestricted shipment on most railways and roads

- Plant life cycle of 60 years

- Refueling intervals of no less than 5 years

- Safety features assuring a core damage frequency of less than $10^{-7}$ per year

- Operation and maintenance personnel of maximum 200 person for a power block plant

- Maximizing the use of off-the-shelf components

- Excluding the use of developmental components; only currently used components with some adaptation are allowed.

This report establishes the success of the project in meeting these goals.

\section{Design Concept}

\subsection{Overview}

This section describes the baseline reactor concept and associated power plant. The basic goal was to make the reactor concept as realistic as possible, but still use available advanced technologies within the power plant framework to develop a cost baseline. An additional goal was to design a pressurized water reactor system with natural circulation as the key characteristic of the concept. Use of natural circulation reduces the number of active components and potentially simplifies the configuration of the NSSS. The purpose was to determine whether this simplified configuration can be realized with an attendant capital cost reduction.

The core concept was based on configurations used in a typical PWR. This approach allows the use of current industry expertise and manufacturing capabilities. The core would use $17 \times 17$ fuel assemblies at power density of $100 \mathrm{~kW} / \mathrm{l}$. Both uranium and thorium-uranium fuels were evaluated.

Passive safety systems were used as much as possible, so that emergency or off-site power would not be required for adequate emergency core cooling. There are no emergency cooling pumps.

Preliminary cost estimates are based on a NPP configuration that has approximately the same electrical production capacity as existing plants. That is, the NPP configuration would comprise multiple-power generation units that have the desired total production capacity. This configuration was for convenience and should not be taken to imply a recommendation for a final deployment strategy. On this basis the baseline concept consists of thirty power generation units to produce a total of $1050 \mathrm{MWe}$. Each power generation unit includes a single pressure 
vessel and its associated containment vessel. Additional supporting information and design details are provided in the remaining parts of this section.

\subsection{Nuclear Steam Supply System}

The NSSS design is a "self-contained" reactor module, consisting of a reactor core and heat exchanger (steam generator) within a single pressure vessel that is surrounded by a cylindrical containment as shown in Figures 3-1 and 3-2. The nuclear core is located in the lower part of the vessel with the steam generator above it. To effectively use natural circulation, the core is connected directly to the space above the heat exchanger via a large-diameter tube, or riser, which is an upper extension of the core barrel. The primary liquid flow path is upward through the riser, then downward around the heat exchanger tubes with return to the bottom of the core via an annular space. The piping within the reactor module is shown in the diagram in Figure 3-3.

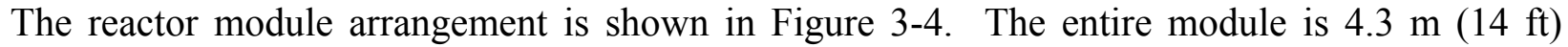
diameter and $18.3 \mathrm{~m}(60 \mathrm{ft})$ long, which allows it to be entirely shop fabricated and transported to site on most railways or roads. The containment is partially filled with water to provide pressure suppression and liquid makeup capabilities in the event of a piping rupture inside the containment. The entire module is submerged in a large pool of water, which serves as the ultimate heat sink. Details of the system safety design and the performance of the module following pipe rupture events are discussed in Section 4.

\subsubsection{Primary Vessel}

\subsubsection{Design}

The primary system vessel houses the reactor core and steam generator, as was shown in

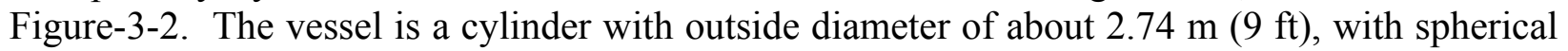

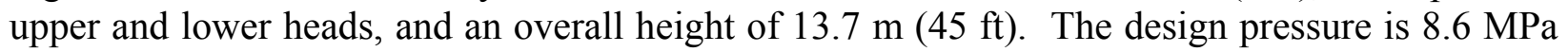
(1250 psia). A flange connection in the lower part of the vessel provides access during refueling and maintenance. The upper head of the vessel provides support for the control rod drive mechanisms. A baffle plate divider in the top of the vessel separates the liquid from the steam space above it. The vessel is bottom supported.

\subsubsection{Materials}

The reactor vessel will be constructed of stainless steel since it is at all times in contact with water or water vapor inside and outside. Alternatively, carbon steel with nickel-chromium-iron alloy cladding could be used. The latter would result in vessel wall thickness reduction from about 5 in. to 2.5 in. However, it is questionable whether the cladding would remain intact during the 60 year life of the plant. 


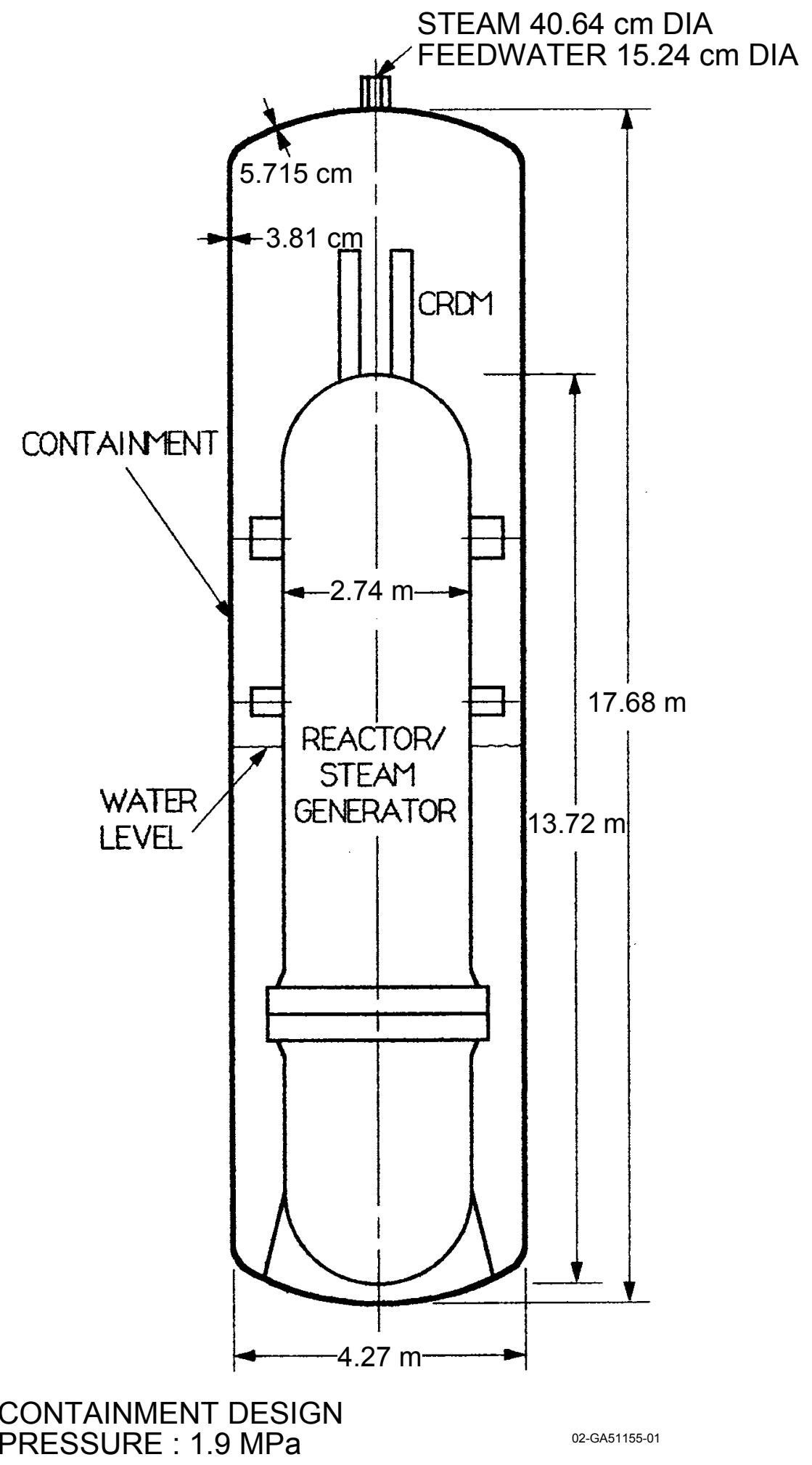

Figure 3-1 Containment and Internals. 


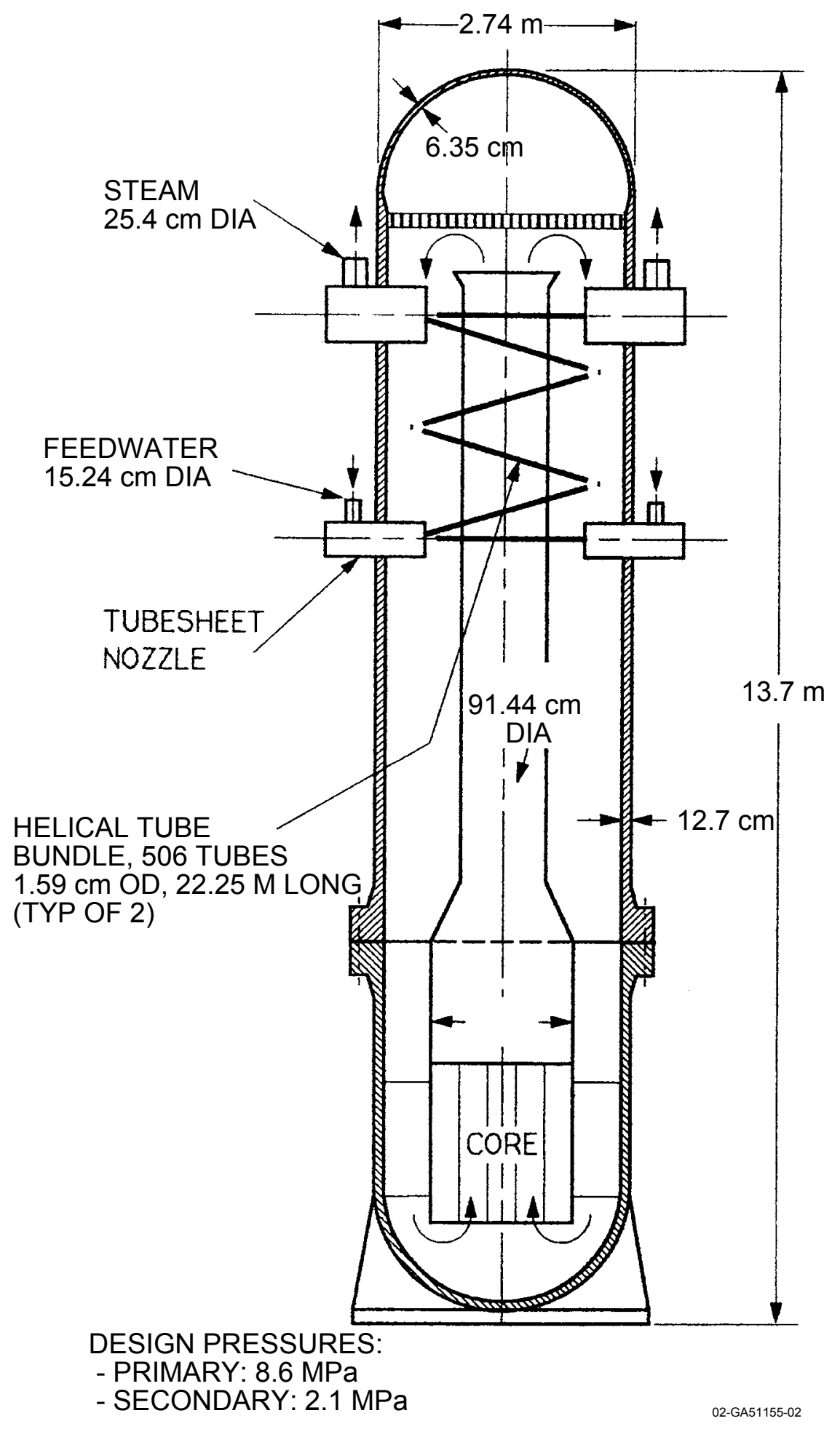

Figure 3-2 Modular Primary System Vessel 


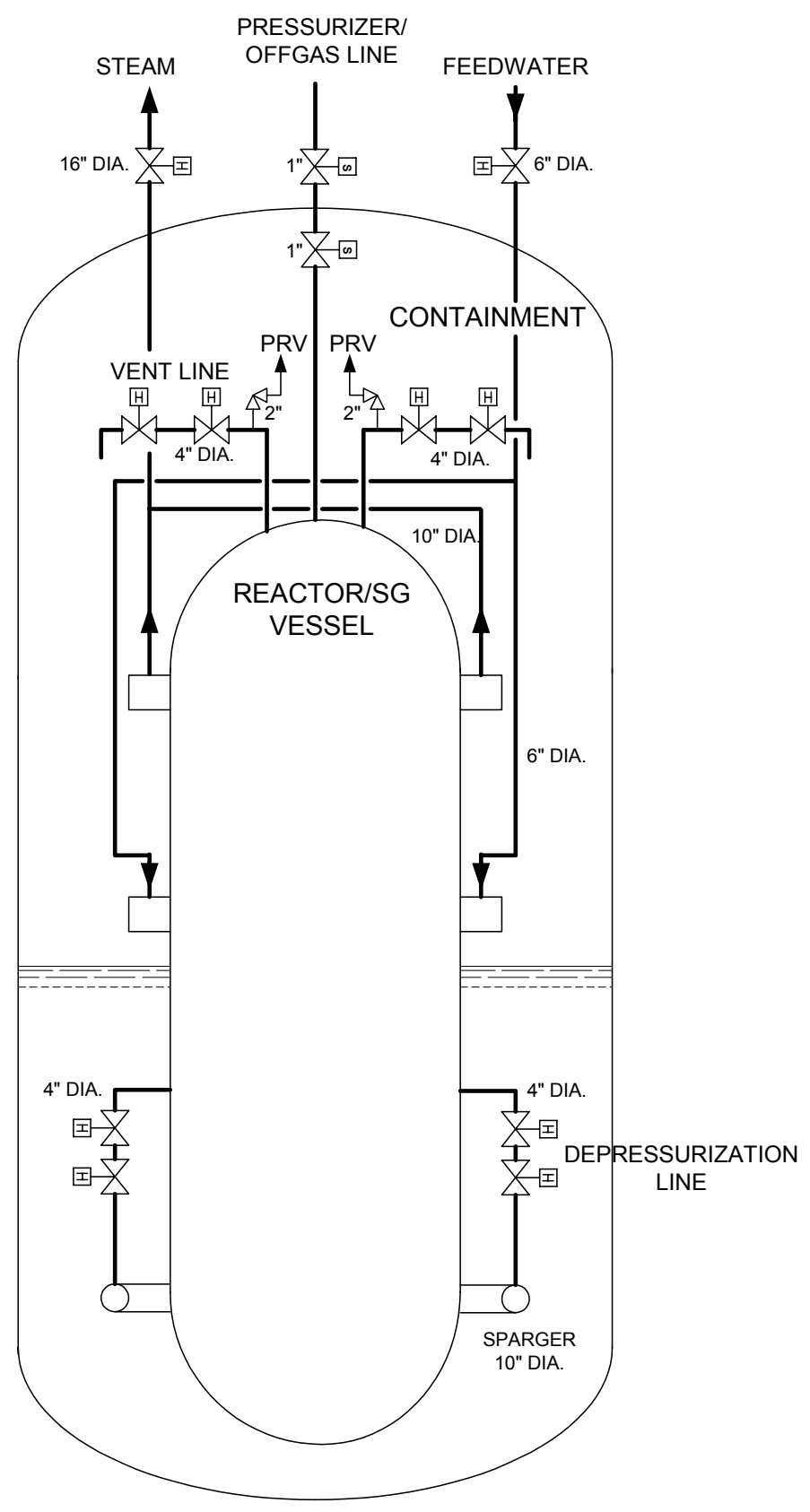

Figure 3-3 Reactor Module Piping Diagram 

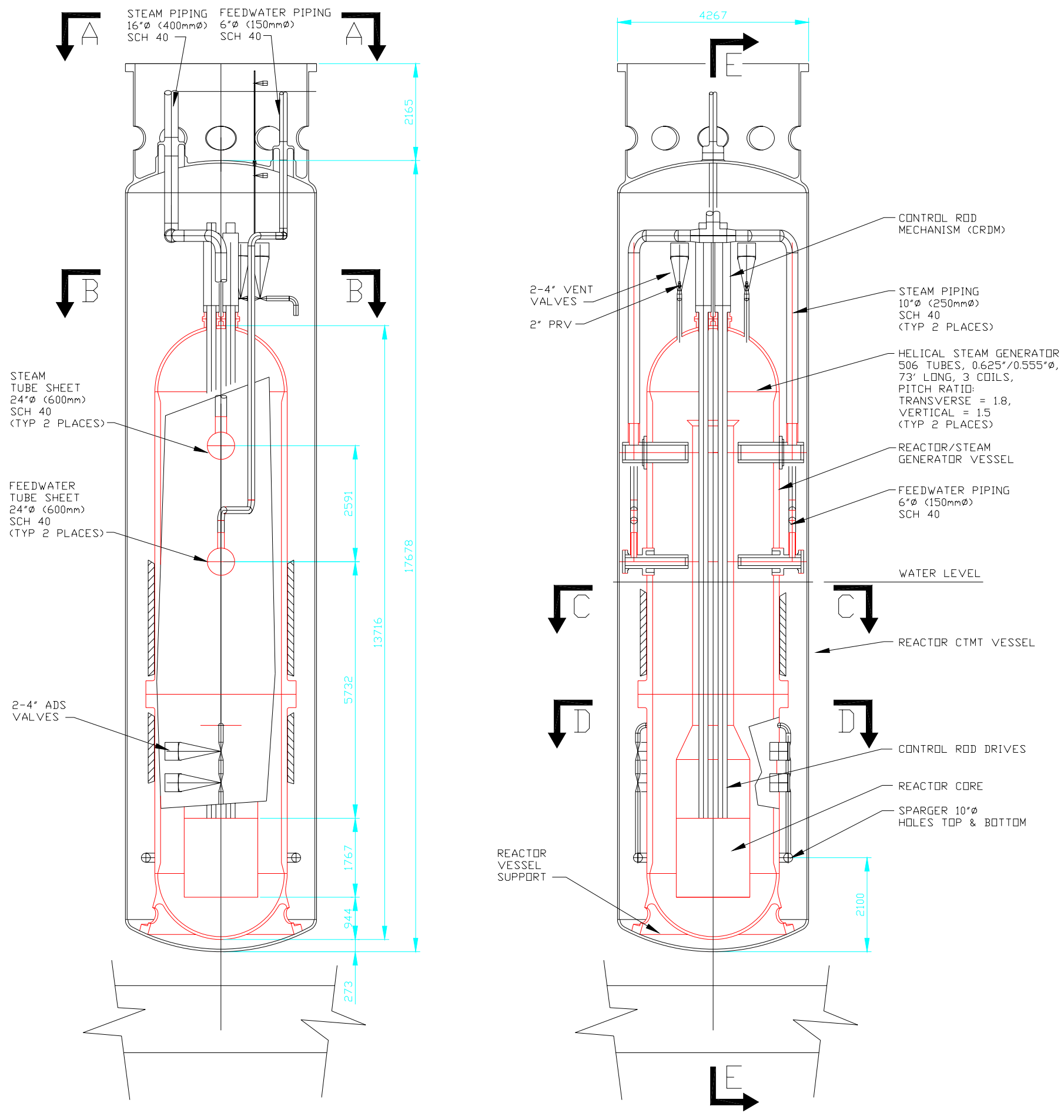

Figure 3-4 Reactor Module Arrangement 


\subsubsection{Insulation}

The entire vessel will be insulated on the outer surface to limit the heat losses. Since the reactor/SG vessel will be partially immersed in water, a moisture-resistant insulation is required. A preliminary investigation shows that a glass foam insulation may be appropriate for this application. This material is light in weight and is composed of completely sealed glass cells to prevent moisture intrusion. However, there is no actual data available confirming that the insulation will keep its integrity during the 5 years period between refueling. Therefore, the insulation would have to be tested for specific conditions applicable to MASLWR. Other types of insulation, preferably metal, should also be investigated.

\subsubsection{Removal}

An overhead traveling crane is provided in the reactor building to lift the entire reactor module and move it under water between the reactor cavity in the reactor building and the adjacent reactor refueling and maintenance facility.

\subsubsection{Fuel Assembly and Core Configuration}

The reactor core was scaled from a typical PWR core, and consisted of 24 assemblies of standard $17 \times 17$ design fuel assemblies for a total of 6336 fuel rods. The heated length is approximately $1.35 \mathrm{~m}(4.43 \mathrm{ft})$ and the equivalent diameter, dia $=2 \sqrt{\frac{\text { area }}{\pi}}$ is approximately $1.2 \mathrm{~m}$. Figure 3-5 shows a cross-section view of the core. The design average power density at $150 \mathrm{MWt}$ is 100 $\mathrm{kW} /$ liter. The $17 \times 17$ assemblies had a pitch of approximately $21.5 \mathrm{~cm}$. The core was arranged so that a 2-4-6(x2)-4-2 assembly pattern was formed. The fuel pin parameters are discussed in Section 3.2.3. The MASLWR core concept retains typical geometrical features of fuel rod diameter, pitch, subchannel geometry, grid spacer hydrodynamic performance, and lower and upper core plate configurations. Therefore, the hydraulic performance calculated by the thermalhydraulic software should represent the characteristics of the actual core reasonably well. Also, the core design is consistent with existing industry experience and manufacturing capabilities. Note that optimization of the core should performed, including changes in enrichment, fuel element configuration, etc. It is expected that this optimization will increase core thermal power to $200 \mathrm{MWt}$. This step has not been done in the present design because the objective was to characterize overall system performance while maintaining a core design consistent within current engineering experience and manufacturing capabilities.

\subsubsection{Fuel Characteristics}

The fuel studied for the baseline design was based on a typical fuel pin that is used in a typical 17x17 PWR assembly. The generic parameters used can be seen in Table 3-1. The active fuel length was kept constant at $100 \mathrm{~cm}$ with enrichments that varied from $4.5 \%$ to $19.5 \%$. The cladding used was Zircalloy-4, and 25 positions in the assembly were unfueled for controlrod/instrumentation/burnable-poison-rods. This left a total of 264 fueled positions in the assembly. 


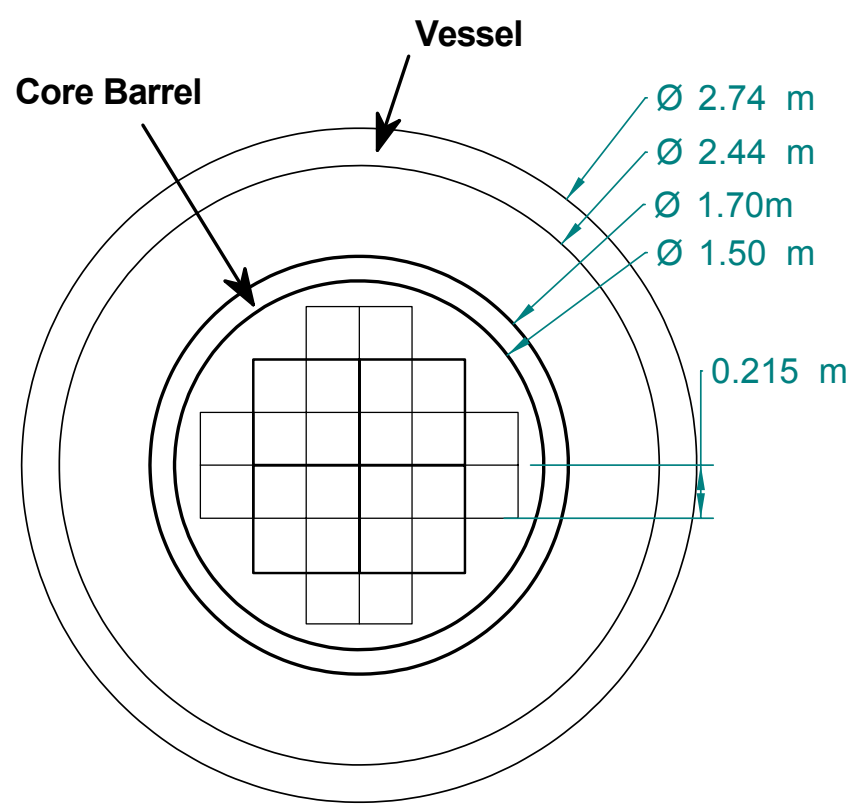

Cross Section at Reactor Core

Figure 3.5. Core Cross Section.

Table 3-1 Parameters of the fuel pin at hot full power.

\begin{tabular}{|cc|}
\hline Parameter & Value \\
Fuel Average Temperature & $900 \mathrm{~K}$ \\
Fuel Diameter & $8.259 \mathrm{~mm}$ \\
Cladding ID & $8.379 \mathrm{~mm}$ \\
Cladding OD & $9.522 \mathrm{~mm}$ \\
Pin Pitch & $12.626 \mathrm{~mm}$ \\
\hline
\end{tabular}

\subsubsection{Control Rod Configuration}

The inner square block of 16 assemblies will have control rods, and the 8 peripheral assemblies will be unrodded. Four control rod support spiders will be provided, one for each of the four rodded assemblies in each quadrant of the core. There will be four control rod drive lines, one per support spider, that extend inside the riser pipe from the region above the core to the top of the vessel, penetrating the upper head. The four control rod drive mechanisms will be mounted on the upper head. We have assumed a classical control rod configuration, which is within the current experience and manufacturing capabilities of the industry.

The following types of control rod drive mechanisms (CRDM) have been considered: magnetic jack, nut/screw, and hydraulic. A preliminary assessment concludes that the most suitable drive for the MASLWR application is the nut/screw drive. 


\subsubsection{Fuel Physics Performance}

The code MOCUP was used to analyze the reactivity performance and isotopic content of the previously described fuel pins. MOCUP uses MCNP4B to calculate the eigenvalues, reaction rates, and neutron fluxes for 3-dimensional geometries, and couples it with ORIGEN2.1 for fission product and actinide generation, depletion, and decay. In calculating the reactivity swing with burnup, a pin cell model was used to represent a single fuel rod in an infinite lattice, where the boundary conditions included axial leakage with radially reflecting boundaries. The hot, full power conditions were used for each burnup step, using temperature dependent cross sections whenever possible.. The predicted single-batch lifetime for an 8\% (U-235) enriched fuel is 1825 effective-full-power-days ( $\sim 5$ years). An isotopic analysis was not performed for this particular enrichment, but the expected composition from beginning-of-life through end-of-life would be typical of a $\mathrm{UO}_{2}$ fuel for the corresponding burnup (i.e., isotopics throughout the life of the fuel are dependent primarily on the burnup). Figure 3-6 is a cross sectional view of the model that was used in the MOCUP calculations.

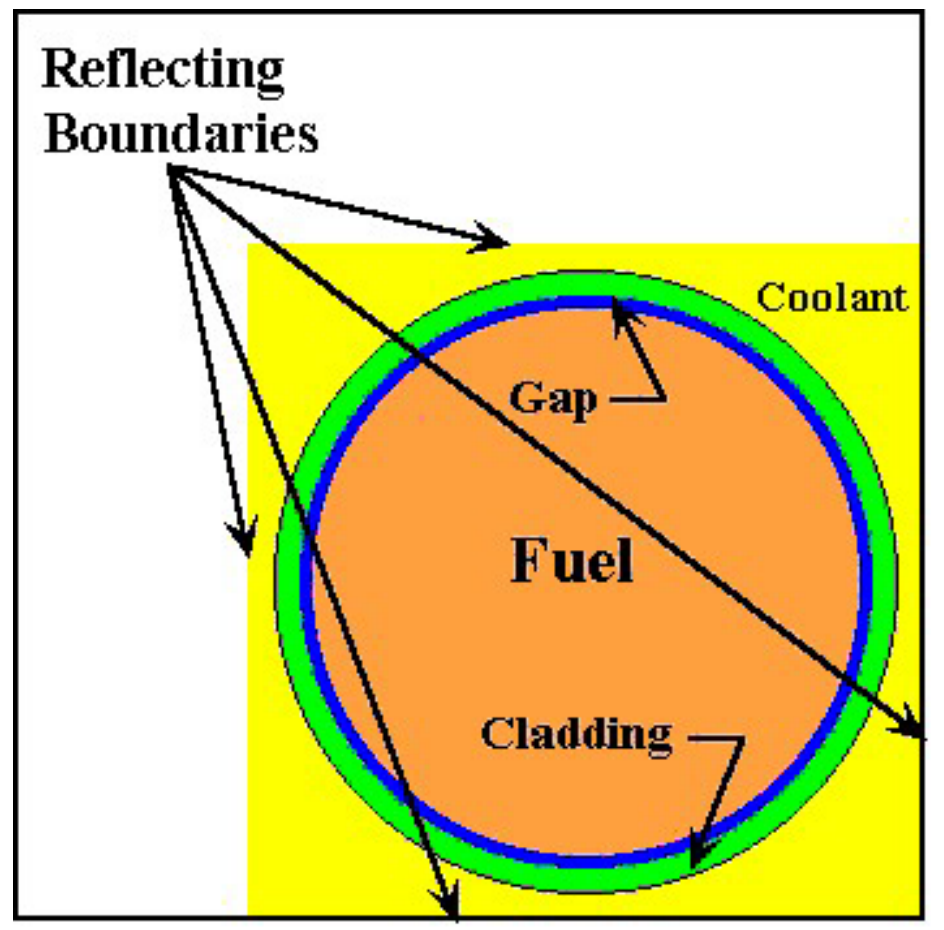

Figure 3-6 Cross sectional view of the pin cell model.

The initial calculations performed for this project were for hot, full power conditions (for each burnup step) using temperature dependent cross sections whenever possible, at power levels of $300 \mathrm{MW}_{\text {th }}$ and $950 \mathrm{MW}_{\text {th. }}$. In addition, a larger core was considered at 109 assemblies. Both uranium and thorium-uranium fuels were used in the calculations. The infinite multiplication factor versus the effective full power days of operation can be seen in Figure 3-7. 


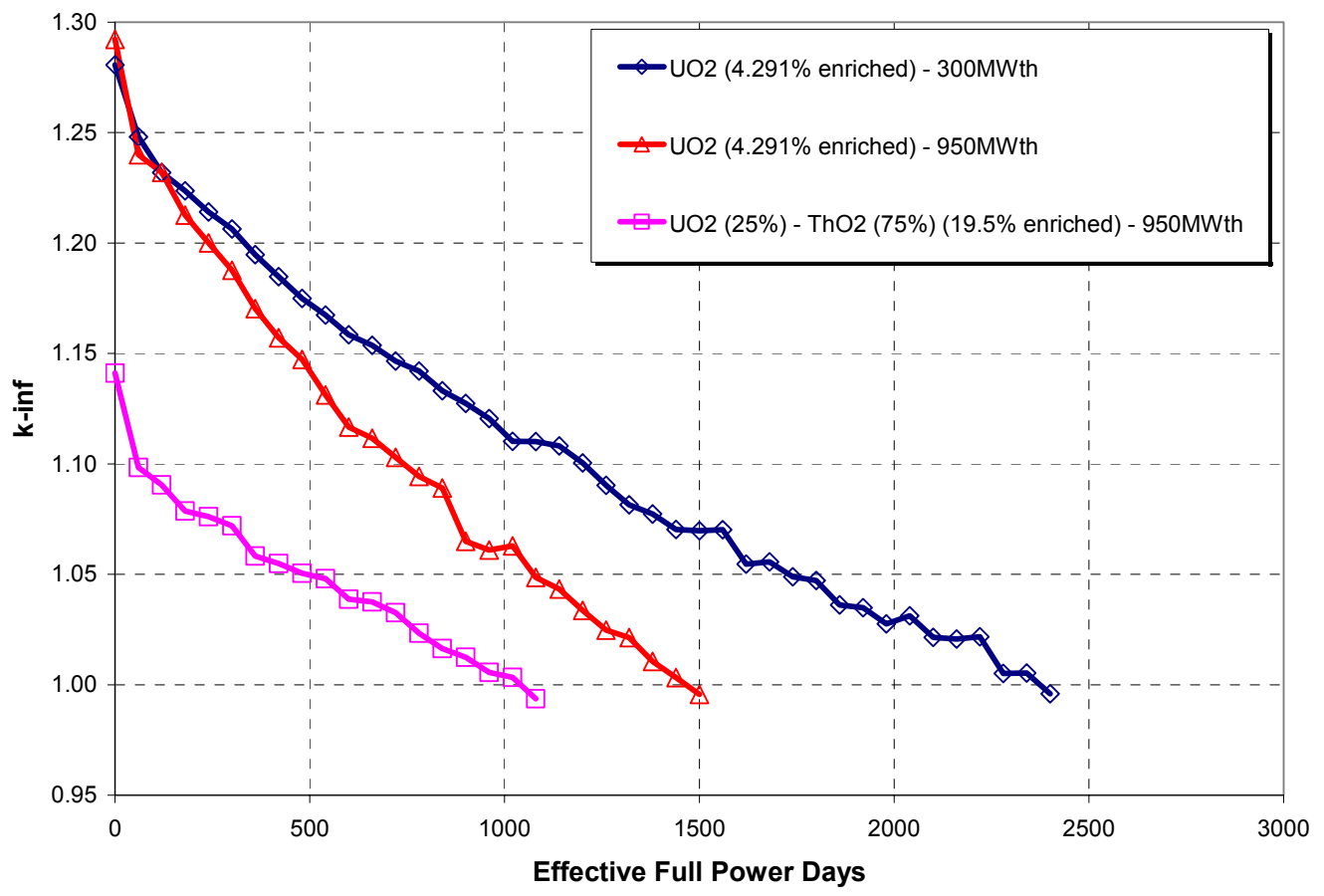

Figure 3-7. Comparison of reactivity versus burnup of uranium and thorium-uranium fuel.

For a single batch core, the reactivity with burnup is the same regardless of the specific power for similar fuel enrichments, with uranium fuels outperforming thorium-uranium fuels at a 75 $\mathrm{wt} \%\left(\mathrm{ThO}_{2}\right)-25 \mathrm{wt} \%\left(\mathrm{UO}_{2}\right)$ ratio. This can be seen in Figure 3-8.

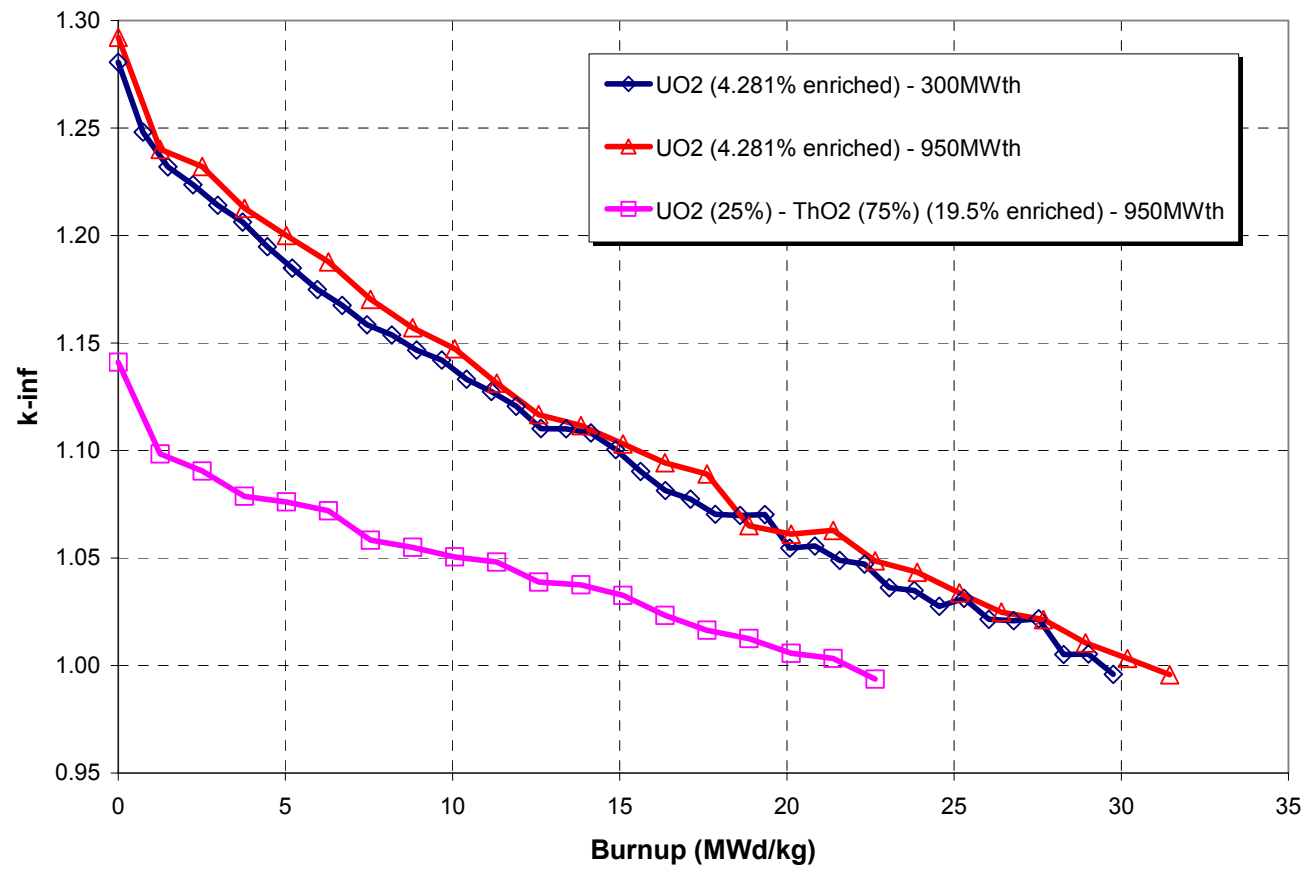

Figure 3-8. Comparison of reactivity versus burnup of uranium and thorium-uranium fuel. 
Further improvements on the burnup of the thorium based fuels can be made by increasing the uranium fraction, but were not studied for the baseline design. However, thorium based fuels contain $2-3$ times less plutonium the all-uranium fuel at similar burnups, as can be seen in Table 3.2.

Table 3.2. Plutonium isotopics at $11 \mathrm{MWd} / \mathrm{kg}$ burnup.

\begin{tabular}{|l|c|c|c|}
\hline & $\begin{array}{c}\mathrm{UO}_{2} \\
\left(300 \mathrm{MW}_{\text {th }}\right)\end{array}$ & $\begin{array}{c}\mathrm{UO}_{2} \\
\left(950 \mathrm{MW}_{\text {th }}\right)\end{array}$ & $\begin{array}{c}\mathrm{UO}_{2}-\mathrm{ThO}_{2} \\
\left(950 \mathrm{MW}_{\text {th }}\right)\end{array}$ \\
\hline Burnup (MWd/kg) & 11 & 11 & 11 \\
\hline & \multicolumn{3}{|c|}{ Plutonium Production $(\mathrm{g} / \mathrm{kg} \mathrm{ihm})$} \\
\hline Pu-238 & 0.010 & 0.010 & 0.010 \\
\hline Pu-239 & 5.026 & 5.079 & 2.005 \\
\hline Pu-240 & 0.578 & 0.593 & 0.270 \\
\hline Pu-241 & 0.268 & 0.285 & 0.153 \\
\hline Pu-242 & 0.017 & 0.018 & 0.011 \\
\hline Total Pu & $\mathbf{5 . 8 9 9}$ & $\mathbf{5 . 9 8 4}$ & $\mathbf{2 . 4 4 8}$ \\
\hline Composition & \multicolumn{3}{|c|}{ Fraction of Total Pu } \\
\hline Pu-238 & $0.2 \%$ & $0.2 \%$ & $0.4 \%$ \\
\hline Pu-239 & $85.2 \%$ & $84.9 \%$ & $81.9 \%$ \\
\hline Pu-240 & $9.8 \%$ & $9.9 \%$ & $11.0 \%$ \\
\hline Pu-241 & $4.6 \%$ & $4.8 \%$ & $6.2 \%$ \\
\hline Pu-242 & $0.3 \%$ & $0.3 \%$ & $0.5 \%$ \\
\hline
\end{tabular}

For the discharge burnup of a single batch core, the amount of plutonium produced in the thorium based fuel is about 4 times less than the uranium fuel, as can be seen in Table 3.3.

Table 3.3. Plutonium isotopics at discharge burnup.

\begin{tabular}{|l|c|c|}
\hline & $\begin{array}{c}\mathrm{UO}_{2} \\
\left(950 \mathrm{MW}_{\text {th }}\right)\end{array}$ & $\begin{array}{c}\mathrm{UO}_{2}-\mathrm{ThO}_{2} \\
\left(950 \mathrm{MW}_{\text {th }}\right)\end{array}$ \\
\hline Burnup (MWd/kg) & 31 & 23 \\
\hline & Plutonium Production $(\mathrm{g} / \mathrm{kg} \mathrm{inm})$ \\
\hline $\mathrm{Pu}-238$ & 0.155 & 0.062 \\
\hline $\mathrm{Pu}-239$ & 9.497 & 2.898 \\
\hline $\mathrm{Pu}-240$ & 2.153 & 0.572 \\
\hline $\mathrm{Pu}-241$ & 1.558 & 0.501 \\
\hline Pu-242 & 0.281 & 0.078 \\
\hline Total Pu & $\mathbf{1 3 . 6 4 3}$ & $\mathbf{4 . 1 1 1}$ \\
\hline Composition & Fraction of Total Pu \\
\hline Pu-238 & $1.1 \%$ & $1.5 \%$ \\
\hline Pu-239 & $69.6 \%$ & $70.5 \%$ \\
\hline Pu-240 & $15.8 \%$ & $13.9 \%$ \\
\hline Pu-241 & $11.4 \%$ & $12.2 \%$ \\
\hline Pu-242 & $2.1 \%$ & $1.9 \%$ \\
\hline
\end{tabular}


If the refueling is changed to a 3-batch core (typical of current LWR's), the burnup will be increased by $50 \%$ in all cases, and result in a lower fuel cost. Also by increasing the discharge burnup of the fuel, the plutonium isotopic fractions tend toward the even numbered plutonium isotopes, which have higher decay heat rates and spontaneous neutrons than the odd numbered isotopes. This will increase the intrinsic proliferation resistance of the fuel.

Given the same power density, the above results can be extrapolated to the current small core design of 24 assemblies.

In addition to the burnup studies using MOCUP, beginning-of-life full core reactivity studies were performed using MCNP. The results are given below.

Neutron Leakage. The burnup versus reactivity studies done previously were based on an infinite multiplication factor $\left(\mathrm{k}_{\text {inf }}\right)$ calculation, and not on the effective multiplication factor $\left(\mathrm{k}_{\mathrm{eff}}\right)$. Typically this is not a problem with large LWR's, where the height to diameter ratio is such that the overall neutron leakage is approximately $3 \%$. In the case of the current MASLWR design, the height to diameter ratio is also approximately 1, but the overall size of the core is significantly smaller than typical LWR's. Thus, to verify the validity of the burnup studies that were performed, a full core model was constructed with MCNP. The calculations were done with $8 \%$ (U-235) enriched $\mathrm{UO}_{2}$ fuel in 24, 17x17 assemblies. Each of the control/instrumentation rod positions were water filled, and the fuel was assumed to have BOL isotopics (i.e., no fission products). The difference in reactivity between the similar BOL infinite lattice calculations and full core calculations was approximately $4 \%$, thus validating the previously given results of the expected average discharge burnup.

Coolant Voiding. An alternative design was considered with coolant boiling in the core, the objective of which was to evaluate the potential for enhancement of natural circulation by having two-phase conditions in the hot leg riser. Calculations were performed to verify the neutronic effects. The effect of voiding due to coolant boiling in an LWR will cause an insertion of negative reactivity. The following void calculations were performed using the core configuration with $24,17 \times 17$ fuel assemblies, and BOL isotopics:

- Steady-state core with 3 coolant density/void regimes

- Voided core (with $29 \%$ void fraction in whole core)

- Non-voided core.

The reactivity comparisons between each of the configurations are shown in Table 3-4. As expected, voiding the entire core will produce a negative insertion of reactivity. However, a steady-state condition followed by a collapse of the bubbles (non-voided) will result in a positive insertion of reactivity. This challenge may be resolved by a combination of control rod insertion rates, and temperature sensitive control rod trips. For the end-of-life void worth, it is expected that the steady-state versus non-voided, and voided versus non-voided core will have less of a reactivity jump due to the poisons (fission products) and small excess reactivity that remain in the fuel. 
Table 3-4 Reactivity comparison of different coolant densities.

\begin{tabular}{|ccc|}
\hline Coolant Configuration & $\mathbf{\%} \Delta \mathbf{k} / \mathbf{k}$ & $\mathbf{\$}$ \\
Steady-State vs. Voided & $-4.8 \%$ & $-\$ 7.38$ \\
Steady-State vs. Non-Voided & $+3.1 \%$ & $+\$ 4.77$ \\
Voided vs. Non-Voided & $+7.9 \%$ & $+\$ 12.15$ \\
\hline
\end{tabular}

An average axial flux profile was calculated using MCNP, as shown in Figure 3-9. This calculation was performed in support of test facility design and scaling. Note that the location of maximum flux is shifted downward from center. This is due to the gradual voiding along the axis as a result of boiling in the upper region of the core.

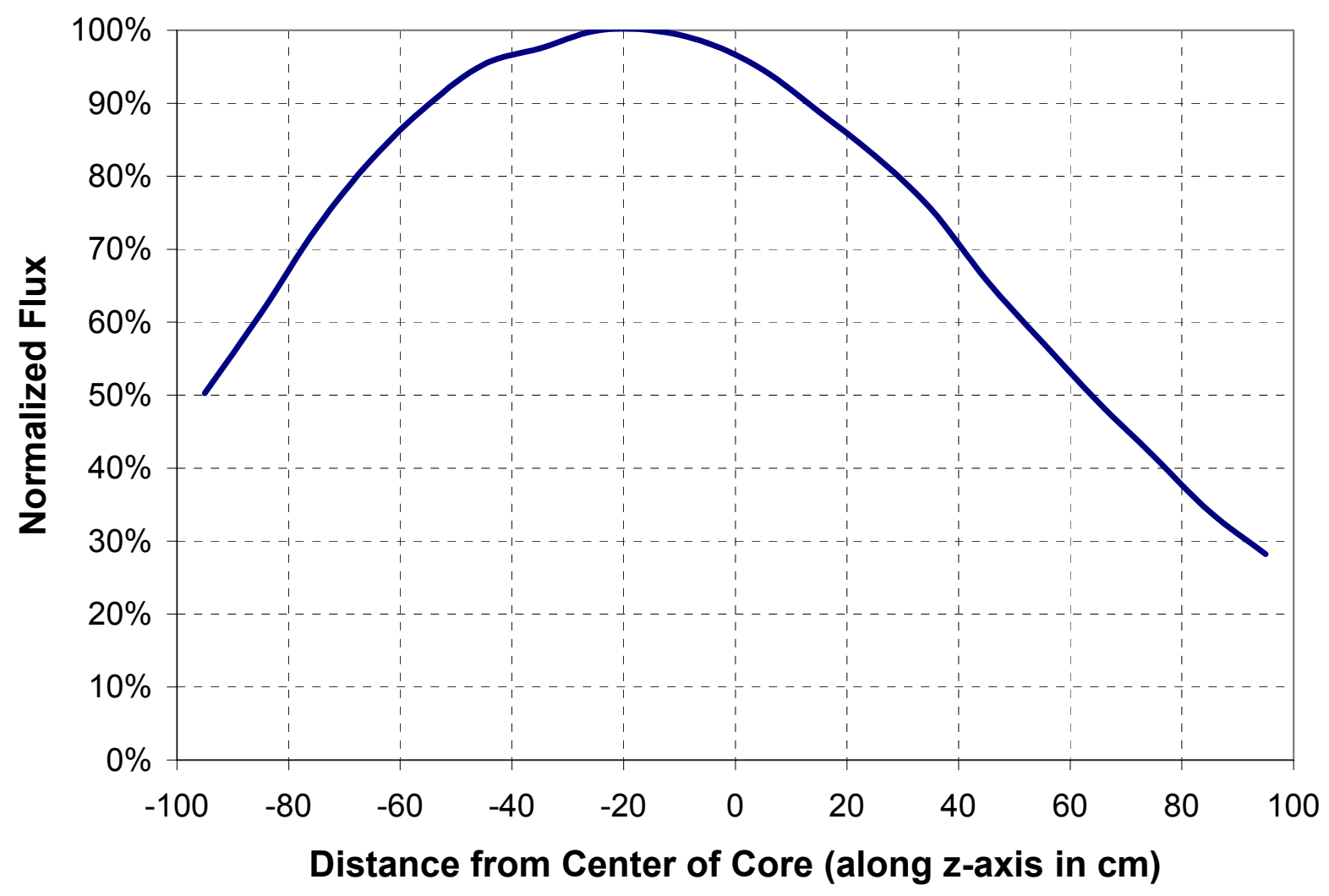

Figure 3-9 Axial neutron flux profile.

\subsubsection{Steam Generator}

The steam generator, as was shown in Figure 3-2, is a helical-tube, once-through heat exchanger, located in a common vessel with the reactor. The heat exchanger consists of 1012 tubes arranged in an upwardly spiraling pattern. Cold feedwater enters the tubes at the bottom, and slightly superheated steam is collected at the top. The generated steam is expanded in a turbine generator to produce power. The steam generator tubes are arranged into two tube bundles with 
the tubes attached to tubesheets through hydraulic expanding and welding. There are 4 tubesheets that are incorporated into the vessel. The tubes are $16 \mathrm{~mm}(0.625$ in.) outside diameter with a $0.9 \mathrm{~mm}(0.035 \mathrm{in}$.) thick walls and a length of $22.3 \mathrm{~m}(73 \mathrm{ft})$ each. The tubes are arranged on a square pitch, with a transverse pitch ratio of 1.8 and a vertical pitch ratio of 1.5. The tubes occupy the space between the hot riser and the vessel cylindrical wall, and there are four rotations in the upward spiral. The material selected for the tubes is thermally treated Inconel 690.

\subsubsection{Reactor Module Support}

The reactor module support shall be designed to:

- Limit the piping loads on the vessels

- Accommodate radial expansion of the vessels

- Accommodate seismic loads in combination with other loads

- Facilitate inspection and maintenance of supports.

Several support concepts of the reactor module, which includes the containment vessel and the reactor/SG vessel were considered. Figure 3-10 shows four concepts that were retained for further investigation. Alternative 3 (top support of the module with bottom support of the reactor) has been selected based on the following considerations.

- Anchor bolts of the entire reactor module are located above reactor cavity water level, therefore, easily accessible for replacement and inspection.

- Reactor/SG vessel is supported at the bottom, providing clear space at the top for routing of piping and cabling.

- Seismic loads should be easily accommodated by top supporting, since the reactor module is located below grade

\subsection{Containment}

The reactor containment with the internal components is diagrammatically shown in Figure 3-11. The reactor containment houses and protects the reactor equipment and associated safety-related systems. The major safety function of the containment is to contain the release of radioactivity following postulated accidents. The major equipment and systems located in the containment are the primary vessel containing the reactor core and steam generator, and the automatic depressurization system. The containment is a pressure vessel, as shown in Figure 3-1, designed to accommodate the transient pressure response anticipated during accident scenarios. 

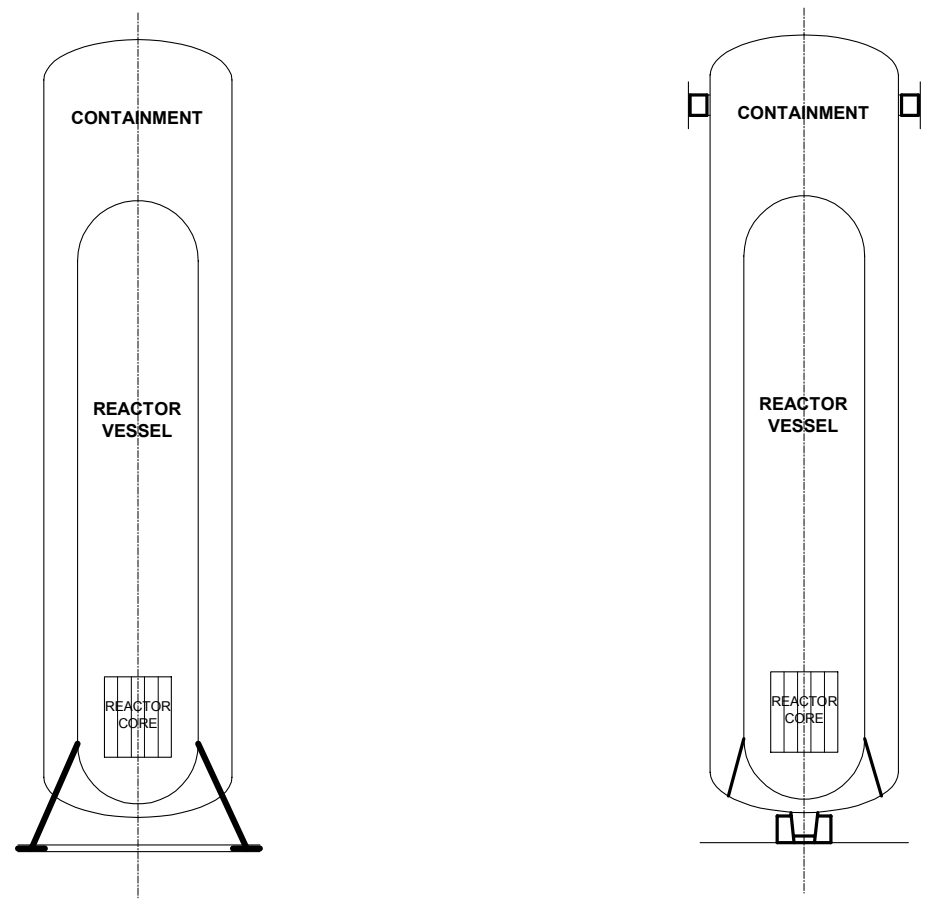

\section{ALTERNATIVE 1}

(BOTTOM SUPPORT -
BOLTED TO FLOOR)

ALTERNATIVE 2

(BOTTOM SUPPORT

THRU CONICAL KEY

SLIDING RESTRAINTS AT TOP)
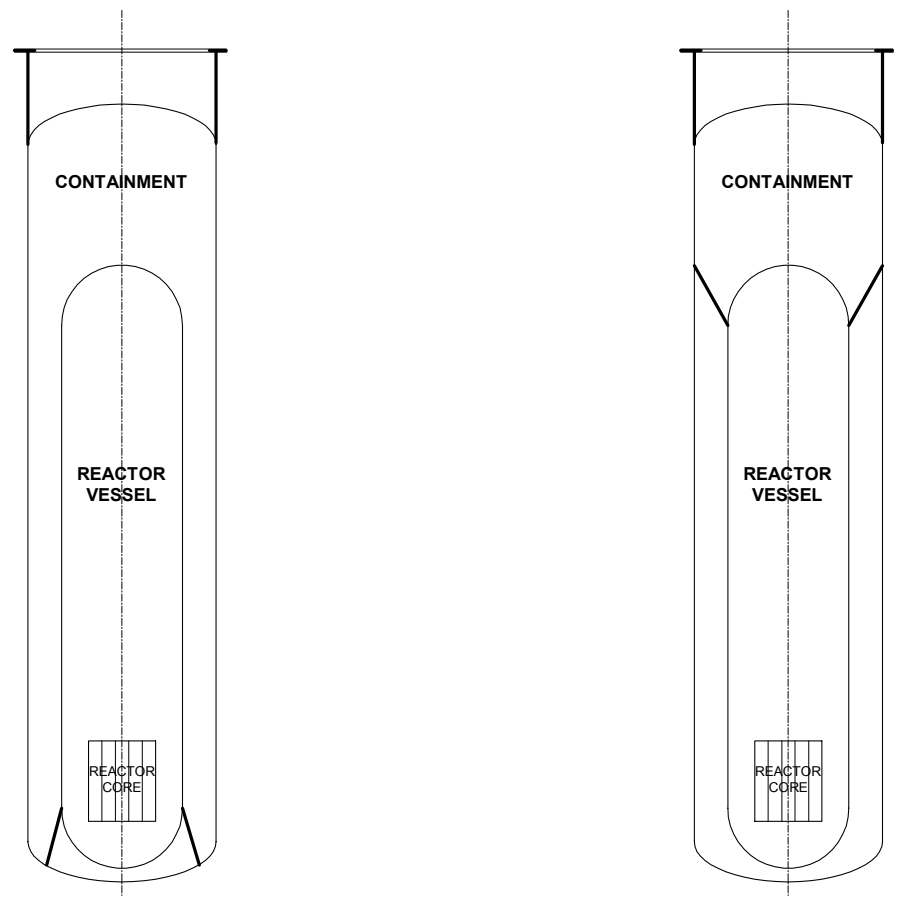

ALTERNATIVE 4

(TOP SUPPORT

BOLTED AT TOP

(TOP SUPPORT
BOLTED AT TOP)

RV TOP SUPPORTED)

Figure 3-10 Reactor Module Support Concepts 


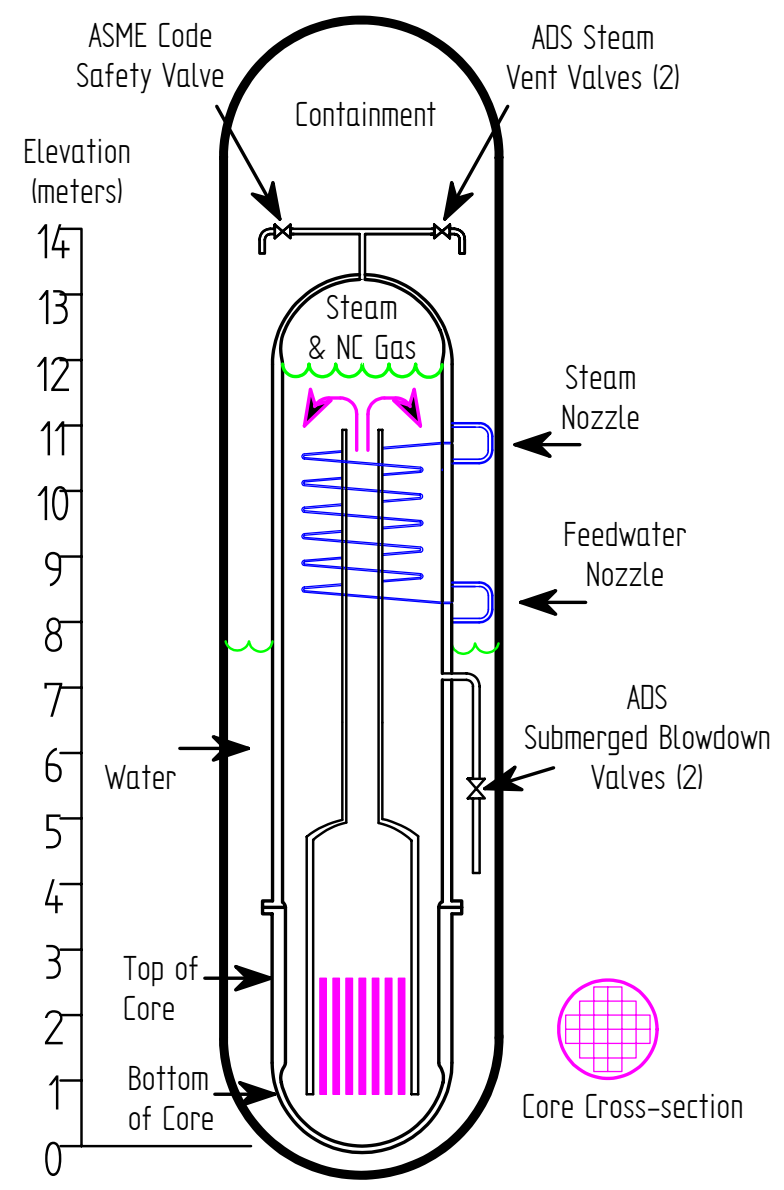

Figure 3-11 Containment with Internal components

\subsubsection{Containment Vessel}

The containment is a vertical cylindrical vessel with elliptical heads. The outside diameter of

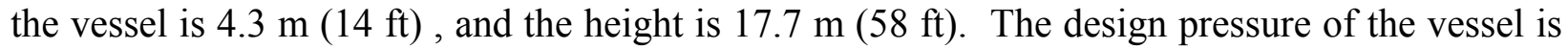
$1.9 \mathrm{MPa}(275 \mathrm{psia})$. This pressure is sufficient to accommodate, with sufficient safety margin, the highest pressure spike during anticipated worst case accident scenario. The vessel is made of stainless steel. The steel containment walls are the pressure boundary and also provide a heat transfer surface for removal of heat from the reactor during normal operation and accident conditions. The containment vessel is entirely welded. No access to the containment is provided during normal operation. Access for refueling and maintenance activities is provided by cutting the vessel in the cylindrical portion at an elevation above the reactor core. 


\subsubsection{Emergency Core Cooling Systems}

A charging and letdown system is required for startup and shutdown, and a high vessel vent line is necessary to remove noncondensible gases from the system and possibly also to provide pressure control during startup and/or shutdown. Ruptures of these piping systems must be considered in the safety studies; hence, accommodations for containment pressure suppression and primary system decay heat removal must be provided in the design. The key elements of the Emergency Core Cooling (ECC) System are the liquid pool and the ADS system, which consists of steam vent lines, attached to the top of the primary vessel, and submerged vent lines, which discharge coolant below the surface of the liquid pool. As noted, the free space within the containment is partially occupied with water, which serves as a liquid pool into which primary coolant is sparged during blowdown, and as makeup reservoir of primary coolant following primary and containment pressure equalization. An automatic depressurization system (ADS) provides pressure suppression and primary system venting. The ADS submerged vent lines discharge fluid into the containment reservoir, thus limiting the maximum containment pressure to within design limits. The ADS high vessel vent lines provide a path for the steam, which is produced by core decay heat, to vent to the containment, where it condenses on the containment wall. Following the equalization of primary system and containment pressures, the ADS submerged vent lines provide a path for makeup inventory to enter the vessel, and the high containment lines provide for venting of steam from core boiloff. Therefore, a natural path for recirculation is established whereby steam is vented from the primary system and condenses on the walls of the containment, and makeup liquid is supplied to the primary system from the containment pool. The containment itself is submerged in water (see next section) to provide cooling for the containment steel wall.

\subsubsection{Containment Cooling}

Two or more reactor modules are located in a reactor building, submerged in a common, below grade cavity filled with a pool of water, as will be described in the Section 3.4 (see, for example, Figure 3-16). The modules are in separate bins to provide physical separation between the modules for seismic considerations. Cooling of the containment during normal and abnormal conditions is accomplished by heat conduction through the steel walls of the containment to the surrounding pool. Heat from the pool is removed through a closed loop circulating system and rejected into the atmosphere in a cooling tower to maintain a pool temperature below $311 \mathrm{~K}$ $(100 \mathrm{~F})$. For the most severe postulated accident, the volume of water in the pool provides a passive ultimate heat sink for 3 or more days to allow the restoration of active heat removal systems.

\subsection{Plant Description}

This section provides a general description of a nuclear power plant based on the MASLWR baseline concept. The baseline plant consists of 30 identical power generation units and common facilities. Each power generation unit has an overall net electrical rating of $35 \mathrm{MWe}$ for a total plant net electrical rating of $1050 \mathrm{MWe}$. The plant capacity was selected to be in the range of current and evolutionary nuclear power plants. However, the plant can be designed for smaller capacities as required. 


\subsubsection{Power Generation Concept}

Major plant performance characteristics are summarized in Table 3.3. The power generation system converts thermal energy from the nuclear steam supply system (NSSS) into electrical energy.

Table 3-3 Plant Performance Characteristics.

\section{Overall Plant}

- Net Electrical Output

- Net Station Efficiency

- Number of Power Generation Units

- Nominal Plant Capacity Factor

Power Generation Unit

- Number of Reactors

- Net Electrical Output

- Steam Generator Number

- Steam Generator Type

- Steam Cycle

- Turbine Type

- Turbine Throttle Conditions

- Steam Flow

- Feedwater Temperature

Reactor

- Thermal Power (Core)

- Cold Leg/Hot Leg Temperature

- Coolant Mass Flow Rate

Reactor Core

- Fuel

- Refueling Intervals
1050 Mwe

$23 \%$

30

$95 \%$

One

35 Mwe

One

Vertical helical tube

Slightly superheated

$3600 \mathrm{rpm}$, single pressure, Two-Flow

13.8 bars abs. $/ 204^{\circ} \mathrm{C}\left(200 \mathrm{psia} / 400^{\circ} \mathrm{F}\right)$

$56 \mathrm{~kg} / \mathrm{s}(445000 \mathrm{lb} / \mathrm{hr})$

$33.3^{\circ} \mathrm{C}\left(92^{\circ} \mathrm{F}\right)$

$150 \mathrm{MWt}$

$489.6^{\circ} \mathrm{K} / 560.2^{\circ} \mathrm{K}$

$424 \mathrm{~kg} / \mathrm{s}$

UO2, $8 \%$ enriched

5 years

Figure 3-12 shows a simplified diagram of one power generation unit, and Figure 3-13 shows it in an isometric view. The heat transfer system consists of a reactor and a steam generator. During operation, the reactor coolant (water) is circulated by natural circulation between the reactor core and across the steam generator tube bundles located at an appropriate height above the reactor. The circulating reactor coolant transfers the heat generated in the reactor core to the steam generators. In the steam generator tubes, the reactor coolant heat is used to evaporate feedwater and heat the steam, thus producing slightly superheated steam. A commercially available, one stage low-pressure turbine associated with the reactor is supplied with this steam. After expanding in the turbine, the steam is exhausted to a condenser where it is condensed. The condensate is pumped back by the feedwater pump without any pre-heating to the steam generator tubes. The condenser is cooled with circulating water in a closed loop system. The 
heat from condensing steam is ultimately rejected to the atmosphere in an evaporative mechanical-draft cooling tower. A portion of the condensate flow $(5 \%)$ is processed in condensate polishers to maintain water quality. The generator, driven by the turbine, generates electric power that is delivered to the utility grid through a step-up (main) transformer.

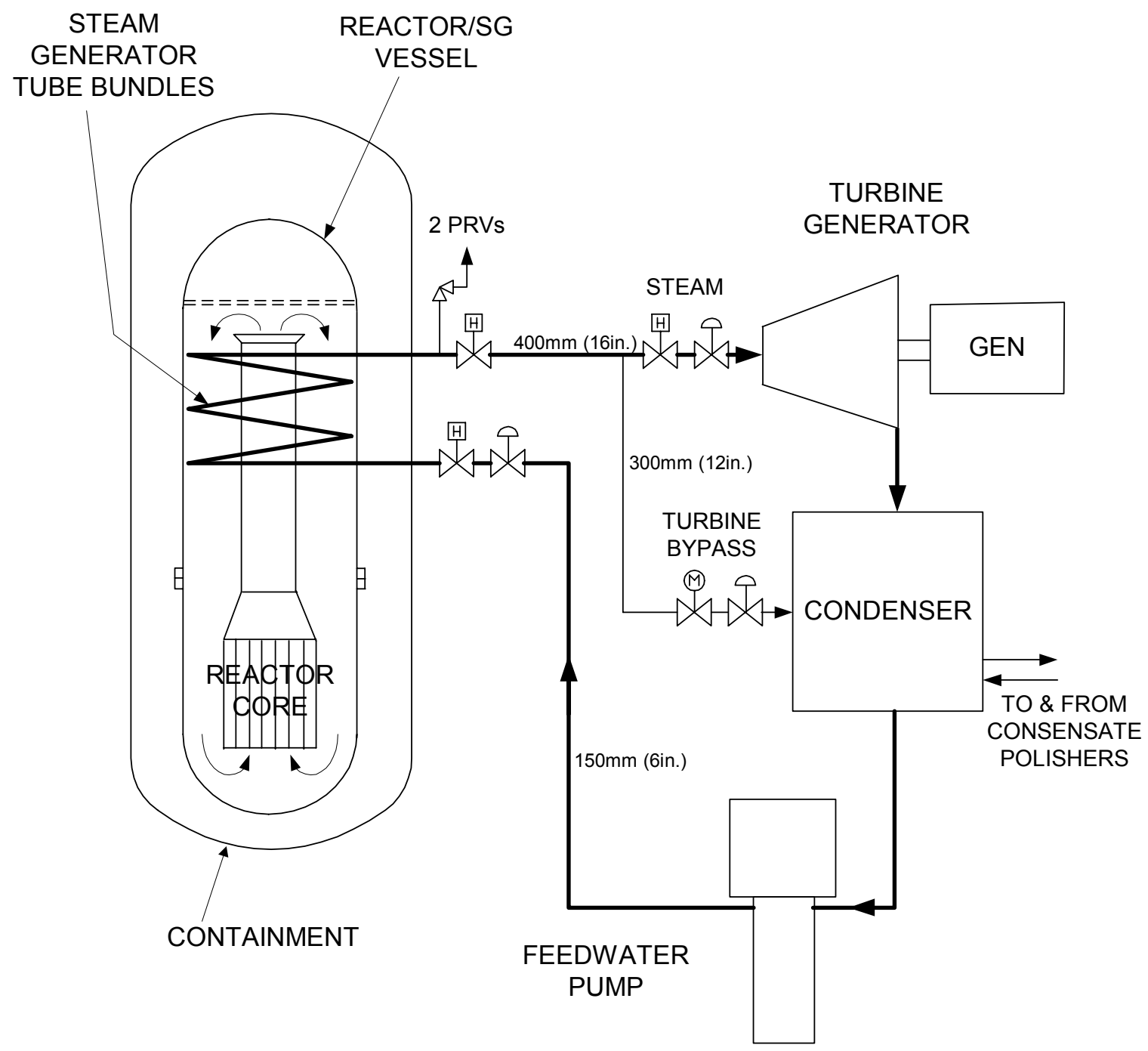

Figure 3-12 Simplified Heat Cycle Piping Diagram. 


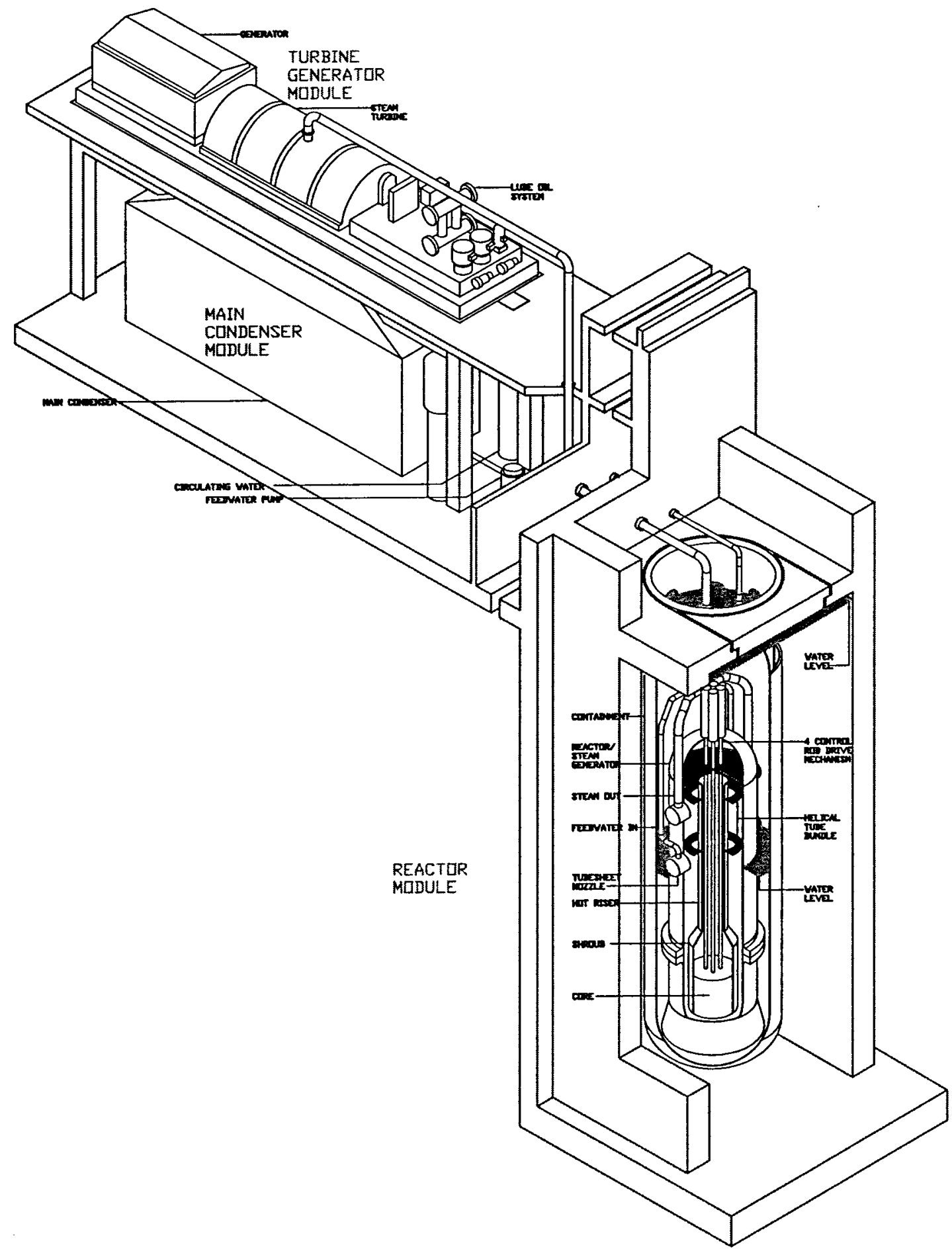

Figure 3-13 Power Generation Unit 


\subsubsection{Overall Plant Arrangement}

The overall plant arrangement is shown in Figure 3-14. The plant consists of a power generation complex and common facilities. The power generation complex for the baseline plant consists of 30 power generation units (30 reactors and associated turbine generators), and reactor assembly and disassembly and fuel handling equipment. The plant area is about $390 \mathrm{~m}(1280 \mathrm{ft})$ by $350 \mathrm{~m}$ (1160 ft) or about14 ha (34 acres).

The plant net total output is 1,050 MWe. The plant is separated into the nuclear island (NI) and the non-safety area (NSA). The NI encompasses the safety-related systems and structures, and the power generation complex. The reactor buildings and related common support facilities are located in the NI. Although the turbine generators, condensers, related structures, and common support facilities are not safety-related, they are also located in the NI for practical reasons. The distinct physical separation between NI and the non-safety area minimizes the safety area footprint.

Spent fuel is temporarily stored inside the fuel handling building before being shipped offsite to a central reprocessing facility. The plant is provided with a rail access. The rail is connected to the fuel handling and maintenance building to allow easy offsite transfer of new and spent fuel, receiving new reactor modules and shipping offsite radioactive waste.

The in-line arrangement of reactors provides for sequential construction of power generation units. This allows for power to be generated as soon as a unit is completed, while installation and testing may progress on the following units.

The cooling towers are located as close as practical to their respective turbine-generator buildings to minimize the length of the large-diameter circulating cooling water pipes. The switchyard should be located up-wind of the cooling towers to minimize the effect of cooling tower vapor drift on electrical equipment.

All the common facilities such as the training center, the administration building, the control building, the plant services building, the maintenance facility, etc., are located at the main entrance of the plant to provide for easy access to the various buildings without going through the entire plant. Areas on the far end of the plant are designated for use during construction.

From the point of view of safeguards and security, division of the plant into safety and non-safety related areas is used to advantage. The safety-related NI area and the non-safety related areas have separate guardhouses with a personnel access control level appropriate to the area. The NI area is protected with a double fence and intrusion detection equipment. The nonsafety area is protected with a single fence. An owner-controlled area surrounds the plant.

Road and rail provide transportation access to the plant. Barge access is desirable but not mandatory. 


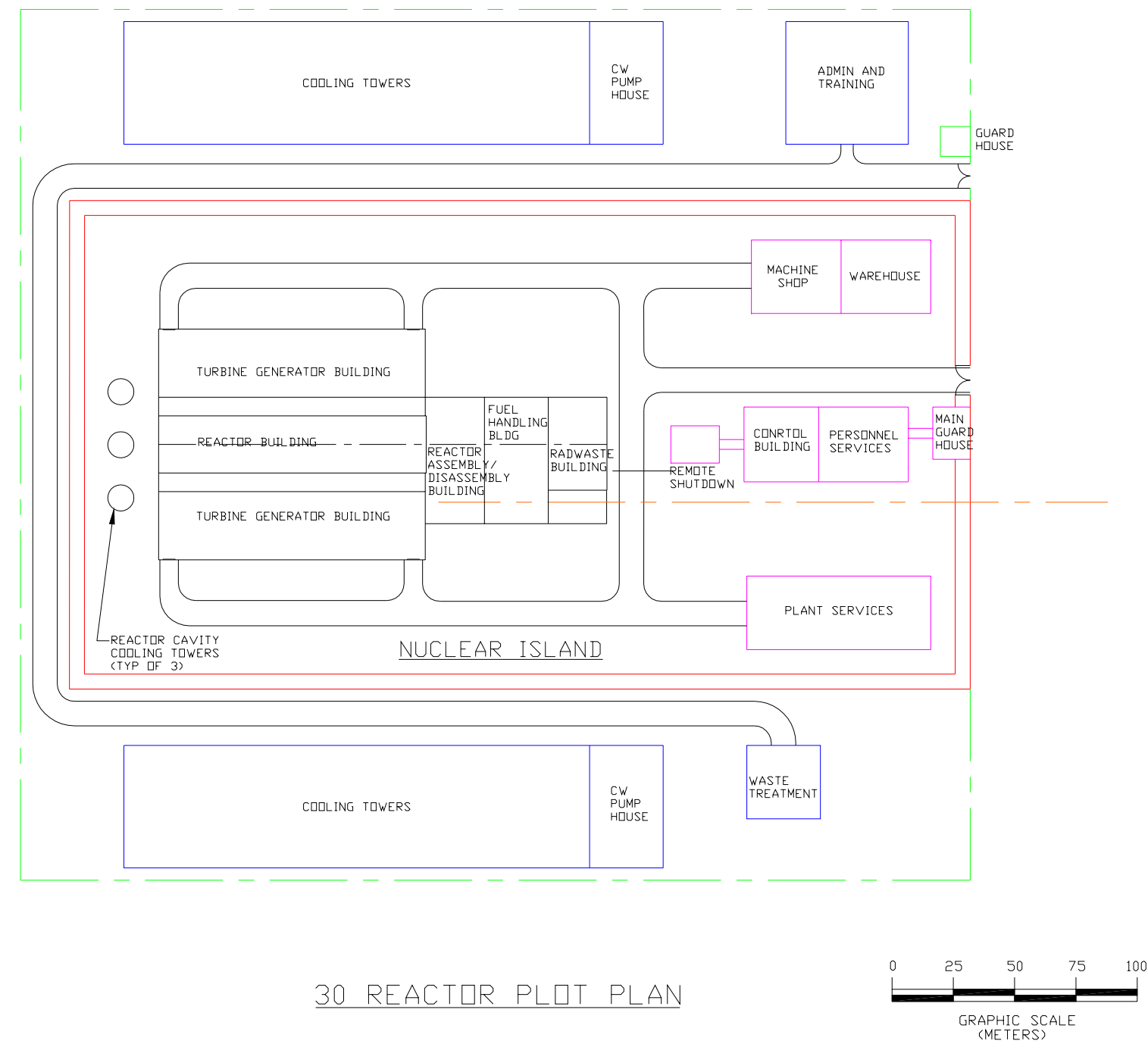

Figure 3-14 Overall Plant Arrangement 


\subsubsection{Power Generation Complex}

The power generation complex is an integrated structure that houses the power generation units and includes the following major facilities:

- Reactor building

- Turbine generator buildings

- Fuel handling and maintenance building

A plan view of the power generation complex arrangement for the baseline plant consisting of 30 power generation units is shown in Figure 3-15 for the above grade portion and in Figure 3-16 for the below grade portion. Elevation views of the complex are shown in Figure 3-17 through Figure 3-19. The overall dimensions in plan view of the complex are $182 \mathrm{~m}(597 \mathrm{ft})$ long and 94 $\mathrm{m}$ (308 ft) wide. The building is partially located below grade. The power generation complex consists of a reactor building located longitudinally in the center of the building with two turbine buildings adjacent to each side of the reactor building. The fuel handling building and the reactor assembly/ maintenance building are adjacent to one end of the reactor/turbine generator buildings. This allows for phased construction of the reactor/turbine generator buildings and power generation units. Initially only the number of power generation units needed can be constructed. Then, power generation units can be added as needed at different stages.

\subsubsection{Reactor Building}

A plan view of the reactor building is shown in Figure 3-15 and Figure 3-16. A longitudinal elevation view of the building is shown in Figure 3-17 and a transversal elevation view is shown in Figure 3-18.

The reactor building arrangement and design enable systems and components required for safe plant operation and shutdown to withstand or to be protected from the effects of sabotage, environmental conditions, natural phenomena and postulated design basis accidents. The reactor building also provides radiation protection to plant operation and maintenance personnel. The reactor building is a reinforced concrete structure, seismic Category I, designed in accordance with Regulatory Guide 1.29. In addition, the reactor building is tornado hardened in accordance with Regulatory Guide 1.76. 


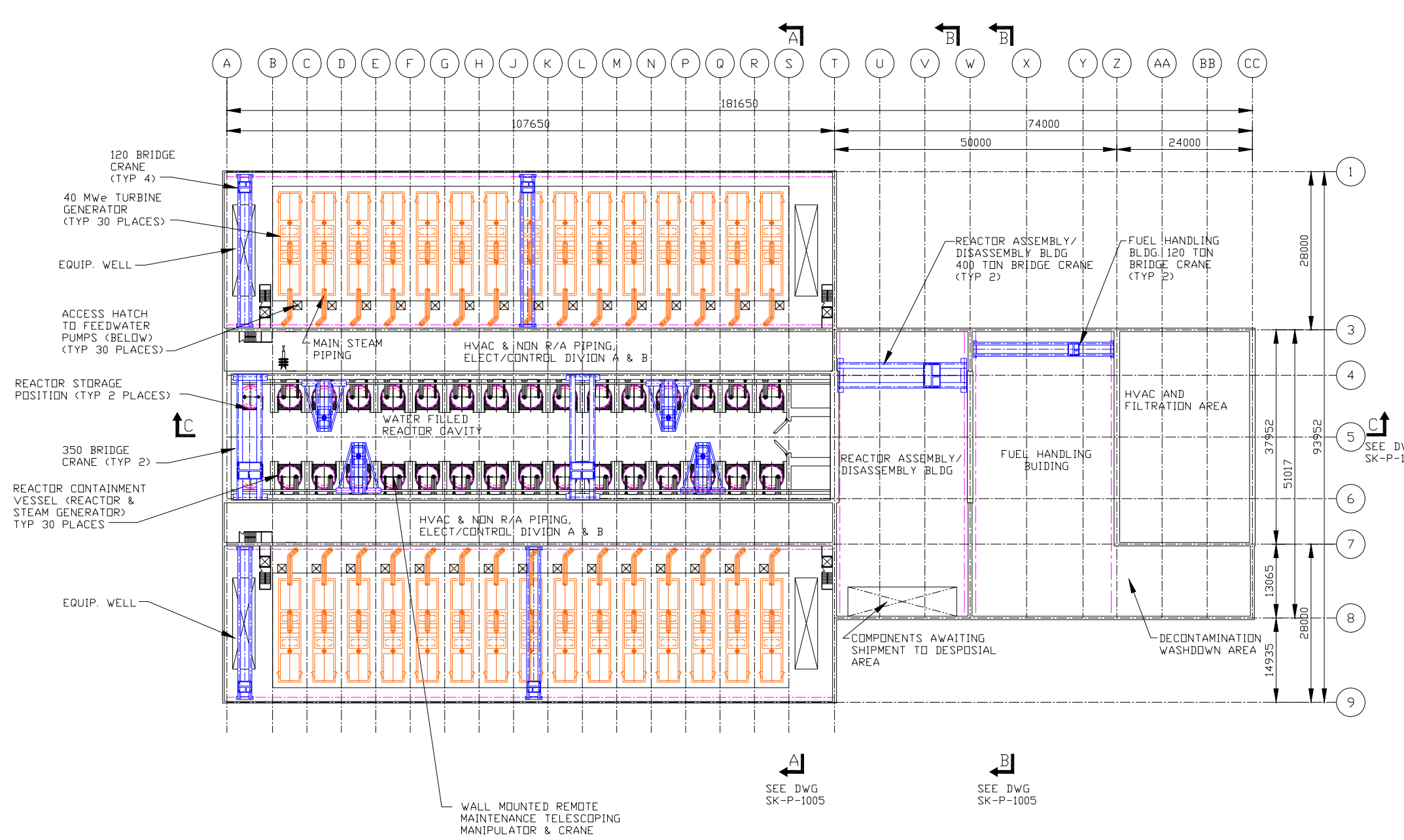

Figure 3-15 Power Generation Complex - Plan View Above Grade 


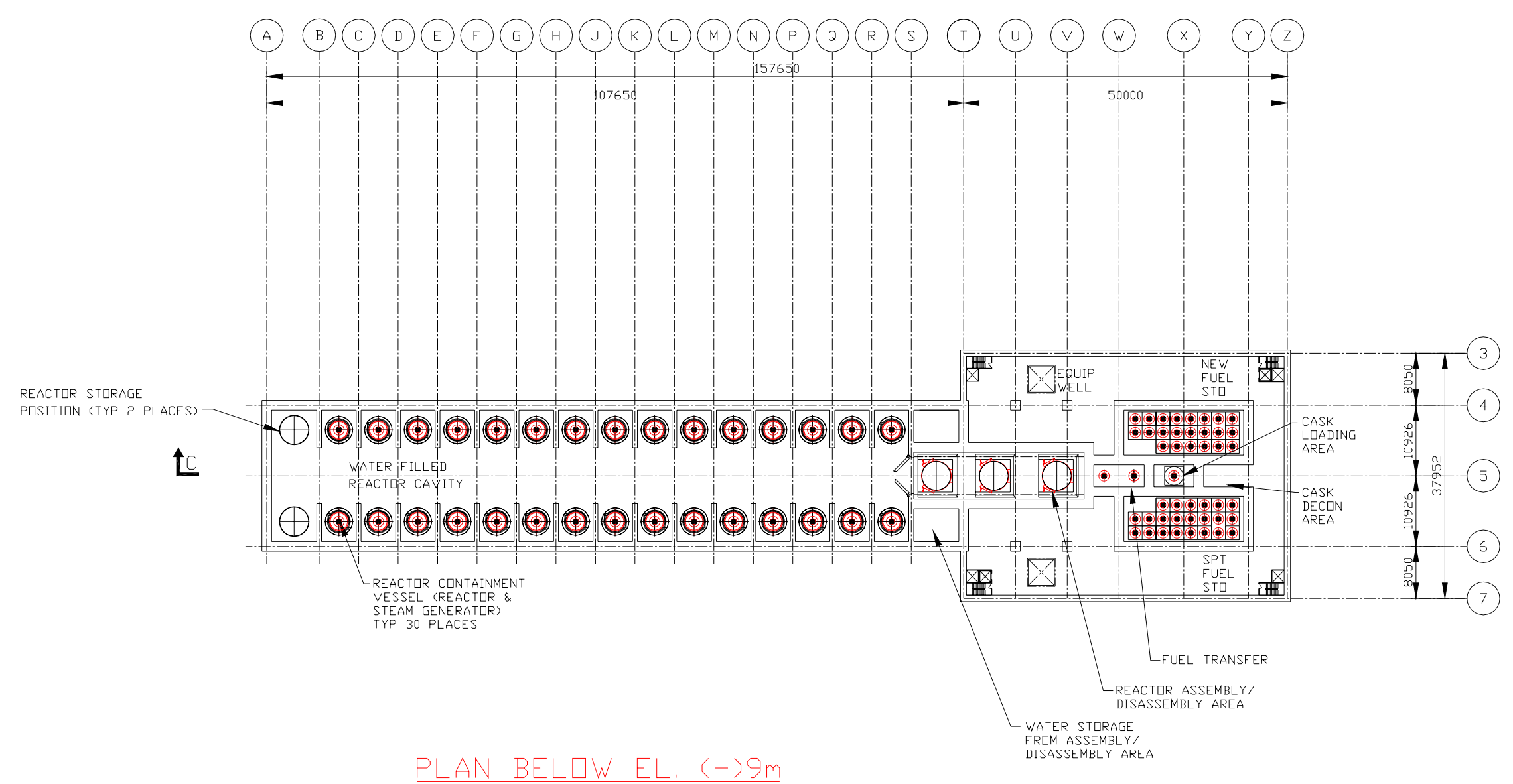

Figure 3-16 Power Generation Complex - Plan View Below Grade 


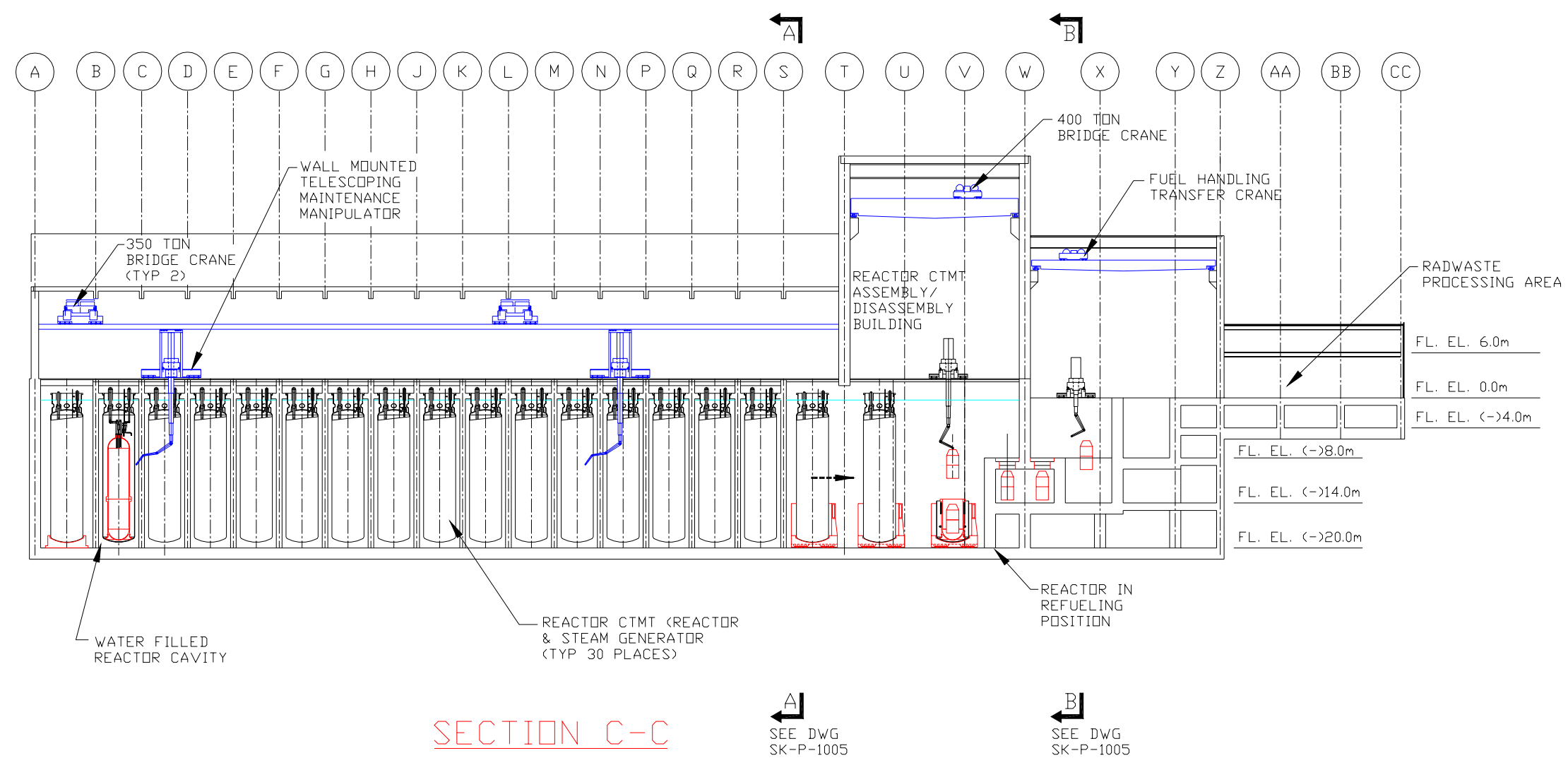

Figure 3-17 Reactor Building/Fuel Handling \& Maintenance Building Longitudinal Elevation View 


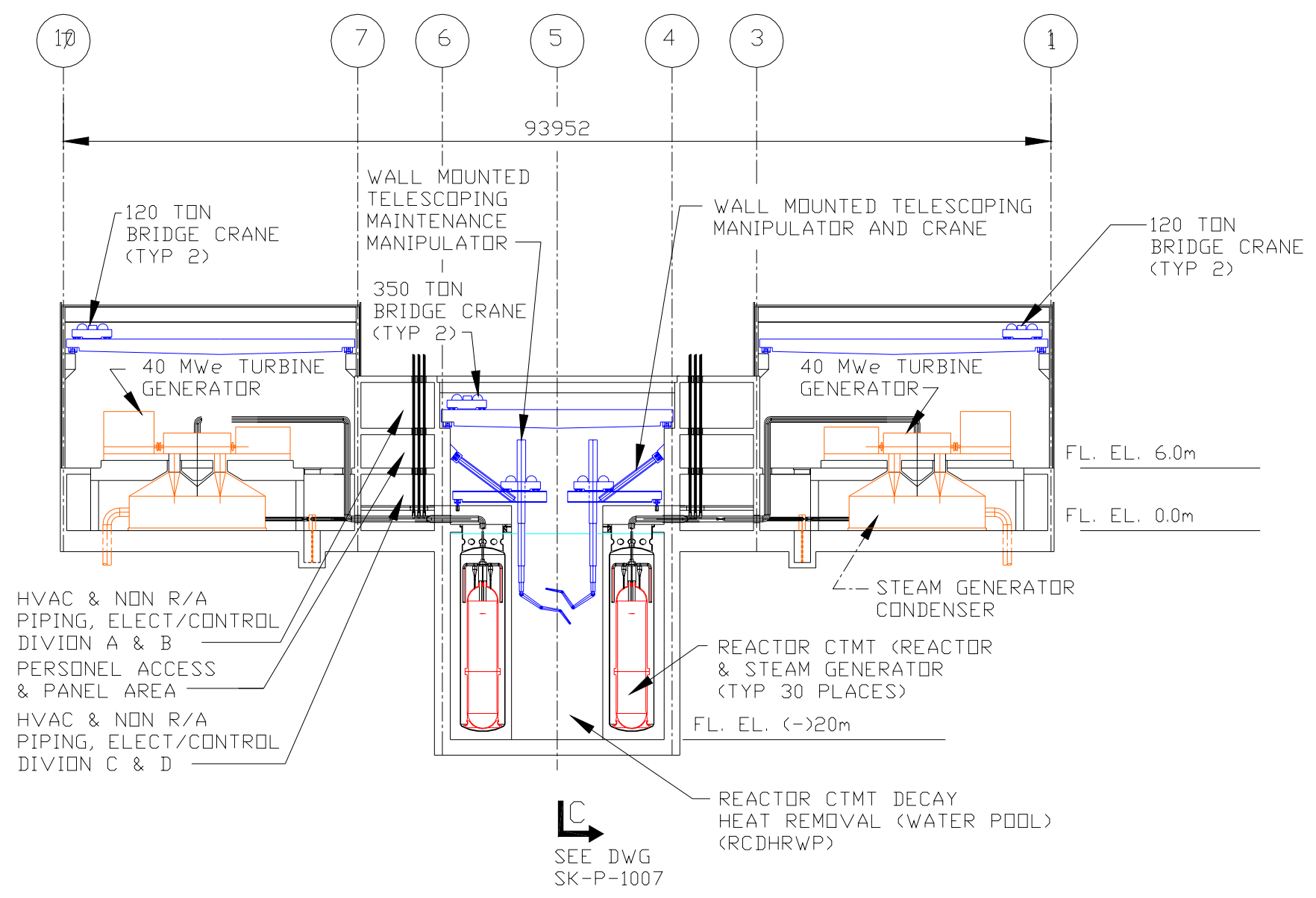

Figure 3-18 Reactor Building/Turbine Generator Buildings Transversal Elevation View 


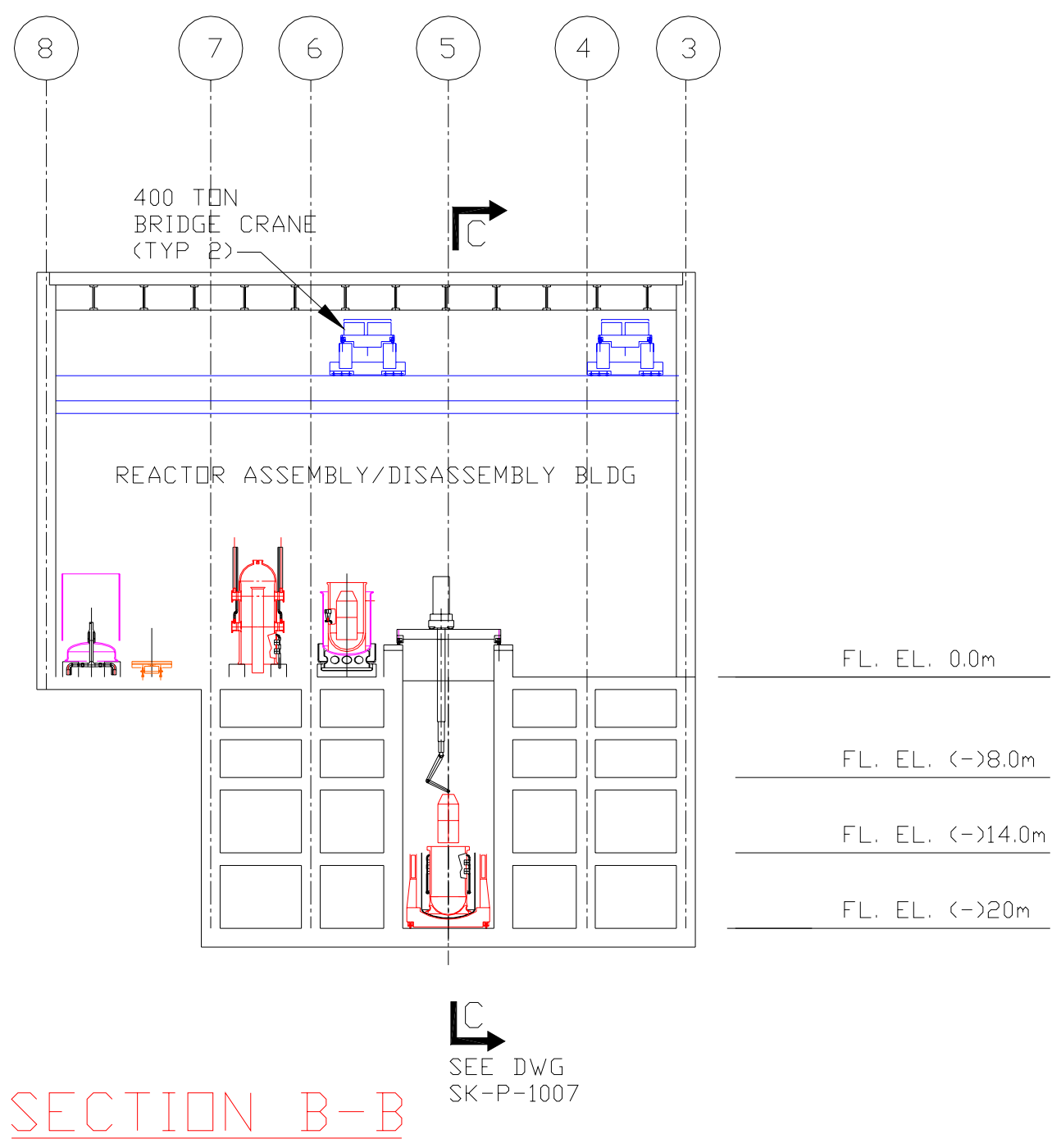

Figure 3-19 Fuel Handling and Maintenance Building - Elevation 
The reactor building consists of an embedded reactor cavity with an above-grade structure that houses hoisting and handling equipment. Also located above grade are equipment vault structures that house electrical equipment and instrumentation for reactor control, monitoring and protection, containment isolation, and miscellaneous support and services equipment. Space is also provided in the equipment vault structures for routing of piping, wiring and cabling, HVAC

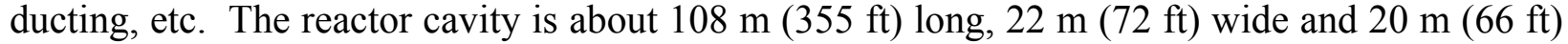
embedded below grade, and is filled with water up to the grade level. The space above the reactor cavity extends about $15 \mathrm{~m}(50 \mathrm{ft})$ above grade and houses hoisting and manipulating equipment. The equipment vaults are located on each side of the reactor cavity. They are about $9 \mathrm{~m}$ (30 ft) wide and $15 \mathrm{~m}$ high (49 ft) arranged in three levels. The reactor modules are installed in a vertical position and are arranged into two rows of 15 modules each, along the external cavity walls. There are two additional spaces in each row for temporary storage of reactor modules. Vertical separation walls are provided between reactor modules for protection of reactor modules. A space is provided in the middle between the two rows of modules to allow for moving of the reactor modules between the reactor cavity and the fuel handling and maintenance building adjacent to one end of the reactor building. Four wall-mounted traveling manipulators are provided in the reactor cavity above the water level, two on each side, for connecting and disconnecting piping and electrical wiring and cabling during installation, replacement and removal of reactor modules. The equipment vaults are partitioned to provide separation between power generation units to the maximum extent practical. Also, the layout of safety-related electrical system provides for division separation required by the nuclear power plant regulatory requirements.

\subsubsection{Turbine Generator Buildings}

A plan view of the turbine buildings is shown in Figure 3-15; a transversal elevation view is shown in Figure 3-18.

There are two separate turbine generator buildings, each associated with one row of reactor modules. The turbine generator buildings are above-grade structures which house the main turbine-generators with their auxiliaries, the main condensers, and the feedwater systems. Each reactor module has an associated and dedicated turbine generator, condenser and feedwater pump. The turbine generator buildings are above-grade structures adjacent to the reactor

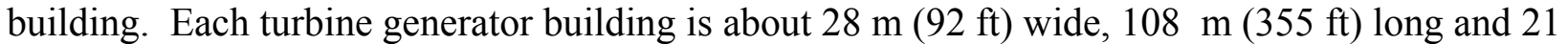
$\mathrm{m}(70 \mathrm{ft})$ high. The turbine-generators are supported about $6 \mathrm{~m}(20 \mathrm{ft})$ above grade by a pedestal constructed of structural steel and reinforced concrete. Each condenser is of the longitudinal type and is located at grade level within the pedestal under the related turbine generator. The turbine generators are oriented to preclude the possibility of a turbine blade missile hitting the reactors. Two overhead traveling cranes are provided for installation and maintenance in each turbine-generator building. The turbine generator buildings are steel-framed structures with insulated metal wall siding and roof decking. Each turbine generator consists of two skidmounted modules: turbine with auxiliaries such as lube-oil system and generator with auxiliaries. The turbine generator buildings are non-safety related. However, they are seismic Category II since they are structurally connected to the reactor building, which is seismic Category I. 


\subsubsection{Fuel Handling and Maintenance Building}

The fuel handling and maintenance building plan view above grase is shown in Figure 3-15 and below grade in Figure 3-16. Elevation views are shown in Figures 3-17 and 3-19. The building is partly above grade and partly below grade. It is adjacent and structurally connected to one end of the reactor and turbine generator buildings. The building is a reinforced concrete structure,

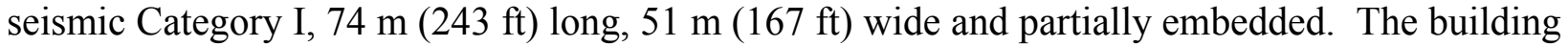
consists of many rooms and compartments needed to accommodate the various equipment and systems, and their functions and separation requirements. The reactor cavity is connected directly to the fuel handling and maintenance facility, thus allowing for moving reactor modules under water between the two buildings. The building also provides radiation protection for plant operation and maintenance personnel. The building is a complex of facilities, which includes the following major facilities:

- Reactor module assembly and maintenance

- Fuel handling

- Radioactive waste treatment.

The reactor module assembly and maintenance facility houses equipment, systems and structures needed for providing access inside the reactor vessel through cutting the containment wall and unbolting the reactor vessel flanged connection, performing the necessary maintenance activities, and reassembling the reactor vessel and containment vessel after refueling and maintenance. The facility also includes the necessary inspection and testing equipment needed for the reactor module. The facility has rail car access for receiving new reactor modules and shipment offsite of used reactor modules.

The fuel handling facility protects mainly equipment, systems and structures related to fuel receiving, unloading, temporary storing and preparation for shipment of spent fuel. The facility has rail car and truck access for new fuel receiving and shipment of spent fuel.

The radioactive waste treatment facility houses equipment and systems for processing the plant radioactive gaseous, liquid and solid wastes and preparation for shipment offsite. It also provides a temporary storage for radioactive wastes. The facility has rail access.

\subsubsection{Remaining Facilities}

The following major other facilities are provided for proper operation of the MASLWR plan:

- Heat rejection

- Machine shop (NI)

- Warehouse (NI)

- Personnel services (NI)

- Control building (NI)

- Remote shutdown building (NI)

- Plant services (NI)

- Administration and training

- Waste treatment

- Guardhouses (NI and NSA). 
The function of the main heat rejection system is to reject the turbine generator exhaust heat of condensing steam to the atmosphere. The main heat rejection system consists of two identical heat rejection sub-systems, each associated with a turbine generator building. A heat rejection sub-system comprises a cooling tower, a circulating water pumphouse and circulating water piping connecting the main condensers located in the turbine building with the pumphouse/cooling tower. The cooling tower consists of a below-grade water basin and an above-grade structure containing the water dispersion section and the forced-air fans. The cooling towers are seismic Category III structures.

The machine shop building houses equipment and provides space for servicing and maintenance of non-radioactive components. The building is a one-story, above-grade structure, seismic Category III.

The warehouse provides space and handling/hoisting equipment for controlled storage of spare modules, spare parts and tools. The building is an above grade structure, seismic Category III, adjacent to the machine shop.

The personnel services building houses the health physics services for controlled access of personnel to the nuclear island yard and facilities. It also houses various personnel support services, such as, locker rooms, showers, toilet facilities, lunch and conference rooms, and first aid. The building is a two-story above-grade structure, seismic Category III.

The control building houses the plant main control room, the technical support center, the information management center, and the maintenance and operation support areas. The control building is an above-grade, two-story structure, seismic Category I, tornado hardened. An underground tunnel connects the control building with the remote shutdown building.

The remote shutdown building provides for prompt shutdown of reactors in case these emergency procedures cannot be performed from the main control room. The building is an above-grade, one-story structure, seismic Category I, tornado hardened.

The plant services facility provides the plant common services such as demineralized water, compressed air, potable water, fire protection water, auxiliary steam. The building is an abovegrade, seismic Category III, one-story structure with large storage tanks located outside.

The administration building houses the administration services and the training center. It is an above-grade, two-story structure, seismic Category III.

The waste treatment facility houses the equipment and systems needed to treat all plant nonradioactive wastes before offsite disposal. It is seismic Category III.

There are two guardhouses: the NI guardhouse and the non-safety related guardhouse. They provide for controlled access and protection of the NI and the non-safety area respectively. The NI guardhouse is a Seismic Category I structure, tornado hardened, with a basement. 


\subsubsection{Modularization}

Modularization refers to the construction of certain plant facilities using factory fabricated modules, preassemblies, or fabricated items that are transported to the site and connected together with minimal field effort. These modules are shipped to the job site by rail, road, or barge for erection.

Factory fabricated modules are used to the maximum extent practical in the various plant structures and systems. Modularization is adopted because it is expected to provide the following advantages over conventional field fabrication:

- Lower capital cost

- Shorter construction schedule

- Better control of capital cost

- Improved productivity of field work

- Less risk of exceeding cost and construction schedule

- Improved quality achieved in a factory environment

The following types of modules are used in the plant facilities:

- Steel-framed (box module). The steel-framed modules are complete and include as applicable: structural steel, equipment, piping, HVAC ducting, cable trays and conduits, wiring and cabling, roofing, and siding. The steel-framed modules constitute all or part of the building or structure.

- Skid-mounted module - consists of one or more pieces of heavy equipment, operating and maintenance platforms, stairs and ladders, associated piping, instruments, cabling and other components mounted on a base frame.

- Structural module - consists principally of structural components which may include room and floor framing systems, columns, reinforcing bars, and wall elements (inner and outer wall liners) to accommodate onsite concrete placement.

- Pre-assembled module - comprised of factory-fabricated sections or modules shipped to the site and then assembled onsite into a large section or assembly prior to in-situ installation.

- Pre-cast concrete panels.

The shop fabricated modules are limited in size to about a $4.3 \mathrm{~m}(14 \mathrm{ft})$ diameter and a $18.3 \mathrm{~m}$ (60 ft) length, with a maximum weight of 275 mtons (303 tons) to allow for either rail or road shipment on most rail or road ways. The major entirely shop fabricated modules used for the baseline plant are as follows:

- Reactor modules (quantity: 30)

- Turbine with auxiliaries, skid-mounted modules (quantity: 30)

- Electric generator with auxiliaries, ski-mounted modules (quantity: 30)

- Main condenser modules (quantity: 30). 


\subsubsection{Smaller Plants}

While the MASLWR baseline plant consists of 30 power generation units, plants with smaller total capacity can be designed. The same basic configuration and capacity of the power generation unit will always be used. However, plants with a smaller final capacity will have smaller common facilities, such as the fuel handling and maintenance facilities, thus reducing appreciably the plant capital cost. A power generation complex was developed for a plant with a final capacity of $210 \mathrm{MWe}$, consisting of 6 power generation units. Figure 3-20 shows a plan view of the complex. The 6 reactor modules are arranged into one row. As can be seen, the size of the fuel handling and maintenance facilities is significantly reduced when compared to the baseline plant. However, the only way to accommodate further expansion of the plant is to add a new power generation complex.

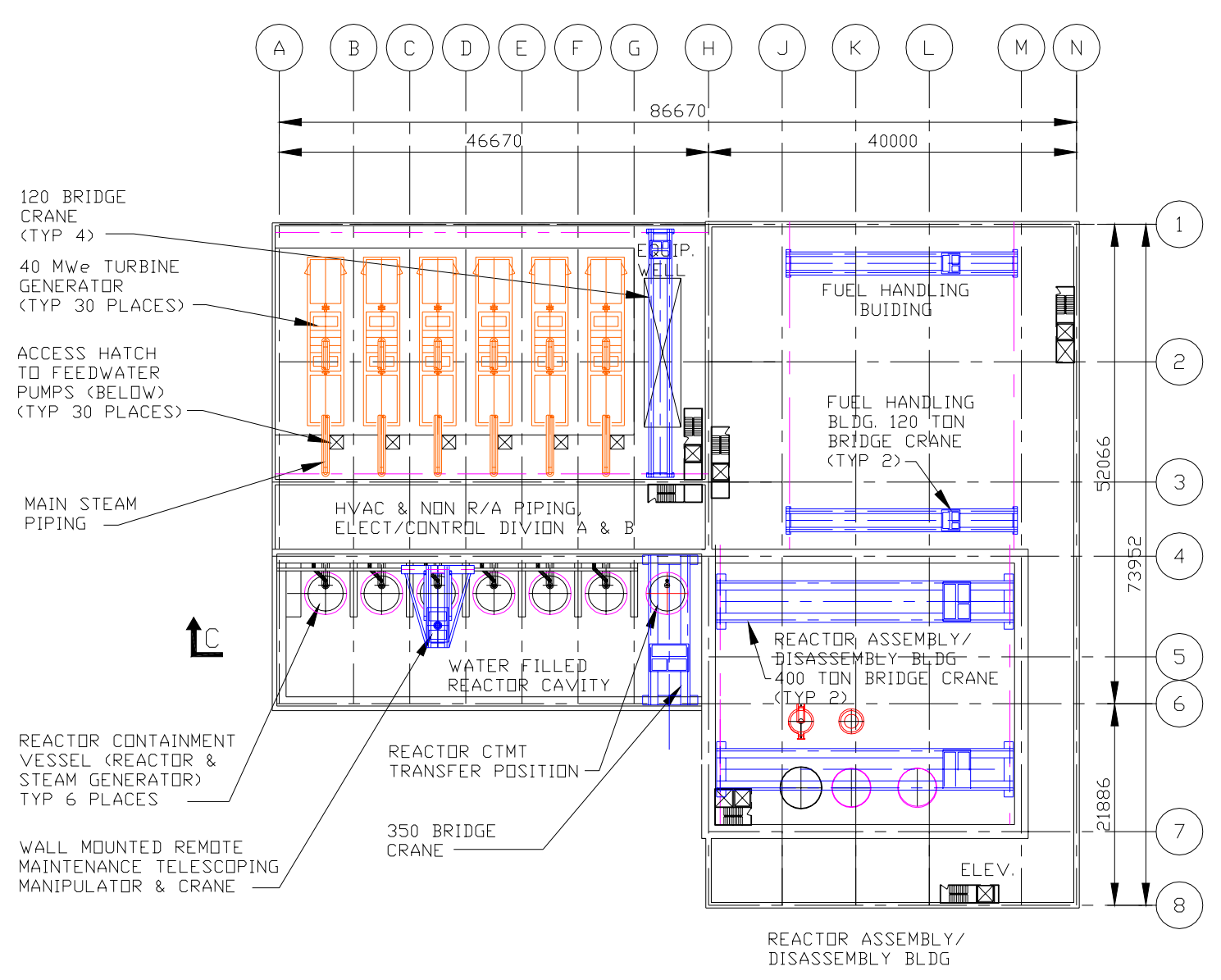

Figure 3-20 Six Reactor Module Plant - Plan View 


\subsubsection{Single Module Plant}

The single module plant preliminary concept developed is based on a 60-year life cycle consisting of two autonomous (self-reliant) 30-year period of operation. This will be achieved through a combination of longer fuel cycle and onsite storage of new fuel, spent fuel and spare parts. A preliminary plot plan of the power generation complex is shown in Figure 3-21. An initial conceptual arrangement of the reactor/turbine generator building is shown in Figure 3-20 in plan view and Figure 3-22 in elevation. The reactor module is submersed in a below grade cylindrical cavity filled with water. The above grade enclosure is used for refueling, inspection and maintenance activities. During reactor operation, the cavity is closed. During refueling and maintenance activities, the hatch on the top of the cavity is partially or fully removed. The containment head and the reactor head with control rod drive mechanisms are removed and temporarily store in the refueling/maintenance enclosure. Also, the steam generator coils are removed and moved to the inspection/maintenance stand. The spent core is removed from the reactor vessel as one complete assembly and stored in the cavity under water. A new core assembly from the new fuel storage room is taken, inspected and lowered into the reactor vessel. On the left side of the reactor building there are three levels of miscellaneous rooms and vaults to house the control room, electrical and control equipment, mechanical equipment, etc.

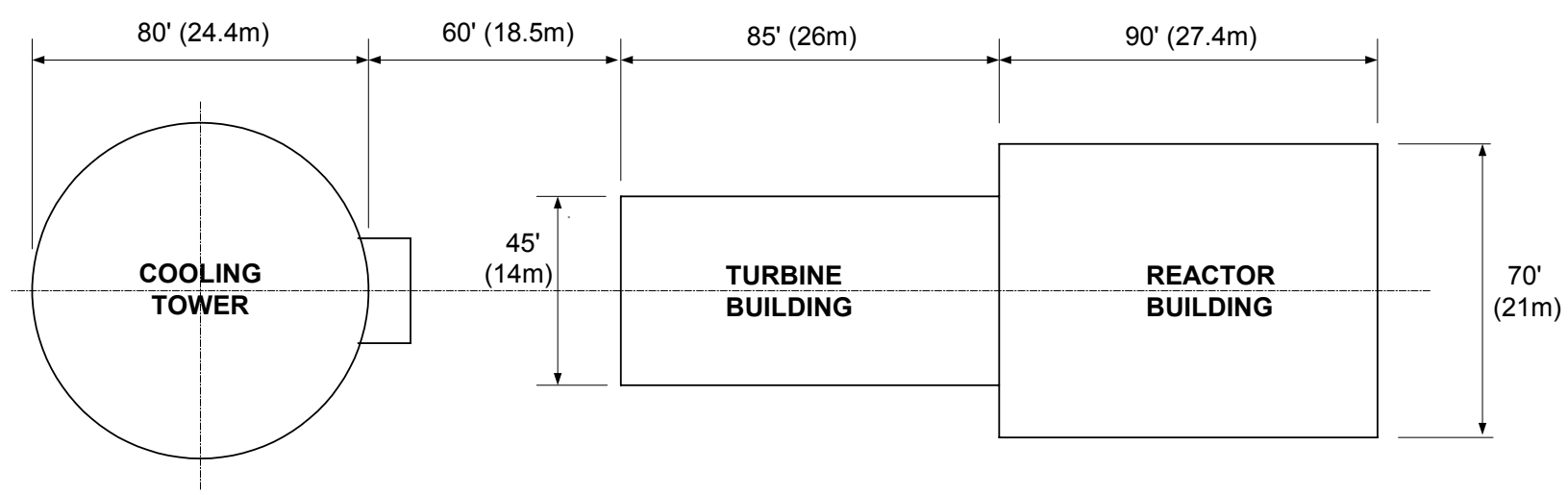

Figure 3-21 Single Module Power Generation Complex

The reactor core will be designed with a long fuel cycle life of 5 to 10 years. As a result, refueling of the reactor will be effected 3 to 6 times during the 30 -year periods of plant selfreliant operation. During refueling, the entire core is removed from the cavity and replaced with a new core. The old core is stored under water in the reactor cavity.

After 30 years of operation, the plant will be shutdown and prepared for the next 30 years of operation. This will be accomplished through detailed inspections, general refurbishing and testing. Radioactive waste generated during the 30 -year periods of plant operation will be stored onsite. After each 30-year period, the radioactive waste including spent fuel will be shipped offsite for disposal/reprocessing in a central facility. New fuel will be brought to the site. 


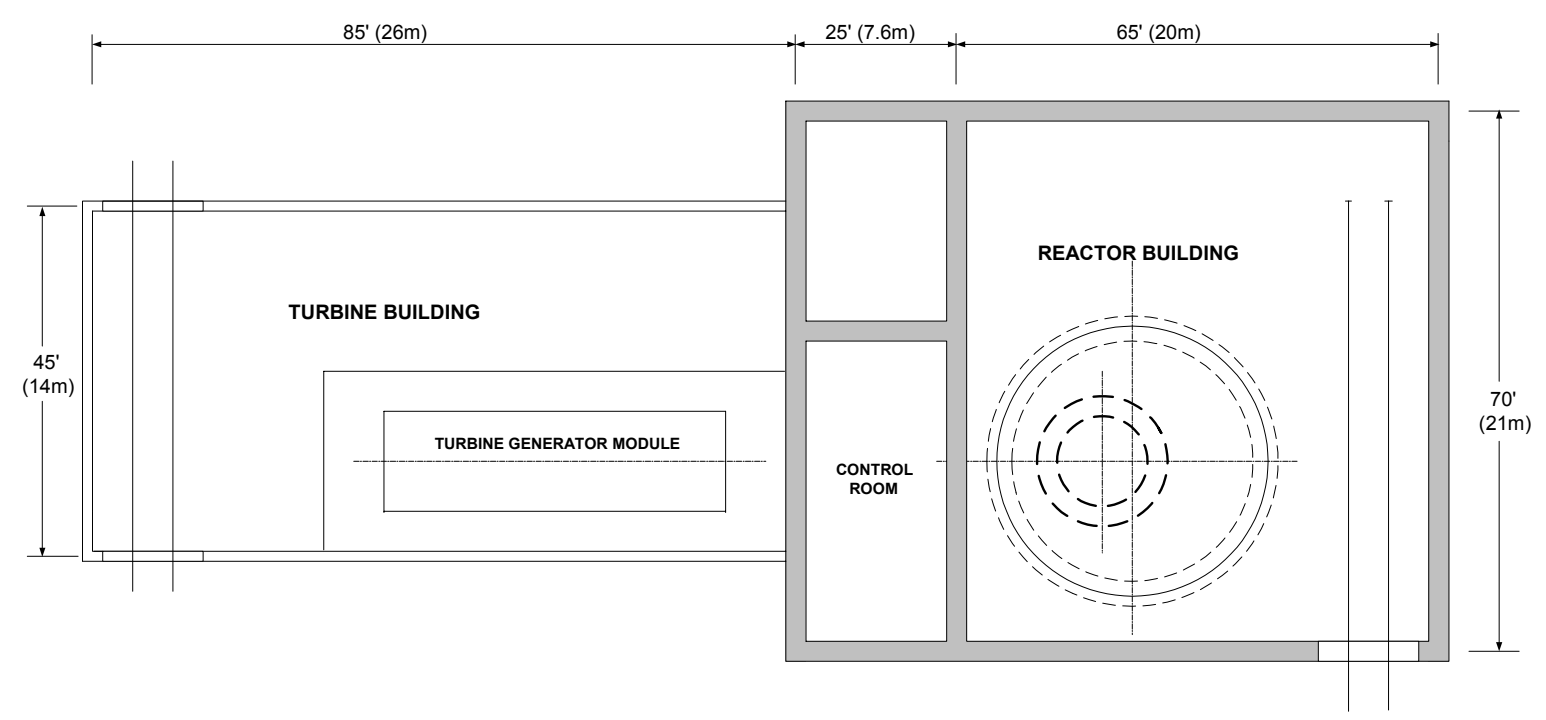

Figure 3-22 Single Module Plant Reactor/Turbine Building Plan View

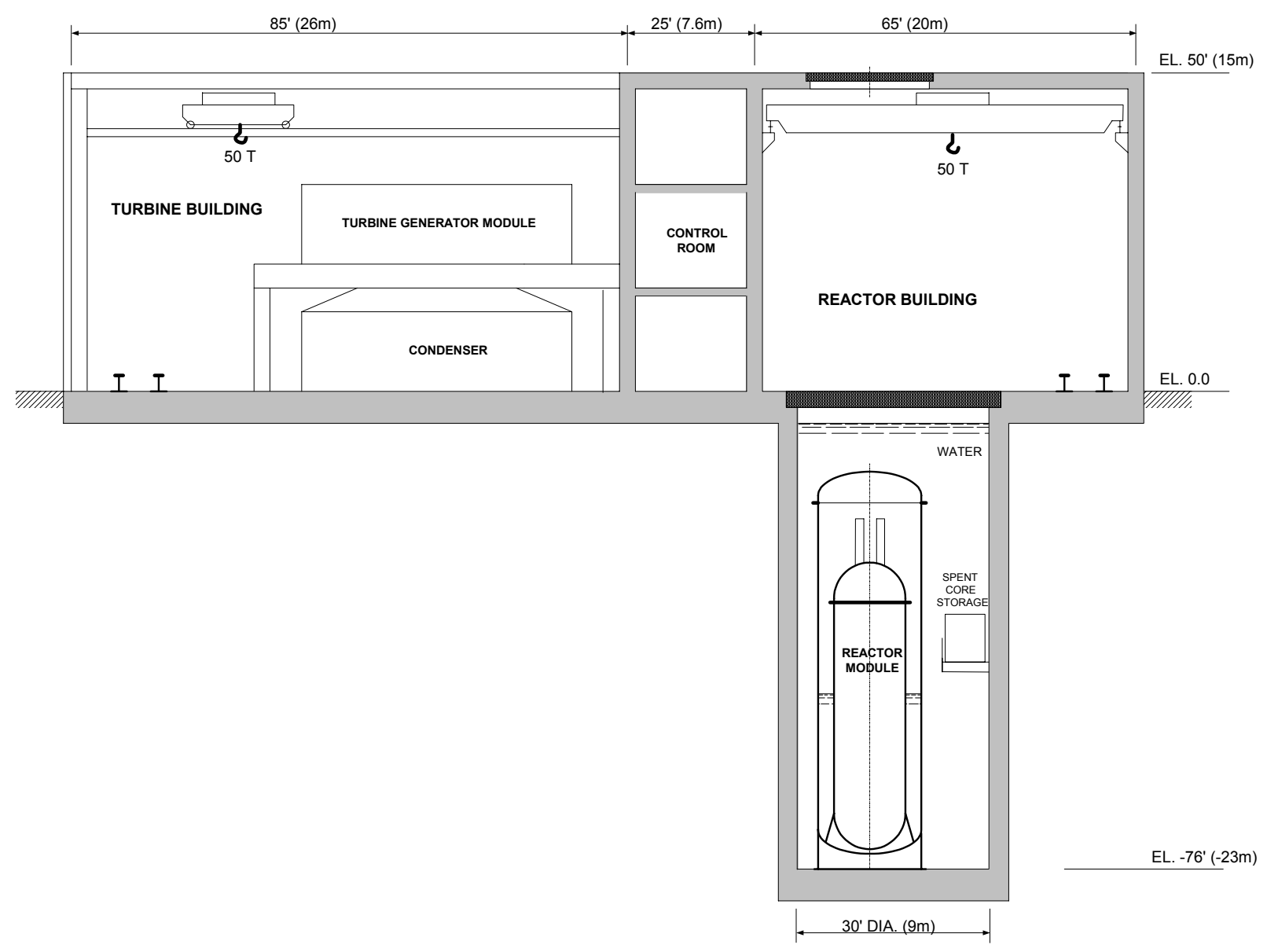

Figure 3-23 Single Module Plant Reactor/Turbine Building Elevation 


\subsection{Reactor Refueling and Maintenance}

Because the MASLWR reactor module is relatively small, a novel approach is used to perform refueling and maintenance activities. The entire module is removed and transported under water to an adjacent refueling/maintenance facility. While the removed module is being refueled and maintained, it is immediately replaced with a spare module. This results in a short down time of the reactor. The refueling and maintenance activities are entirely automated. After decay, spent fuel is shipped off site for disposal/reprocessing. New fuel is brought to the site. The major fuel handling and maintenance activities can be divided into the following categories:

- Moving and replacing reactor modules

- Refueling and maintenance of reactor modules

- Receiving of new reactor modules

- Receiving of new fuel assemblies

- Preparation of spent fuel assemblies for shipment.

Once moved to the refueling/maintenance facility, the reactor module is subject to the process of disassembly in order to get inside the containment and the reactor/steam generator vessel. Since the containment is entirely welded, it is necessary to cut the containment at one place in the cylindrical portion. The sequence of module disassembly is shown graphically in Figure 3-24. The disassembly is performed in such a way that the reactor core remains submerged in water at all times. Reassembly of the reactor module is performed in reverse sequence to assembly.

\subsection{Operation, In-Service-Inspection and Maintenance}

\subsubsection{Plant Operation}

The MASLWR is characterized by the following design features:

- Simple design with extensive use of passive systems

- Extensive automation of control and surveillance functions

- Use of advanced diagnostics, advisory and decision making systems.

As a result, operation of the plant during normal and abnormal conditions is essentially not dependent on operator actions. The main role of the operator is one of monitoring and verifying that the plant operates as intended. The operator is only required to take the following major actions:

- Initiate plant startup

- Initiate plant shutdown

- Set or correct set points that control plant operation

- Take corrective actions if the plant or systems do not operate as intended.

The reactor operator has both a safety role and non-safety role in the operation of the plant. The safety role is one of monitoring the performance and readiness of safety systems. In case of abnormal conditions, the operator verifies, monitors and ascertains that the safety systems are 
performing their functions properly and, if not, takes the appropriate corrective and recovery actions. The non-safety role of the operator is one of ensuring the plant meets the grid electrical demand while protecting the plant capital investment.

The plant consists of multiple power generation units. The plant is intended for operation as a base load plant, i.e. operating at full or close to full load. Each reactor is to be operated at full load. Should the demand be reduced, some of the reactors can be shutdown and kept on hot standby. This will be performed automatically through the plant controls.

There is a main common control room and remote shutdown room serving all power generation units. This is possible because of full automation of overall plant operation. In the unlikely case when the control room becomes inoperable, the operators can quickly and safely access the remote shutdown room through an underground tunnel linking the control building with the remote shutdown building, should the need arise to promptly manually initiate shutdown of the reactors.

\subsubsection{In-Service-Inspection}

The purpose of in-service-inspection (ISI) is to detect a potential failure before it becomes significant that it requires an unplanned power generation unit or plant shutdown. The ISI is performed through periodic inspection at regular interval or through continuous monitoring. Access and monitoring instrumentation is provided for ISI. The following methods are used to achieved that purpose:

- Periodic direct visual inspection of accessible components

- Use of TV cameras mounted on crawlers for remote inspection of inaccessible areas

- Permanently installed instrumentation monitoring levels, temperatures, pressures, dimensional gaging, etc.

- Portable instrumentation.

The reactor containment is to be tested periodically in accordance with the requirements of 10CFR50, Appendix $\mathrm{J}$ that requires integrated leak testing and local leakage rate testing. These tests are performed during plant shutdown for refueling.

\subsubsection{Maintenance}

Equipment and facilities are provided to perform the necessary maintenance of components and systems. The maintenance approach used is to minimize power generation unit or plant shutdown for maintenance especially unplanned maintenance. The following types of maintenance are used for the MASLWR plant:

- Preventive maintenance - Involves regularly scheduled inspections, tests, servicing, repairs, and replacements of components intended to reduce the frequency and impact of equipment failures. Special emphasis is put on preventive diagnostic maintenance to identify imminent failure of components allowing to perform early corrective maintenance.

- Corrective maintenance - Involves unplanned repair or replacement of components. 

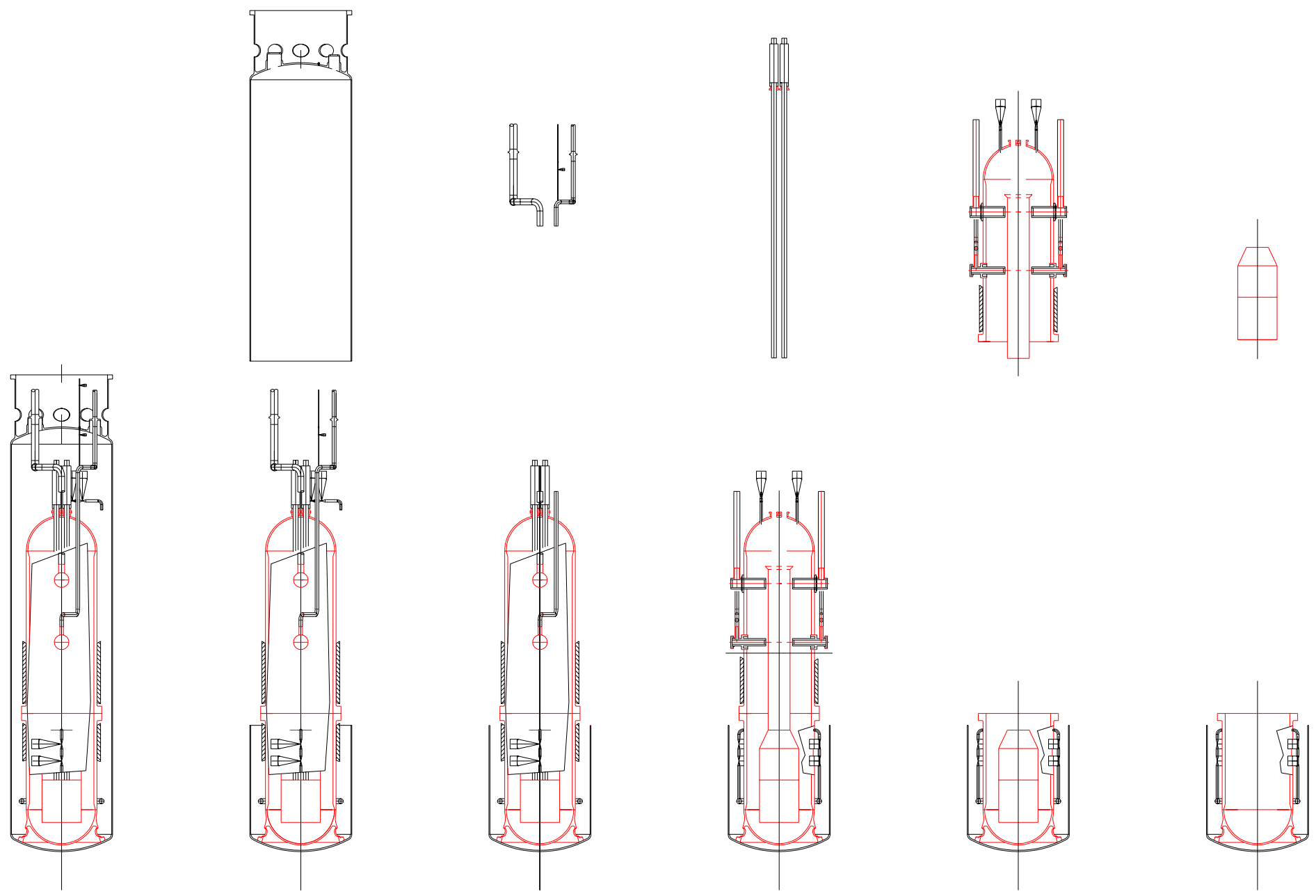

REACTLR CDNTAINMEN
FULLY ASSENBLED
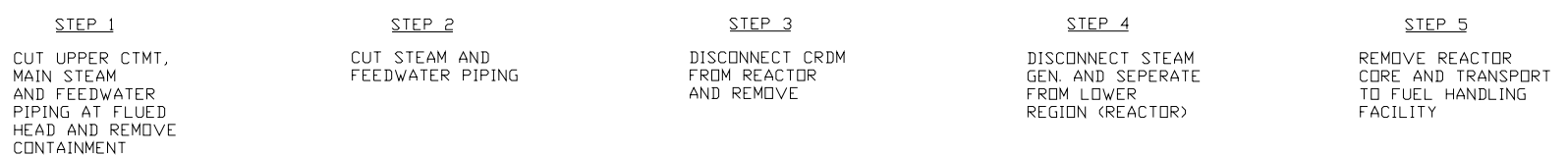

Figure 3-24 Reactor Module Disassembly 
Two maintenance facilities are provided for performing the repair of components:

- Reactor maintenance facility - Carries repairs of radioactive components and includes decontamination of components prior to repair. It is located in the NI.

- Machine shop - Carries repairs of non-radioactive components.

During the design phase of the MASLWR plant special emphasis is put on designing the components for a 60 years life, wherever practical, through simplification of design, use of proper materials, use of passive systems, etc. The building layout provides for easy access and adequate laydown areas needed for maintenance. The system components are designed for easy replacement.

\subsection{Seawater Desalination}

Combining seawater desalination with power generation using a MASLWR plant was investigated in order to assess the economics of using the heat of turbine exhaust steam in the desalination process. The following proven seawater desalination processes were considered for this evaluation:

- Multistage flash distillation

- Multi-effect distillation

- Reverse osmosis.

Both distillation processes require steam and electrical energy for water production. Although reverse osmosis requires only electrical energy, it was considered because recent advances in the process and in particular the membranes render the RO process very cost effective when compared to the distillation processes. The steam used for distillation must be provided at a pressure required by the particular desalination process which is higher than the normal turbine exhaust steam pressure. Increasing the turbine exhaust pressure reduces the amount of power generated. A comparison of the processes was made based on the following assumptions:

- All the turbine exhaust steam from 30 turbines is available for the distillation processes $(445,000 \mathrm{lbs} / \mathrm{hr})$

- Steam is available at the temperature/pressure required by the process

- The seawater temperature is $72{ }^{\circ} \mathrm{F}$ and the condenser outlet is $102{ }^{\circ} \mathrm{F}$ with a total seawater flow of $25,000 \mathrm{gpm}$

- The seawater salinity is $34,400 \mathrm{ppm}$

- Product water salinity should be less than $500 \mathrm{ppm}$

- Cost of electrical energy is $\$ 0.05 / \mathrm{kWh}$.

Table 3-4 summarizes the results of the seawater desalination processes investigation. 
Table 3-4 Desalination Processes Comparison

\begin{tabular}{|l|r|r|r|r|r|r|r|r|}
\hline PROCESS & $\begin{array}{c}\text { TURBINE } \\
\text { EXHAUST } \\
\text { PRESSURE } \\
\text { (PSIA) }\end{array}$ & $\begin{array}{c}\text { POWER } \\
\text { NEEDS } \\
\text { KWHR/ } \\
\text { KGAL }\end{array}$ & $\begin{array}{c}\text { DESAL } \\
\text { POWER } \\
\text { REQUIRED } \\
(\text { MW })\end{array}$ & $\begin{array}{c}\text { MASLWR } \\
\text { POWER } \\
\text { LOSS } \\
(\mathrm{MW})\end{array}$ & $\begin{array}{c}\text { NET } \\
\text { POWER } \\
\text { TO GRID } \\
(\mathrm{MWW})\end{array}$ & $\begin{array}{c}\text { PLANT } \\
\text { PRODUCTION } \\
\text { (MGD) }\end{array}$ & $\begin{array}{c}\text { CAPITAL } \\
\text { COST } \\
\text { (M\$) }\end{array}$ & $\begin{array}{c}\text { ANNUAL } \\
\text { POWER } \\
\text { COST } \\
(\mathrm{M} \$)\end{array}$ \\
\hline NO DESAL & 0.75 & - & - & - & 35.0 & - & - & - \\
\hline MSF & 30 & 15 & 6.4 & 25.8 & 2.8 & 10.3 & 63.1 & 13.4 \\
\hline MED & 5 & 7.6 & 4.9 & 12.2 & 17.1 & 15.4 & 77.1 & 7.1 \\
\hline RO & 0.75 & 15 & 9.6 & - & 25.4 & 15.4 & 62.2 & 4.0 \\
\hline
\end{tabular}

Based on the comparison performed, reverse osmosis is the most attractive seawater desalination process for desalination co-located with a MASLWR plant because of its lowest capital cost and the highest MASLWR net power supplied to the electrical grid.

A schematic flow diagram for a proposed reverse osmosis system is shown in Figure 3-25. The feedwater is from the seawater intake into the power plant condensers (1). The incoming seawater is pumped (2) to a pretreatment system (3), which contains as a minimum, a chlorinator, a filtration system, and a chemical addition system. If necessary, because of influent seawater quality, additional water treatment features can be included, such as coagulation, sedimentation, adsorption of impurities by diatomaceous earth or activated carbon, and manganese-zeolite filtration. From the pretreatment system, the pretreated water is pumped by high-pressure pumps (4) to a number of trains composed of RO elements housed in fiberglass pressure vessels (5). The product water is subject to post treatment (6) to make the water noncorrosive to the distribution system. The treated water (7) is then pumped to the distribution system. The reject brine (8) from the RO modules is nearly at the same pressure as the feed pressure. This brine is sent to an energy recovery device to recover energy (9). This energy can be in the form of direct drive of the feedwater pumps or electrical energy that is fed back into the system. The brine is then discharged to the sea. 


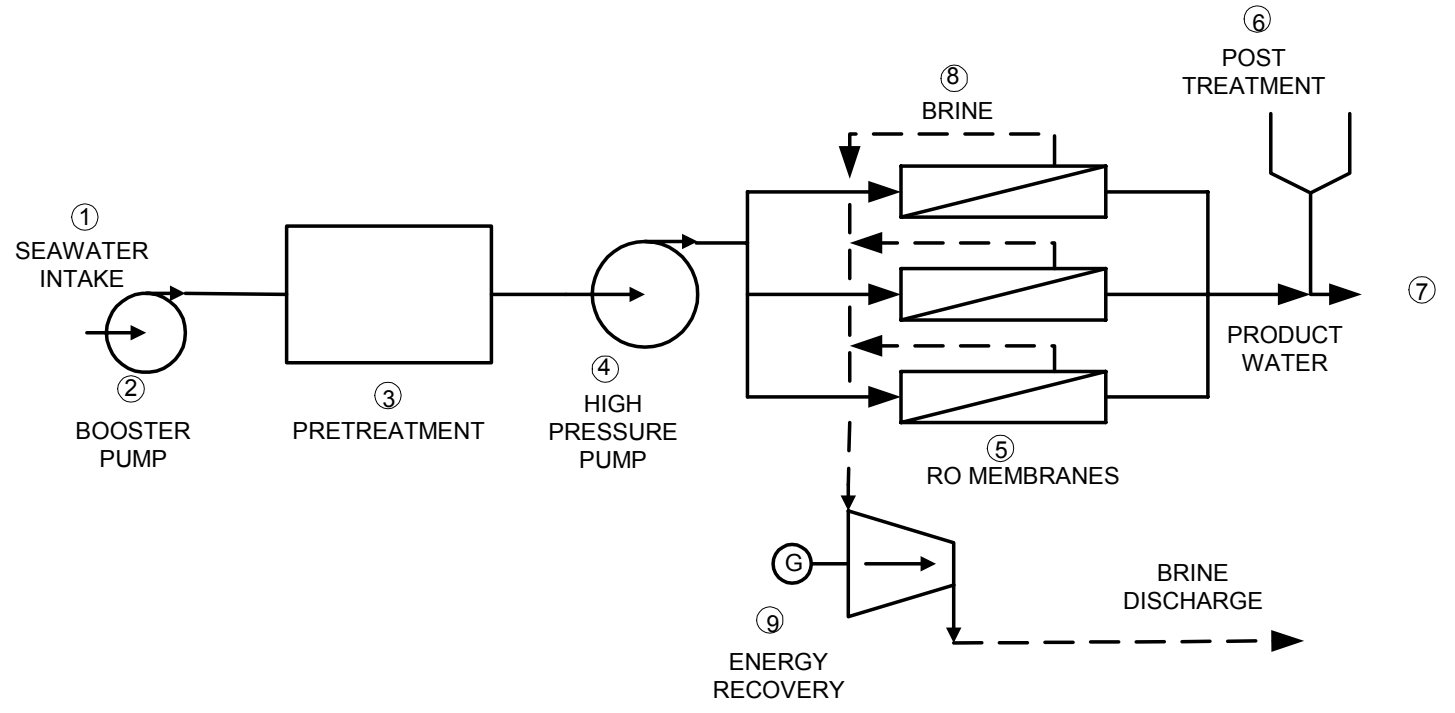

Figure 3-25 RO Flow Schematic

A site plan is shown in Figure 3-26. Seawater enters the pretreatment system. Some of the treated water is stored in backwash tanks for backwash of the pretreatment equipment. The treated water is pumped from the clear well through cartridge filters and then to the high pressure pumps. From the pumps, the water enters the RO modules. The brine is returned to energy recovery devices located with the high pressure pumps. The brine is then discharged. Product water goes to the product water storage tanks for post-treatment and delivery to the water distribution system.

There are advantages to co-locating an RO desalination plant with an electric power plant. The power plant can be can be configured and operated to improve efficiency and increase revenues. The following methods are proposed for this purpose:

- Use of heated seawater from the condenser discharge

- Off-peak water production to maximize power revenue.

Higher seawater temperature increases the membrane production (flux). Also, no additional seawater flow is required, so an intake/outfall system is not necessary. 


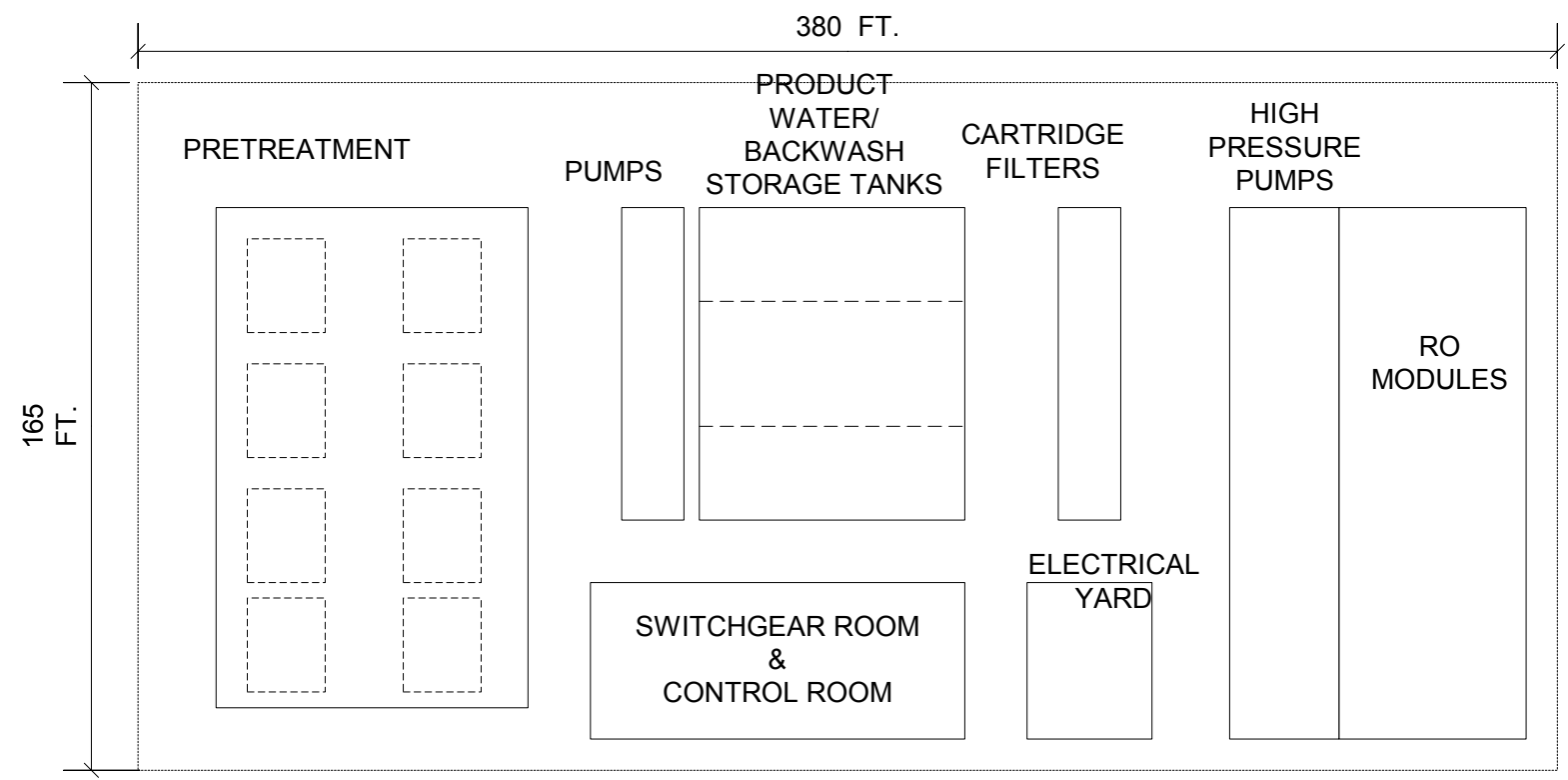

Figure 3-26 RO Plant Site Plan

With a large RO desalination plant, water production can be stopped to supply electric energy to the grid during periods of peak power demand. In the design of an "off-peak water plant", it is possible to select the equipment capacities such that the annual fresh water production is satisfied without the need to operate the desalination plant during peak power demand periods.

\subsection{District Heating and Cooling}

In this application, heat exhausted from the turbines is used to produce hot water in heat exchangers for district heating and/or cooling. Hot water is used during winter for space heating. During summer hot water can be used in absorption chillers as an energy source for generating chilled water for the purpose of space cooling. A schematic diagram of a concept for this application is shown in Figure 3-27.

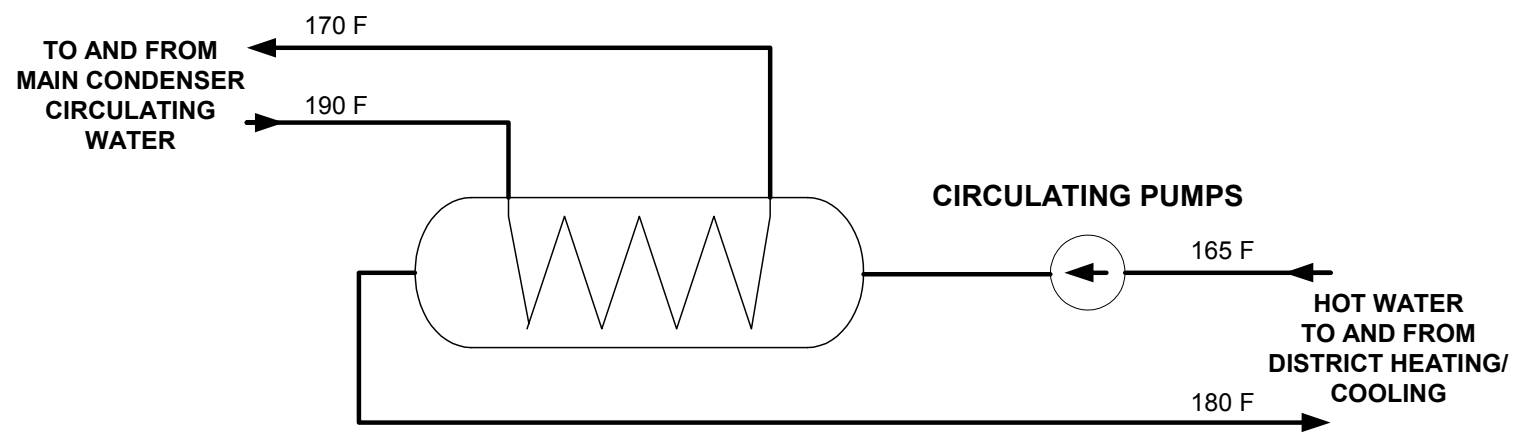

WATER HEAT EXCHANGERS

Figure 3-27 District Heating/Cooling 
A minimum practical hot water temperature for use in heating or cooling is $180 \mathrm{~F}$. This requires a turbine exhaust of 10 psia compared to the normal of 0.75 psia. As a result, the power generated in a single unit is reduced from $35 \mathrm{MWe}$ to $18 \mathrm{MWe}$. With a power generation reduction of such a magnitude, the use of turbine heat exhaust for district heating and/or cooling is questionable from the economics point of view.

\section{Performance and Safety Analyses}

Performance and safety studies have been performed for the MASLWR design using the RELAP5-3D thermal-hydraulic systems code. The purpose of these studies was to evaluate the transient performance characteristics of the design and demonstrate that the passive safety features provide adequate protection for the core.

A diagram of the containment and internals of the MASLWR design was shown in Figure 3-9. The containment is about 18 meters in height, and the primary vessel, containing the reactor core and steam generator, occupies approximately the lower 13 meters. Water occupies the annular region between the lower part of the vessel and the containment wall. In the safety analysis it was assumed that this water is borated. However, boron in the containment is undesirable for a number of reasons. The main concern is that the primary system is designed to depressurize upon loss of heat sink, which can be caused by a loss of feedwater, turbine trip, or other event that is considered likely to occur. Following the depressurization, the boron is introduced into the primary system and must be cleaned out prior to subsequent operation. Therefore, alternate technologies for providing secondary reactivity insertion were investigated. The results of this investigation are described in Section 4.8.

The design includes redundant ECCS piping systems. Two steam vent lines are provided, and each shares a common nozzle with a pressure vessel ASME code safety valve. There are two ADS blowdown lines, each having a separate nozzle, located below the containment waterline.

\subsection{RELAP5 Model}

The RELAP5 nodalization diagram is shown in Figure 4-1. As previously noted, the nuclear core is assumed to be of standard PWR design with 24 fuel assemblies in a standard $17 \times 17$ array with 264 fuel positions and 25 absorber positions. 


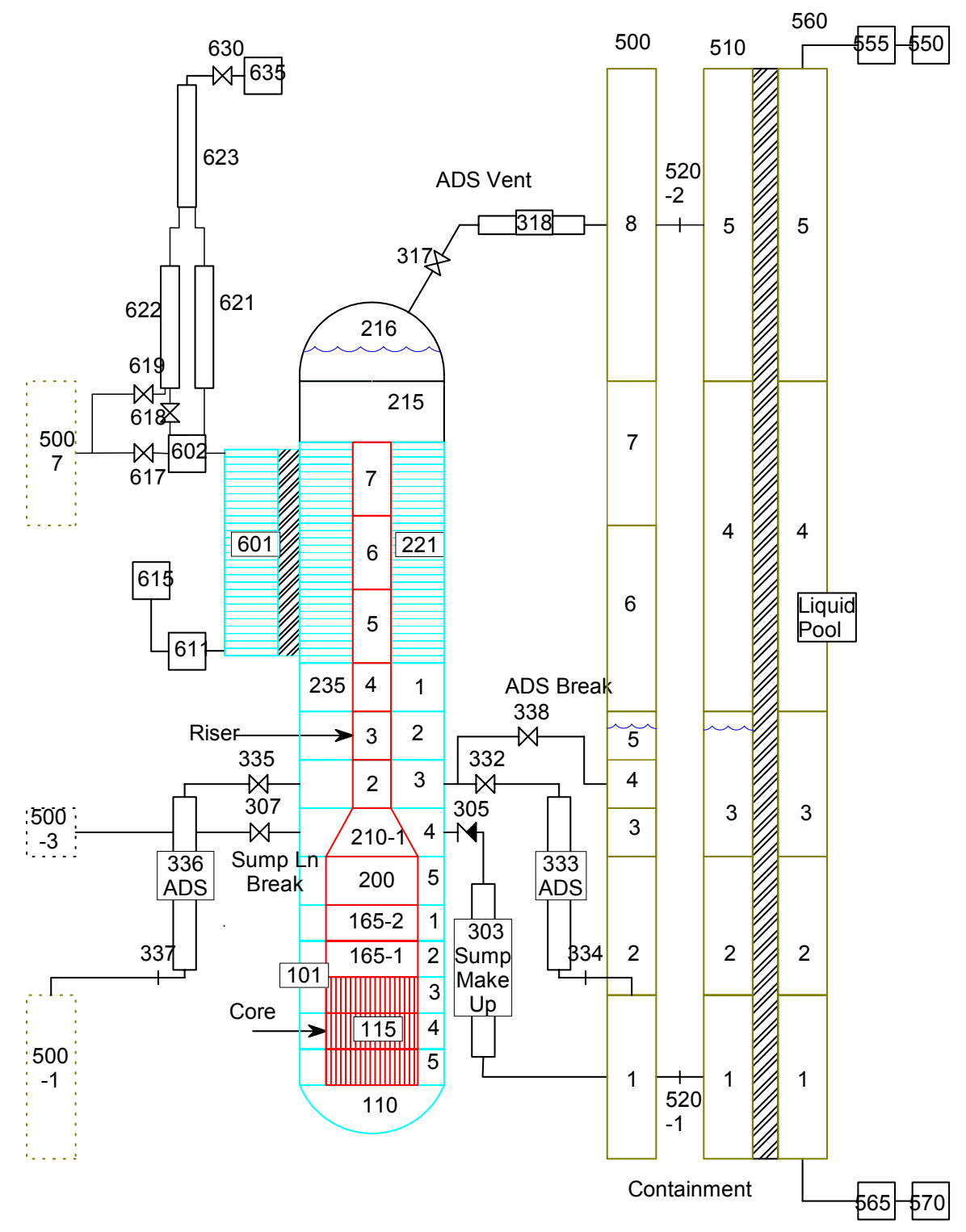

Figure 4-1. RELAP5 model.

In the RELAP5 model, the reactor core has three axial zones, with two parallel flow channels, one representing 23 average fuel assemblies and the other representing 1 hot assembly. Three heat structure components are thermally connected to the core channels, and represent 1) all the fuel rods of the 23 average fuel assemblies, 2) one fuel rod (the hottest rod) in the hot fuel assembly, and 3) the 263 remaining fuel rods in the hot fuel assembly. The riser is connected at the top of the core and provides the upward coolant path to the upper vessel head region. The primary and secondary sides of the steam generator are each represented by a single flow path (components 221 and 601, respectively), and are connected thermally by a heat structure component that simulates the conduction path through the steam generator tube walls.

The secondary side of the steam generator has a flow boundary condition imposed at the inlet (components 615 and 611). The steam outlet manifold (component 602) is connected to two, 
parallel, upwardly-oriented steam lines (components 621 and 622) that join into a single header (component 623). The header is connected to a pressure boundary condition that simulates the turbine (component 635), via the main steam isolation valve/ turbine stop valve component (630). Components 602 and 622 are connected to the containment via a valve arrangement that simulates a main steam line break inside containment.

The containment consists of two annular rings (components 500 and 510). The inner one is adjacent to the vessel, and the outer one is thermally connected to the liquid pool, which is component 560. Junctions connect the top-most and bottom-most cells of the two rings, to allow fluid circulation via natural convection. The inner ring is more finely noded than the outer ring to accommodate the ADS blowdown line break and the main steam line break. The steam vent line consists of a valve (317) and a pipe (318) that is connected to containment cell 500-08, and represents one of the two vent lines in the actual design. The second line is not in the model because the failure of one line to operate is conservative. Each ADS blowdown line is modeled separately, to facilitate the ADS blowdown line nozzle break and the normal operation of one or both sides. Sump makeup lines and a sump makeup line break valve (components 303, 305, and 307) are included in the model, but were not used in the latest version of the analysis.

\subsection{Accident Categories and Acceptance Criteria}

The performance and safety analysis studies considered a variety of hypothetical accident scenarios grouped by estimated frequency of occurrence, and included acceptance criteria for these scenarios that are typical of present day PWRs. The studies to date include only events initiated from normal, full-power operation, at the beginning-of-life core condition. The end-oflife fuel physics calculations have not yet been completed. Also, events arising during periods of shutdown, maintenance, or refueling, have not been considered. The event categories, along with estimated frequency of occurrence and acceptance criteria, are described in the following paragraph.

Normal operation and operational transients are, by definition, expected and must demonstrate a significant margin to onset of critical heat flux. Incidents of moderate frequency are considered likely to occur one or more times during the normal life of the plant, and include operator errors and failures of systems known to have low reliability. The design must be able to withstand the occurrence of these events without damage to the core and with minimum impact on system operability. Infrequent faults are events that are remotely possible, for example piping ruptures. The design must be able to tolerate these events with minimum damage to the reactor core, and with no release of fission products from the fuel. Beyond-design-basis accidents are considered to be noncredible occurrences. Some fuel damage may occur; however, radiation exposure to the public must not occur.

\subsection{Normal Operation}

For normal operation, the following set of parameters was used. The axial core peaking factor was 1.36, based on the results of neutron physics calculations. A hot fuel assembly was included in the model. One of the twenty-four fuel assemblies operated at a power level 1.1 times the core 
average power. This assembly has a 5\% reduction in coolant flow at the inlet, and there is no mixing with the average core. A hot fuel pin was included in the hot assembly model. One of the 264 fuel pins in the hot fuel assembly operated at a power level 1.4 times the core average power. Neutron physics calculations demonstrate that these core peaking factors can be achieved for beginning-of-life operation.

The steady-state operating conditions are listed in Table 4-1. The average reactor core channel operates in subcooled forced convection, with the hot core channel in subcooled nucleate boiling. The results of steady-state simulation resulted in a CHF ratio of 7.2 at the core hot location, indicating a large margin of safety during normal operation. The initial conditions from the analysis of normal operation were used in the accident studies presented in the following paragraphs.

Table 4-1. Steady-state operating conditions.

\begin{tabular}{|l|l|l|}
\hline Primary pressure & $7.8 \mathrm{MPa}$ & $1130 \mathrm{psia}$ \\
\hline Mass flow rate & $596 \mathrm{~kg} / \mathrm{s}$ & $1311 \mathrm{lbm} / \mathrm{s}$ \\
\hline Core inlet temperature & $491.8 \mathrm{~K}$ & $425.6 \mathrm{~F}$ \\
\hline Core outlet temperature & $544.4 \mathrm{~K}$ & $520.3 \mathrm{~F}$ \\
\hline Saturation temperature & $567.4 \mathrm{~K}$ & $561.7 \mathrm{~F}$ \\
\hline
\end{tabular}

\subsection{Incidents of Moderate Frequency}

Incidents of moderate frequency included abnormal control rod withdrawal events, inadvertent ECCS valve openings, losses of normal feedwater, losses of AC power, turbine trips, abnormal increases in feedwater flow, and accidental depressurization of the main steam system.

The abnormal control rod withdrawal event was simulated by inserting a reactivity ramp insertion of 0.115 \$/second into the 1-D neutron kinetics in the RELAP5 model. This ramp rate is typical of what would be used for this event in a present-day PWR. The ramp insertion was terminated by the overpower scram at $165 \mathrm{MW}$ (normal full power $+10 \%$ ) with an instrument time delay of 0.2 seconds. The maximum power was $170 \mathrm{MW}$, and the minimum CHF ratio was 6.9 .

The inadvertent ECCS valve opening transients were evaluated by analyzing the results of breaks of the associated lines, which are more severe. Figure 4-2 shows core hot channel collapsed liquid level and fuel cladding surface temperature at the core hot location for the ADS blowdown line nozzle break scenario. In this case, the second ADS blowdown line opens on the actuation signal, thus maximizing vessel inventory loss. The results show that core collapsed liquid level is sufficient to provide cooling to the fuel, and no fuel cladding thermal excursion occurs. Figure 4-3 shows reactor power compared to containment wall heat rejection and primary vessel and containment pressures for the steam vent line nozzle break scenario. This break location is the most severe for containment overpressure considerations. Additionally, one train of ADS blowdown fails to actuate, thereby minimizing the contribution of ADS blowdown to containment pressure reduction. As shown, the opening of the remaining ADS blowdown line is highly effective in reducing containment pressure. This is because most of the vented mass is 
discharged underwater, and also because the force of the submerged blowdown causes the liquid in the containment pool to be blown upward, thereby increasing the liquid surface area and accelerating the condensation of vapor. Maximum containment pressure is $1.1 \mathrm{MPa}$ (160 psi). Heat rejection through the containment wall exceeds core decay power, thus demonstrating the effectiveness of the liquid pool as an ultimate heat sink for long term control of system pressure and removal of core decay heat. Because the results of the steam vent nozzle line break and the ADS blowdown line break are both more severe than their valve-opening counterparts, and because these scenarios demonstrate sufficient core inventory to prevent fuel cladding heatup, fuel damage will not occur during the inadvertent ECCS valve opening transients.

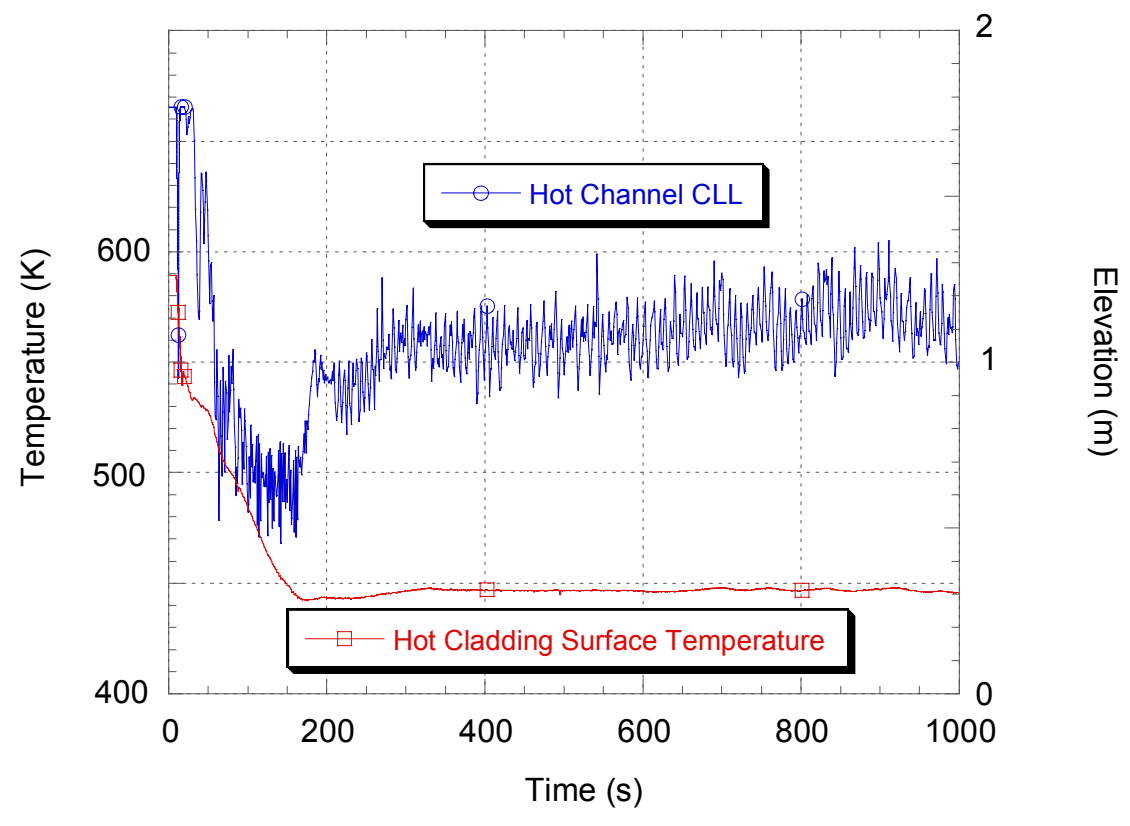

Figure 4-2. Results of ADS blowdown line nozzle break transient 


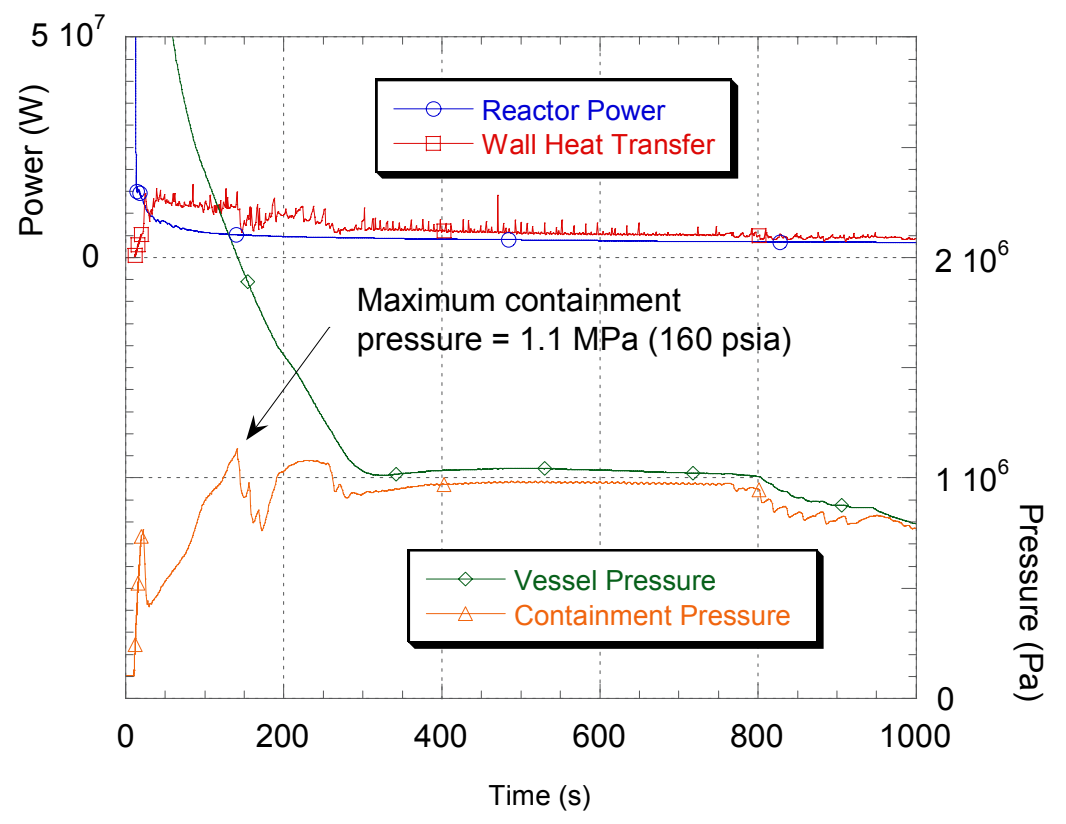

Figure 4-3. Results of steam vent line nozzle break transient.

Secondary-side events are significantly less severe than primary-side blowdowns, because the secondary side mass, particularly in the steam generator, is much smaller than that of the primary system. Secondary-side failures will usually, however, result in actuation of the automatic depressurization system, and if borated water is initially present in the containment, it will be introduced into the primary system, and will necessitate cleanup of the primary prior to returning the unit to operation. The feedwater flow increase event is shown as an example. This transient was initiated at $\mathrm{t}=10$ seconds by introducing a feedwater flow ramp to $250 \%$ of normal in 0.5 seconds. The feedwater flow is terminated on a high steam generator level, which occurs at 15 seconds. At 27 seconds, the steam generator low level is reached and the turbine trip and reactor scram occur. Figure 4-4 shows reactor power and steam generator wall heat transfer, and primary vessel pressure for this event.

Steam generator tube wall heat transfer and reactor power are equal at the start of the transient. When the feedwater flow ramp is introduced, the steam generator tube wall heat transfer increases to approximately $220 \mathrm{MW}$ at $15 \mathrm{~s}$ When the feedwater flow is terminated, the heat transfer drops abruptly to near its initial value and thereafter decreases as the steam generator secondary inventory becomes depleted. Reactor power increases only slightly, reaching a maximum of $152 \mathrm{MW}$ at 17 seconds. Primary system pressure first decreases, with the increased steam generator tube heat transfer, then increases as this heat transfer diminishes. ADS is actuated when primary system pressure exceeds $8.5 \mathrm{MPa}$. Because the reactor power increases only slightly in response to the feedwater increase, and because the reactor scram occurs well in advance of the primary system depressurization, this scenario is significantly less severe than the 
primary side break cases. However, without prompt operator intervention, primary system blowdown is predicted to occur approximately 20 seconds after event initiation. Primary and containment pressures equalize at about 230 seconds. At that time, containment-to-primary makeup flow begins via the submerged ADS blowdown lines, and boron is introduced into the primary system.

The accidental depressurization of the main steam system was also evaluated by analysis of the corresponding line break, i.e. the main steam line break to atmosphere (outside of containment). In this transient, a main feedwater pump trip and a reactor scram occur within about 1 second. Subsequent to the emptying of the steam generator, primary pressure begins increasing, and automatic depressurization occurs when pressure exceeds the actuation setpoint (8.5 MPa).

\subsection{Infrequent Faults}

Infrequent faults include primary system piping breaks (i.e. the ECCS piping), secondary system piping breaks (i.e. the main steam line nozzle break) and the rod ejection accident. As was shown above, the ECCS piping breaks are within the limits defined for the Incidents of Moderate Frequency category. Adequate core cooling is present, and core damage is not expected. The main steam line nozzle break is less limiting in terms of core damage, but because it vents inside the containment, the resulting containment pressure response is the significant issue. The rapid secondary-side depressurization causes a rapid decrease in primary-side pressure. ADS is initiated when primary-side pressure drops below 7.4 MPa. The subsequent ADS blowdown is effective in controlling containment pressure, and the maximum value is $1.5 \mathrm{MPa}$ (218 psia),

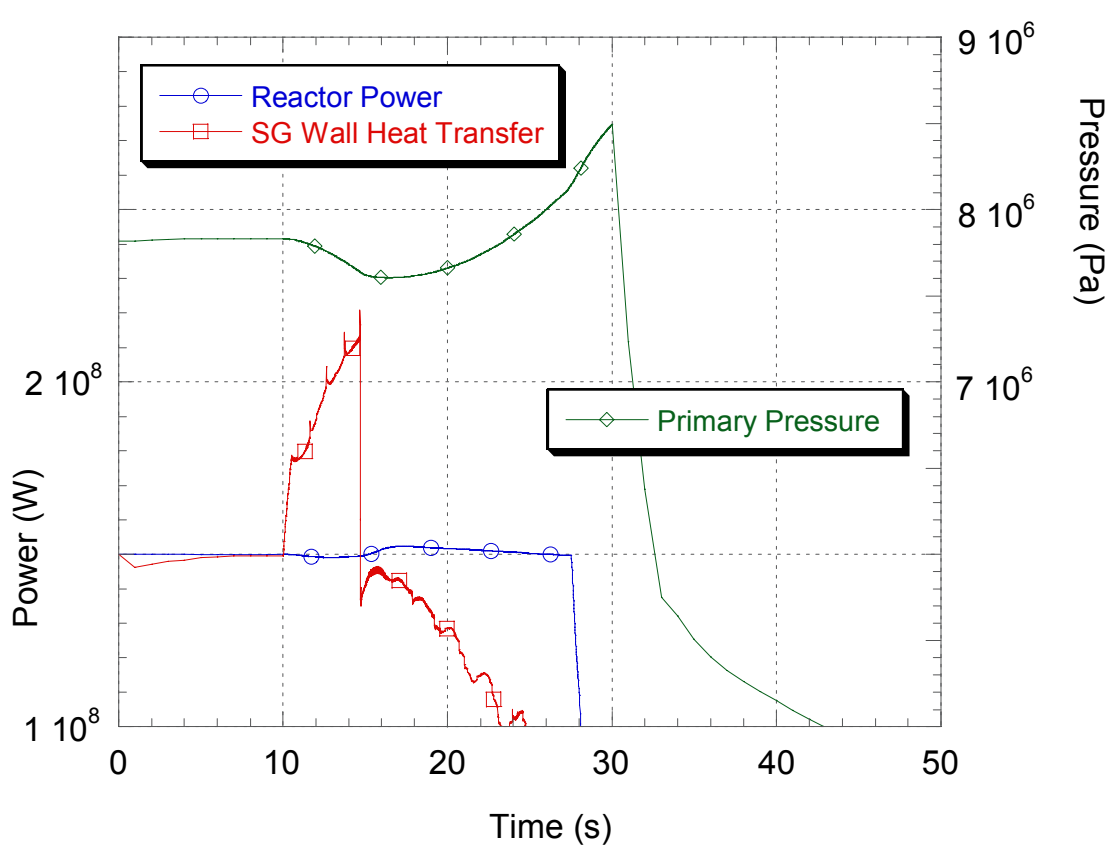

Figure 4-4. Results of feedwater flow increase transient. 
which is within the pressure limits for the present design. The rod ejection accident was modeled by inserting a step (i.e. $1 \times 10^{-5}$ second) reactivity of $0.75 \$$ into the point kinetics. This insertion caused a power spike to $520 \mathrm{MW}$, which was turned by a combination of Doppler and moderator feedback. The fuel centerline temperature increased approximately $75 \mathrm{~K}$ in the hot fuel rod, and the coolant temperature increased about $5 \mathrm{~K}$. Therefore, the Doppler coefficient ($0.005 \$ / \mathrm{K})$ and the moderator coefficient $(-0.08 \$ / \mathrm{K})$ were about equally effective for power turning. The fuel enthalpy in the hottest fuel pin was calculated to be $18 \mathrm{cal} / \mathrm{gm}$. No fuel damage is predicted for this event.

\subsection{Beyond Design Basis Accidents}

Beyond design basis accidents include anticipated transients with a failure of the reactor to scram. The most severe of these cases is the inadvertent opening of one of the ECCS steam vent valves. Reactor power and hot fuel pin centerline temperature responses are shown in Figure 4-5. In this transient, the initial depressurization results in voiding of the core, thereby causing reactor power to decrease. Subsequently, however, the core refloods with liquid that is at coldside temperature and a power spike occurs. The vapor production in the core causes the core to void and power again decreases. The cycle repeats until the combination of core average void fraction and system temperature results in net negative reactivity. As shown, the power spikes have a maximum amplitude of approximately $3500 \mathrm{MW}$. The spikes are very narrow, however, and significant energy deposition into the fuel does not occur. Maximum fuel enthalpy increase

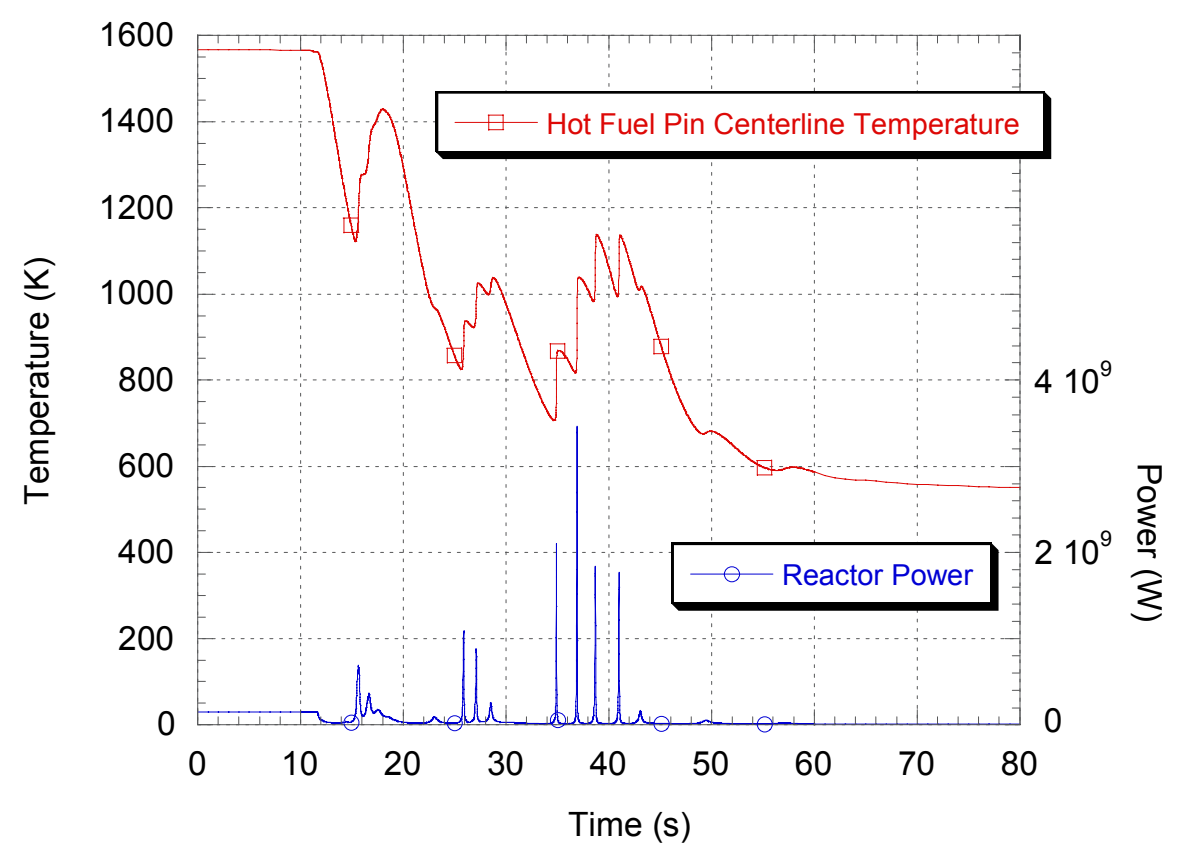

Figure 4-5. Inadvertent opening of steam vent valve with failure of reactor to scram. 
is about $70 \mathrm{cal} / \mathrm{gm}$. No significant fuel heatup is noted during the transient, and there is no fuel damage. Eventually (i.e. after approximately 8 minutes in this case), the borated water enters the core and provides shutdown margin.

\subsection{Summary of Results.}

A summary of the transient cases performed and the results is shown in Table 4-2. The results show that significant margins to the stated acceptance criteria are present for all cases analyzed. There are no significant transient cladding temperature excursions, and containment pressure remains within design parameters. All transient cases demonstrate that the system final condition is a stable state with adequate coolant recirculation between the containment and the vessel. Vessel collapsed liquid level is stable, the reactor core is receiving adequate cooling, and rejection to the ultimate heat sink is sufficient for the decay heat load.

\subsection{Novel Passive Safety Systems For The MASLWR.}

As discussed in previous sections, safety of MASLWR depends on the reactor shutdown system (reactor scram, the ADS, natural circulation between the reactor vessel and containment, and finally heat transfer from the containment through the containment wall to the surrounding pool of water. The energy transfer from the core to the ultimate heat sink, the large pool of water in which the reactor module is submerged, relies only on physical laws with no pumped systems

Table 4-2. Scenarios categorized by frequency of occurrence.

\begin{tabular}{|c|c|c|c|c|}
\hline Frequency & Normal Operation & $\begin{array}{l}\text { Incidents of } \\
\text { Moderate } \\
\text { Frequency }\end{array}$ & Infrequent Faults & $\begin{array}{l}\text { Beyond Design } \\
\text { Basis Accidents }\end{array}$ \\
\hline $\begin{array}{l}\text { Scenarios } \\
\text { Analyzed }\end{array}$ & $\begin{array}{c}\text { - } \begin{array}{c}\text { Full power, } \\
\text { beginning-of-life }\end{array} \\
\text { - } \quad \text { Axial } \\
\text { Peaking }=1.36 \\
\text { - } \quad \text { Hot Assy } \\
\text { Factor }=1.1 \\
\text { - } \quad \text { Hot Pin } \\
\text { Factor }=1.4\end{array}$ & $\begin{array}{l}\text { - } \text { Control Rod } \\
\text { Withdrawal } \\
\text { - } \text { Inadvertent } \\
\text { ECCS valve } \\
\text { opening cases } \\
\text { - Loss of main } \\
\text { feedwater, loss } \\
\text { of AC power, } \\
\text { turbine trip } \\
\text { cases } \\
\text { - Feedwater } \\
\text { flow increase } \\
\text { - Accidental } \\
\text { depressurization } \\
\text { of main steam } \\
\text { system }\end{array}$ & $\begin{array}{l}\text { - } \text { ECCS piping } \\
\text { breaks } \\
\text { - } \quad \text { Main steam } \\
\text { line break } \\
\text { - } \quad \text { Rod ejection } \\
\text { accident }\end{array}$ & $\begin{array}{c}\text { - ECCS valve } \\
\text { opening with } \\
\text { failure to scram } \\
\text { - Loss of main } \\
\text { feedwater with } \\
\text { failure to scram }\end{array}$ \\
\hline Results & CHF Ratio $>7$ & $\begin{array}{c}\text { No occurrence of } \\
\text { CHF }\end{array}$ & No fuel heatup & $\begin{array}{l}\text { No significant } \\
\text { fuel damage }\end{array}$ \\
\hline
\end{tabular}


and no conventional heat exchangers. This completely passive emergency operation is actuated by an actuation signal that is generated electronically from signals from sensors monitoring certain system parameters such as pressures, level or temperatures. The ADS system is then operated via electrical motors to open depressurization valves. Additionally, the water in the containment was assumed to contain boron to provide a secondary shutdown system. However, boron was shown to be not particularly effective as a reactor shutdown method for some transients. It also significantly impacts the recovery time of the module following a loss of heat sink, which can be caused by a loss of feedwater, turbine trip, or other event that is considered likely to occur, and which results in ADS actuation, because the boron is introduced into the primary system and must be cleaned out prior to subsequent operation. To increase the reliability of the design, to remove the dependence of the passive safety features on active systems, and to eliminate the use of boron as a reactor shutdown system, we have designed a passive emergency shutdown system and a passive ADS.

The passive shutdown system was designed to provide a secondary reactor scram. This design is inherently safe and fail-safe. Its operation is based solely on inexorable physical laws. The operation of the rod in its emergency function does not require the intervention of a human operator, nor does it rely on any signal from a monitoring or safety system. Although the concept could be applicable to a variety of reactors (provided a normal temperature range is specified), in this paper, the concept is applied to the MASLWR. During normal operations, the control rod is held outside the core region by an electromagnet (E-M). The electrical supply line to the E-M includes a portion that passes in or near the core exit zone. In this way, its temperature is imposed by the core exit conditions. That portion of conductor is made of a material of known temperature-dependent resistively. As the temperature in the core exit region rises above a prescribed set point, the temperature in the conductor rises, and hence the resistance. This in turn decreases the current that powers the E-M, and therefore the E-M lift force. When the lifting force drops below the weight of the control rod assembly (corrected for any buoyancy or upward drag from the coolant), the rod drops into the core by gravity. No switch, no signal, and no operator intervention is needed to actuate the control rod. Fuses within the circuit limit the current. All failures are fail-safe, as they result in the rod being dropped into the core. The concept has been shown, via modeling, to be workable for a steel conductor segment. Once released, the behavior of the rod (drop time, reactivity worth) is similar to any other rod dropping by gravity into the same location within the core. Locating the rod within a guide tube that has a large number of lateral holes on the wall lowers resistance to the fall. A preliminary design of the electromagnet assembly, running at a voltage of $1.5 \mathrm{~V}$ and a current of slightly under 1-Ampere was analyzed. It is shown that this setup is able to suspend a rod of mass slightly above $9.8-\mathrm{kg}$ outside the core, when the reactor is operating under normal conditions and within nominal bounds. These normal operating conditions include a core exit temperature of about $544 \mathrm{~K}$. Using the model, it is shown that an increase of $5 \%$ in the core exit temperature results in a decrease of the electromagnet force to under $8.9 \mathrm{~kg}$. Therefore, if a rod of $9.8 \mathrm{~kg}$ is used, it would fall under the effect of its own weight when the core exit temperature exceeds $572 \mathrm{~K}$. The evaluated control rod, centrally located, provides $-\$ 2.05$ worth and is capable of fully shutting down the reactor. In further design optimization the worth of the rod will be increased to $-\$ 2.50$. The system can be calibrated using an adjustable resistor series. A similar rod concept is now under investigation for rod drop actuation when the core exit temperature drops by a similar fraction. 
The passive ADS replaces the standard ADS valves with passively actuated depressurization valves. The valve is actuated by pressure difference between the reactor vessel and an accumulator filled with water and nitrogen. The accumulator pressure is set to the desired ADS actuation pressure. If the reactor vessel pressure decreases below the accumulator pressure the piston in the valve is moved towards the reactor vessel side, thereby opening the submerged ADS blowdown lines and upper containment steam vent lines. The subsequent depressurization and cooling are the same as for the actively actuated ADS. The responses of the system to the previously described scenarios, which are initiated by primary system depressurization, are unchanged by the substitution of the passively actuated valve. During scenarios involving lossof-primary heat sink and which result in system over-pressurization, i.e. the turbine trip, the loss of main feedwater, and the loss of $\mathrm{AC}$ power, the depressurization is initiated by the opening of the ASME code safety valve on high system pressure. Therefore, the ASME code safety valve must be designed so that it does not reseat until primary system pressure has fallen to below the set pressure for activation of the passive ADS.

\subsection{Conclusions}

The results of the safety studies demonstrate that the reactor core will be provided with a stable cooling source adequate to remove decay heat without significant cladding heatup under all credible scenarios. The response of the system to accident conditions is a controlled depressurization, whereby most of the primary system blowdown occurs via the submerged ADS blowdown pathway. This controlled blowdown ensures that containment overpressure will not occur, and provides a recirculation flow path is established between the vessel and the containment via the submerged ADS blowdown and steam vent lines. This recirculation path provides sufficient capability for removal of decay heat from the vessel. The heat rejected through the containment wall to the surrounding pool of water exceeds the amount of decay heat produced by the reactor core.

In the initial safety analyses, the liquid in the containment was assumed to be borated. However, the results of the safety studies show that the boron is not effective for mitigation of non-credible events (i.e. failure of the reactor to scram). In addition, boron may be introduced into the primary vessel following anticipated events, e.g. turbine trips and feedwater pump trips, because loss-of-primary heat sink events result in system depressurization. There are additional problems with preventing precipitation of the boron into the bottom of the containment, and potential corrosion issues with boric acid. Therefore, a passive reactor shutdown system has been designed as secondary shutdown system.

The MASLWR baseline design includes safety systems with electronically generated actuation signals and subsequent valve repositioning using electric or electro-hydraulic operators. To increase reliability of theses systems a passive actuation system for the ECC system was developed that uses the pressure in an accumulator as a setpoint for valve actuation. When primary system pressure drops below that of the accumulator, vent pathways are opened that relieve primary system pressure via the submerged ADS blowdown and steam vent lines. The passively actuated valves produce system response characteristics similar to those of their electrically activated counterparts. 


\section{Licensing Approach}

The underlying licensing philosophy for the MASLWR has two major elements:

- To promote a stabilized regulatory basis that leads to advanced certification with high assurance of licensability, and

- To employ a set of design requirements that provides a standardized plant.

The licensing and regulatory requirements of the USCFR are invoked in their entirety for this project, but are not documented in this report. Licensing relies on licensing and certification experience from AP600. For the safety systems used in MASLWR, i.e. the ADS, containment liquid pool, etc., extensive experience and database is available. The certification will be based on a two-step approach:

- Testing in an integral test facility for validation of system analysis codes, and

- Final certification based on prototype testing.

\section{Plant Construction and Schedule}

This section discusses the proposed approach to constructing the MASLWR plant and the estimated preliminary construction and startup schedule.

\subsection{Constructibility}

The construction of the MASLWR plant is based on the plant being located at an EPRI hypothetical site of Kenosha, Wisconsin per DOE Cost Estimate Guidelines for Advanced Nuclear Power Technologies. While the general construction approach will be applicable to any other site, there will be some differences due to site topography, soil conditions, access to site, etc. The most significant aspects of the MASLWR plant construction approach are as follows:

- Extensive use of modularization

- Use of "Rolling 4-10s" work schedule

- Staggered construction of power generation units

- Parallel construction activities

- Application of advanced construction methods.

Modularization is the main aspect of the proposed construction approach. It is characterized by the extensive use of factory fabrication and pre-assembly prior to in situ installation and construction. As a result, a large amount of fieldwork in a conventional stick-built approach to power plant construction is moved from the field to a much better controlled and predictable factory environment and, therefore, more efficiently performed than in situ. From the construction standpoint modularization maybe divided into factory or field-fabricated modules and field pre-assembled modules. The latter is especially important for sites without barge access. 
The "Rolling 4-10s" work schedule is a seven-day-a-week, ten-hour-a-day work schedule where one team of craftsmen and supervisory personnel work four days of ten hours each then takes four days off. A second group begins a similar four-day, ten-hour shift while the other is off. The result is continuous construction seven days a week rather than the usual five. Compared to a second shift alternative, the "Rolling 4-10s" work schedule results in a more efficient working arrangement while providing a similar construction schedule reduction.

Staggered construction of power generation units consists of building the units sequentially instead of constructing them all at once. While this necessitates a longer construction schedule, it results in a lower total capital cost due to a much lower number of field crafts required and a less crowded and, therefore, more efficient construction. In the staggered approach, when a team of craftsmen completes a construction activity in a power generation unit it moves to the next power generation unit, while the next team comes to perform the next activity. This levels all the resources required for construction.

Parallel construction consists of performing on-site activities side-by-side to reduce schedule. For instance, in constructing the baseline plant consisting of two rows of reactor modules, two teams will be working in parallel. Parallel construction has to be investigated in conjunction with staggered construction to arrive at the optimum combination from the economic standpoint (construction duration and capital cost).

Using of advanced construction methods not only reduces the construction schedule but also leads to a lower capital cost. Some typical examples of advanced construction methods are: use of pre-engineered forming systems, use of automatic welding machines, use of robots, and use of quick connectors for wiring.

\subsection{Schedule}

The preliminary construction and startup schedule for the MASLWR baseline plant consisting of 30 power generation units is based on the construction approach described in Section 6.1 and a nth-of-a-kind plant where the full benefits of the learning curve experience has been achieved. In addition, the following assumptions were made to develop the schedule:

- The critical path is in erecting the power generation complex which includes the reactor building

- The reactor modules and the facility modules can be timely fabricated and delivered to the site whenever they are needed.

Construction and startup of the plant and specifically the power generation complex involves the following major activities:

- Site preparation and grading

- Excavation for the complex embedded portion

- Construction of the complex embedded structure

- Construction of the complex super structure

- Installation of fuel handling and reactor module assembly equipment 
- Nuclear fuel load into the reactors

- Installation of the reactor modules

- Installation of turbine generator modules

- Installation of other mechanical and electrical equipment

- Installation of piping

- Installation of cabling and wiring

- Pre-operational testing of systems

- Power generation units startup (power ascension and turbine generator synchronization).

Many of these activities are performed in parallel in order to reduce the construction schedule. The estimated construction and startup schedule is as follows:

- First two power generation units (70 MWe): 18 months

- Baseline plant consisting of 30 power generation units (1050 MWe): 36 months.

\section{Capital and Busbar Cost Estimates}

The plant energy generation cost or busbar cost is defined using the following major cost items:

- Capital cost

- Operation and maintenance cost

- Nuclear fuel cost

- Decommissioning cost

The cost estimates were developed using the ground rules, assumptions and requirements set in the DOE guidelines: "Cost Estimate Guidelines for Advanced Nuclear Power Technologies", ORNL/TM-10071/R3, May 1993. These guidelines provided a consistent basis for assessment of cost variations as the concept evolved. Where applicable, cost data given in the guidelines have been escalated to January 2002 before use in the MASLWR project.

\subsection{Capital Cost}

The plant capital cost represents the cost required to build the plant and includes equipment, materials, labor, engineering, land, etc. The plant total capital cost consists of the following major cost components:

- Direct construction costs - Includes those construction and installation costs directly associated with the operating plant structures, systems and components. They consist of land and land rights, factory-fabricated equipment, direct field labor and field materials and supplies.

- Indirect costs - Includes those construction support activities required to design and build the operating plant structures and systems. They consist of construction services (temporary facilities, tools and equipment, permits, insurance and taxes), engineering and home office services (engineering, quality assurance, project management), and field supervision and field office services (field offices, construction supervision, field QA/QC, plant startup and testing). 
- Owners costs - Include management/engineering/integration, taxes and insurance, spare parts and initial supplies, staff training, startup, general and administration. Since the MASLWR is of simple design and will be developed as a standard certified plant, the owners costs will be substantially lower than in present LWR plants. Therefore, the owners cost was assumed to be $5 \%$ of the sum of total direct costs and indirect costs excluding the owners cost

- Contingency - Includes an allowance for indeterminates in the cost estimate where there is equal probability that the real cost will be higher or lower than that cost. A contingency is a judgement adder which depends on many factors such as, how far the design has progressed, the level of design details available, whether they are quotes from the suppliers, available data from similar projects, etc. Although the MASLWR project is in a preliminary conceptual phase of development, its simplicity of design and the use of components that do not require substantial development cost and effort does not necessitate a high contingency.. Therefore, the contingency was assumed to be $12 \%$ of the plant base construction cost (sum of total direct and total indirect costs).

- Interest during construction - As expenses associated with the plant construction cost are paid, a return on this money (interest) must be paid until the plant starts operation.

The DOE Energy Economic Data Base (EEDB) Code of Accounts structure was used to estimate the various costs. As a starting point, the available cost estimates for an advanced $600 \mathrm{PWR}$ plant were used. Using these costs and a combination of quantity takeoffs, scaling factors, engineering and estimating judgment and experience, design data and drawings developed for the MASLWR project, in-house available cost data base, other advanced reactor plant cost estimates, cost estimates were developed. Preliminary bottoms-up cost estimates based on quantity takeoffs were developed for the following facilities:

- Reactor building

- Fuel handling and maintenance building.

Vendors' budgetary quotes were obtained for the reactor modules and turbine generators. The results of the cost estimates are presented at the 2-digit code of accounts in Table 7-1. The costs are in January 2002 dollars and represent the nth-of-a-kind (NOAK) plant in which the learning curve benefits have been fully achieved. Based on the cost guideline definition, this occurs when a cumulative plant capacity of $4500 \mathrm{MWe}$ has been constructed. For the MASLWR it will happen when about four baseline plants have been built.

The estimated unit capital cost is $\$ 1241$ per $\mathrm{kWe}$ of capacity installed for an NOAK plant. For a first-of-a-kind plant this cost is expected to be 15 to 20 percent higher than for an identical NOAK plant.

\subsection{Operation and Maintenance Cost}

The operation and maintenance (O\&M) costs are related to the commercial operation of the plant. They are incurred throughout the operating life of the plant and include all the costs excluding the nuclear fuel cost, whether the plant is operating or shutdown for refueling or maintenance. The O\&M costs consists of the following major cost categories: 
Table 7-1 Capital Cost Estimate (in Millions of January 2002 Dollars).

\begin{tabular}{|c|c|c|}
\hline EEDB Account & Description & Total Cost* \\
\hline 20 & Land and Land rights & 6 \\
\hline 21 & Structures and Improvements & 126 \\
\hline 22 & Reactor Plant Equipment & 267 \\
\hline 23 & Turbine Plant Equipment & 201 \\
\hline 24 & Electric Plant Equipment & 131 \\
\hline 25 & Miscellaneous Plant Equipment & 45 \\
\hline \multirow[t]{2}{*}{26} & Main Condenser Heat Rejection & 30 \\
\hline & Total Direct Costs & 806 \\
\hline 91 & Construction Services & 129 \\
\hline 92 & Engineering and H.O. Services & 31 \\
\hline 93 & Field Superv. and Office Services & 74 \\
\hline \multirow[t]{8}{*}{94} & Owners Cost & 52 \\
\hline & Total Indirect Costs & 286 \\
\hline & Base Construction Cost & 1092 \\
\hline & Contingency & 126 \\
\hline & Total Overnight Cost & 1218 \\
\hline & Interest During Construction & 85 \\
\hline & Total Capital Cost & 1303 \\
\hline & Unit Cost & $\$ 1241 / \mathrm{kWe}$ \\
\hline
\end{tabular}

- On-site personnel

- Supplies and expenses

- Off-site technical support

- Pensions and benefits

- Regulatory fees

- Insurance premiums

- Other general and administration.

At this conceptual design stage of the MASLWR plant, it is difficult to estimates the various categories of the O\&M cost with a reasonable accuracy. Therefore, the overall O\&M was estimated using O\&M cost estimates for other advanced reactor plants which have many of the MASLWR plant features. Further simplification of design and increased application of passive systems, was considered in further reducing these O\&M costs. The estimated O\&M cost arrived at is: 0.7 cents $/ \mathrm{kWh}$. When the project reaches the stage in which the design is better defined, a more detailed estimate of the O\&M cost will be developed. 


\subsection{Nuclear Fuel Cost}

Various nuclear fuels were investigated for the MASLWR project as described in Section 3.2.3. For the cost estimate, a fuel with a 5-year cycle was assumed to coincide with the turbine generator overhaul, which requires that the corresponding power generation unit be shutdown. The fuel selected is made of uranium oxide with $8 \%$ enrichment. The estimated cost of this fuel for a single batch cycle is 1.3 cents $/ \mathrm{kWh}$.

\subsection{Busbar Cost}

The methodology used for calculating the busbar cost is a year-by-year revenue requirements approach together with leveling over the economic life of the plant. It is based on the DOE document, Nuclear Energy Cost Data Base, DOE/NE-0095, September 1988. The annual revenue requirements are the year-by-year revenues needed to pay operating costs, taxes, capital investment depreciation and return on undepreciated capital investments. Levelization consists of defining a single price, which will produce the same present worth of revenues as the stream of actual year-by-year prices. The levelized price is expressed in constant dollars indexed to January 2002. An economic and plant life of 60 years is used for calculating the busbar cost. The start of plant commercial operation is assumed to be January 2010. A plant overall capacity factor of $95 \%$ is assumed. The remaining assumptions are per the DOE guidelines. The calculated busbar cost for a NOAK MASLWR baseline design plant is 3.4 cents $/ \mathrm{kWh}$. The cost breakdown is given in Table 7-2.

The capital and busbar costs were estimated using the DOE "Cost Estimate Guidelines for Advanced Nuclear Power Technologies". These guidelines were developed to allow assessment of cost attractiveness of various concepts on a consistent basis. The total capital costs estimated using these guidelines are all inclusive and include such items as Owner's cost, substantial contingencies, and interest during construction. Very often capital costs quoted appear to be very attractive because they do not include these items, which can account up to one third of the total capital cost.

Table 7-2 Busbar Cost Estimate (in Cents/kWh).

\begin{tabular}{|lc|}
\hline Busbar Cost Item & Busbar Cost \\
Capital Cost & 1.3 \\
Operation and Maintenance & 0.7 \\
Nuclear Fuel Cost & 1.3 \\
Decommissioning & 0.1 \\
Total Busbar Cost & $\mathbf{3 . 4}$ \\
\hline
\end{tabular}




\section{Testing Program}

A detailed scaling analysis was performed using the $150 \mathrm{MW}$ thermal design as the baseline case. The scaling analysis included the development of a Phenomena Identification and Ranking Table (PIRT) for the inadvertent opening of an ADS and/or primarily relief vent valve. The scaling analysis was used to establish the component geometry and system operating conditions for the test facility. Based on the results of the scaling analysis, a reduced scale test facility was designed and constructed at OSU. The OSU MASLWR scaling analysis results have been issued as a separate report. The purpose of the OSU MASLWR Test facility is to assess the operation of MASLWR under nominal full pressure and full temperature conditions and to assess the passive safety systems under transient conditions.

\subsection{Description of the OSU MASLWR Test Facility}

The MASLWR Test Facility has been constructed using all stainless steel components. It is designed for operation at full system pressure and temperature. All components are 1:3 height scale and 1:254.7 volume scale. The test facility includes:

- Reactor Pressure Vessel with a $600 \mathrm{~kW}$ electrically heated core bundle with spacer grids.

- A core shroud and hot leg riser

- A pressurizer

- Two ADS lines, two Sump recirculation lines, and one head vent line, One main steam line

- A Helical Tube Steam Generator

- A Variable Speed Feedwater Pump and Storage Tank

- Instrumentation Package: 3 Power Measurements, 32 Fluid Thermocouples, 1 Vortex Flow Meter, 3 Coriolis Flowmeters, 1 Magnetic Flowmeter, 1 Mass Vortex Flowmeter, 1 DP Flowmeter, 5 Gauge Pressure Meters, 6 Differential Pressure Meters, 2 Level DP Meters

- Complete Data Acquisition System and Programmable Logic Controls

- Balance of plant; water supply, chemical treatment, air supply, power supply

- Containment Vessel

Figure 8-1 shows the P\&ID for the test section. The containment tank is not shown is this figure. 


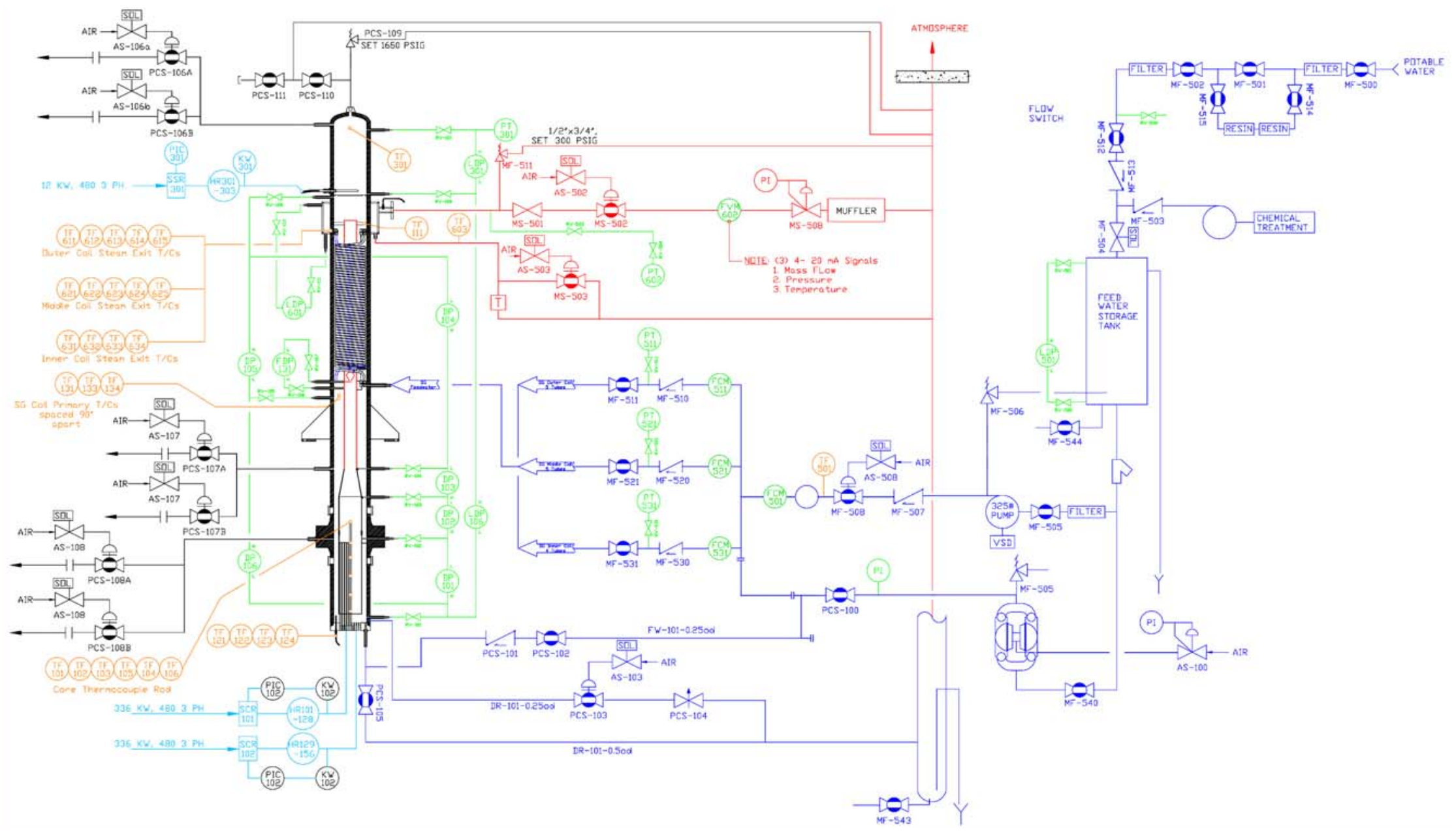

Figure 8-1 P\&ID Drawing for the MASLWR Facility 
Figure 8-2 shows a schematic of the Reactor Pressure Vessel (RPV), and Figure 8-3 shows a photograph of the test facility at the OSU Radiation Center. The following sections provide an overview of the test facility components.

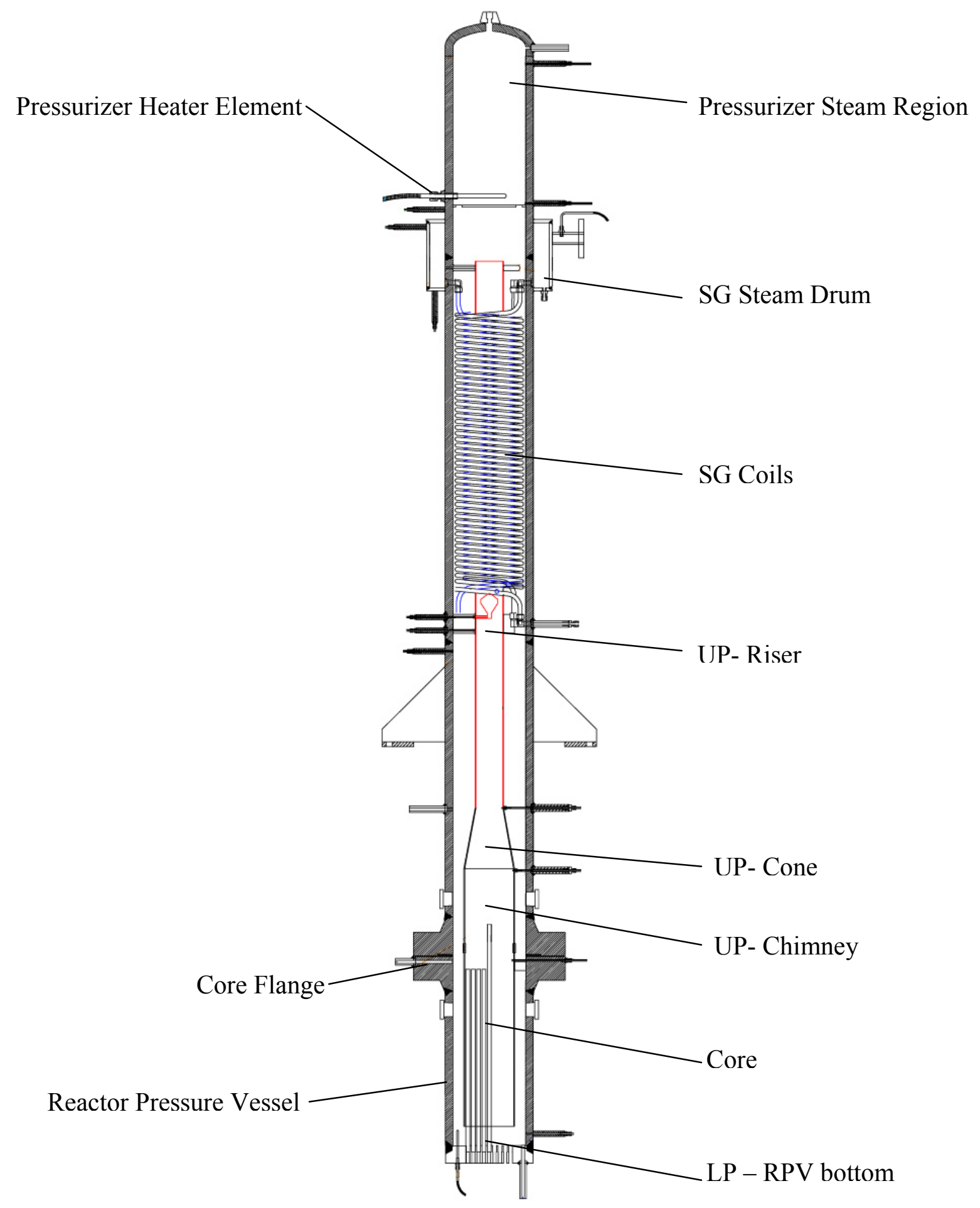

Figure 8-2 Schematic of the OSU MASLWR Primary Side Components. 


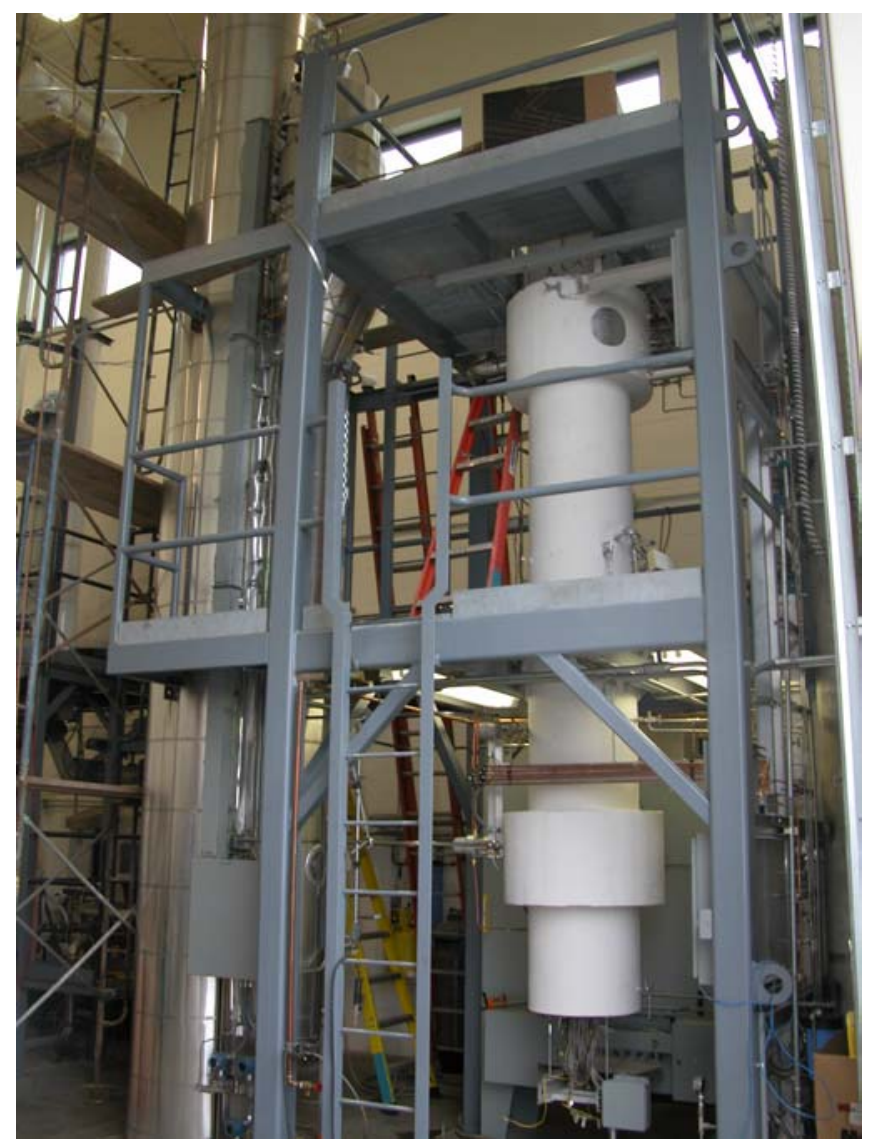

Figure 8-3 Photograph of the MASLWR Test Facility at OSU

\subsubsection{Integrated Reactor Vessel and Primary Circuit}

The OSU reactor pressure vessel models the "self-contained" integrated reactor core and steam generator system. The electrically heated core bundle is centrally located in the lower part of vessel, with the helical coil steam generator (SG) tubes located in the annulus above it. The relative placement of the core and SG provides natural circulation (NC) flow as the designed method of heat transfer between the SG and core. The integrated nature of this system is apparent in the minimal use of required support structures, i.e. the core is connected directly to the space above the SG via a tube (riser), which is an upper extension of the core barrel, instead of with the use of hot and cold legs that penetrate the pressure boundary.

The MASLWR test facility cooling circuit is a model of the primary loop typical of a double-circuit NSSS. The primary loop located inside the RPV has a once-through type 
SG. The primary loop coolant flow path is upward through core and riser, then downward around the SG tubes to the bottom of the core via the lower plenum (LP).

The RPV houses the core modeled by 57 electric heaters, each rod having an external diameter of $15 \mathrm{~mm}(5 / 8$ inches $)$ and a heated length of $686 \mathrm{~mm}(\sim 27$ '). The maximum core power is $600 \mathrm{~kW}$. The overall core geometry has been preserved on a scaled basis. This includes the core flow area, the hydraulic diameters and the local heat flux. The heater rods are distributed in the core in a square array with a pitch to diameter ratio $\mathrm{P} / \mathrm{D}=$ 1.33. Internal design of the core and heater locations are shown in Figure 8-4, and the electric power connection installations are shown in Figure 8-5. Details of the primary loop component geometries are provided in Table 8-1.

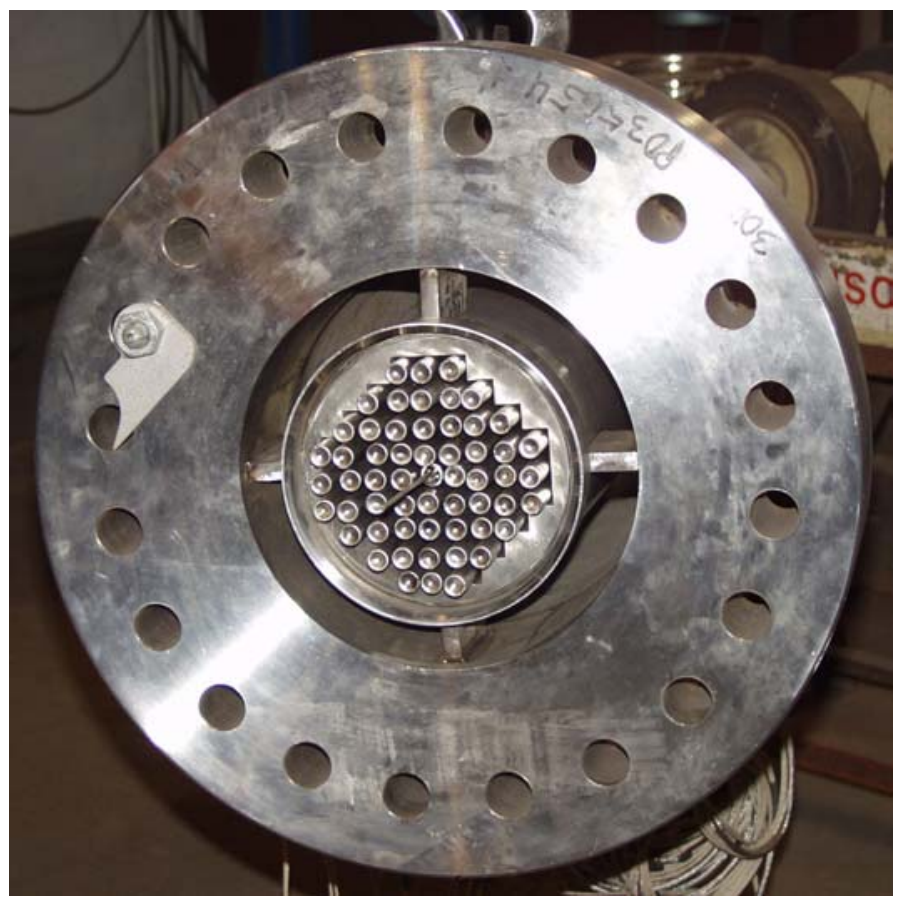

Figure 8-4 Electrically Heated Core Bundle in OSU MASLWR 


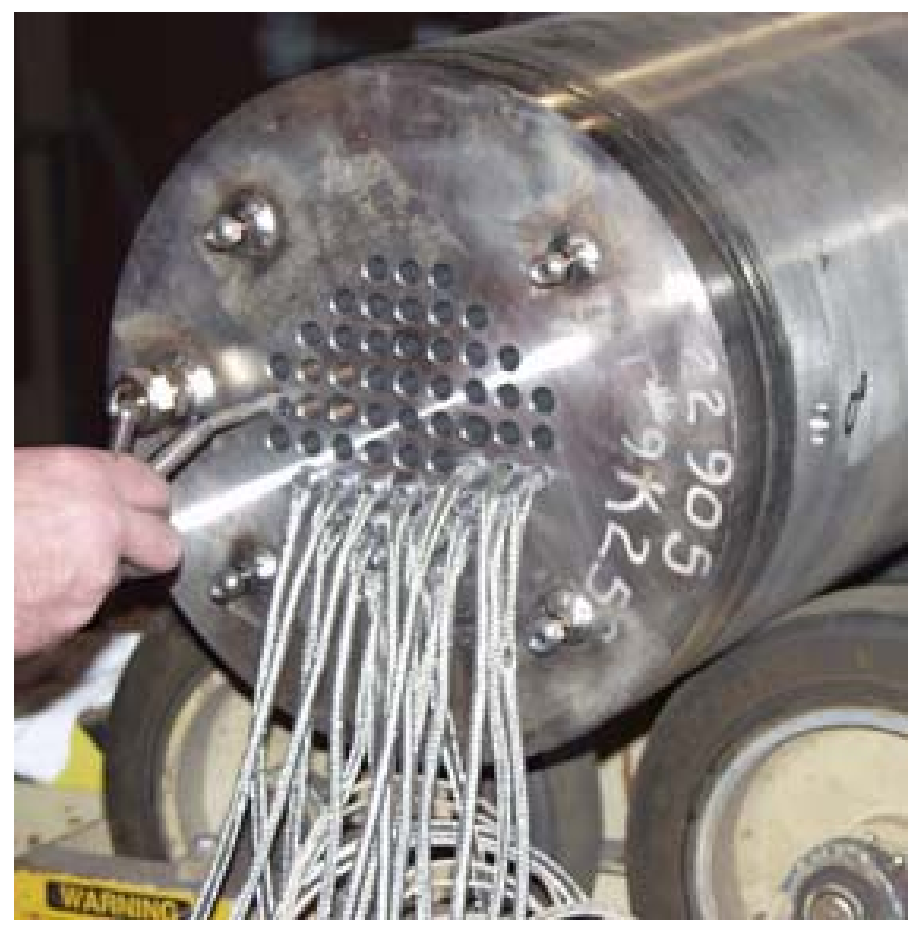

Figure 8-5 Electrical Connections for the OSU MASLWR Core Bundle (RPV Bottom Plate). 
Table 8-1 Primary Loop Data

\begin{tabular}{|c|c|c|c|c|c|}
\hline & Component & $\begin{array}{l}\text { Length } \\
(\mathrm{m})\end{array}$ & $\begin{array}{c}\text { Cross } \\
\text { Section }\left(\mathrm{m}^{2}\right)\end{array}$ & $\begin{array}{l}\text { Length } \\
\text { (in.) }\end{array}$ & $\begin{array}{l}\text { Cross Section } \\
\left(\text { in }^{2}\right)\end{array}$ \\
\hline 1 & Core & 0.5970 & 0.008422 & 11.955 & 13.055 \\
\hline 2 & Core top plate & 0.0127 & 0.019231 & 0.5 & 29.807 \\
\hline 3 & Lower hot leg 1(lower chimney with TC wiring) & 0.1778 & 0.030481 & 7 & 47.246 \\
\hline 4 & Lower hot leg 2 (lower chimney) & 0.2477 & 0.030513 & 9.75 & 47.295 \\
\hline 5 & Hot leg cone & 0.2445 & 0.018820 & 9.625 & 29.17 \\
\hline 6 & Mid hot leg (mid riser) & 0.8604 & 0.008213 & 33.875 & 12.73 \\
\hline 7 & Hot leg flow meter area & 0.1111 & 0.006565 & 4.375 & 10.175 \\
\hline 8 & Upper hot leg & 1.2287 & 0.008213 & 48.375 & 12.73 \\
\hline 9 & Upper plenum & 0.3175 & 0.008213 & 12.5 & 12.73 \\
\hline 10 & Pressurizer & & & & \\
\hline 11 & Upper steam bustle & 0.2000 & 0.056751 & 7.875 & 87.965 \\
\hline 12 & SG coil outlet & 0.0762 & 0.05108 & 3.0 & 79.174 \\
\hline 13 & SG coil section & 0.8096 & 0.036954 & 31.875 & 57.279 \\
\hline 14 & SG coil inlet & 0.0921 & 0.052058 & 3.625 & 80.689 \\
\hline 15 & Upper downcomer annulus & 0.1413 & 0.056751 & 5.563 & 87.965 \\
\hline 16 & $\begin{array}{l}\text { Mid downcomer annulus } 1 \text { (with hot leg } \\
\text { supports) }\end{array}$ & 0.0762 & 0.053364 & 3.0 & 82.715 \\
\hline 17 & Mid downcomer annulus 2 & 0.7795 & 0.056751 & 30.688 & 87.965 \\
\hline 18 & $\begin{array}{l}\text { Mid downcomer annulus } 3 \text { (with hot leg } \\
\text { installation tube) }\end{array}$ & 0.0064 & 0.055864 & 0.25 & 86.59 \\
\hline 19 & Mid downcomer annulus 4 & 0.0191 & 0.056751 & 0.75 & 87.965 \\
\hline 20 & Downcomer annulus cone region & 0.2445 & 0.046702 & 9.625 & 72.388 \\
\hline 21 & Lower downcomer annulus 1 & 0.0191 & 0.034583 & 0.75 & 53.603 \\
\hline 22 & $\begin{array}{l}\text { Lower downcomer annulus } 2 \text { (with hot leg } \\
\text { installation tube) }\end{array}$ & 0.0064 & 0.033978 & 0.25 & 52.666 \\
\hline 23 & Lower downcomer annulus 3 & 0.3429 & 0.034583 & 13.5 & 53.603 \\
\hline 24 & Lower downcomer annulus 4 (with core support) & 0.0064 & 0.033978 & 0.25 & 52.666 \\
\hline 25 & Lower downcomer annulus 5 & 0.0508 & 0.034583 & 2.00 & 53.603 \\
\hline 26 & Core downcomer annulus 1 (with core seal ring) & 0.0191 & 0.032524 & 0.75 & 50.413 \\
\hline 27 & Core downcomer annulus 2 (with core supports) & 0.1016 & 0.032325 & 4.00 & 50.103 \\
\hline 28 & Core downcomer annulus 3 & 0.4001 & 0.034583 & 15.75 & 53.603 \\
\hline 29 & Core downcomer annulus 4 (with core support) & 0.1016 & 0.032325 & 4.00 & 50.103 \\
\hline 30 & Lower plenum & 0.0635 & 0.008422 & 2.50 & 13.055 \\
\hline 31 & Flow plate & 0.0127 & 0.004362 & 0.50 & 6.762 \\
\hline
\end{tabular}




\subsubsection{Steam Generator and Secondary Side}

De-ionized Feed Water (FW) is provided by the city water supply, and the steam generated in the helical coils is vented to the atmosphere. The SG is a helical-tube, oncethrough heat exchanger located inside the PRV, in the annular space between the hot leg riser and the internal surface of the RPV, and at an elevation above the core. The SG consists of three separate parallel sections; an outer coil consisting of 5 tubes, a middle coil consisting of 5 tubes, and an inner coil consisting of 4 tubes for a total of 14 tubes.

Each coil section can be completely isolated using individual manually operated valves. All three sections are joined at the outlet header to ensure pressure equilibrium in the coils. The design of the SG is shown in Figure 8-6. Cold FW enters the tubes at the bottom of the SG and is boiled off after a length along the flow path determined by the core power and SG FW flow rate. The facility design and desired operation modes are such that this length is less than the linear length of the coils, producing superheated steam. The exhaust of each individual coil is combined in the steam drum and subsequently vented to atmosphere via the main steam line.

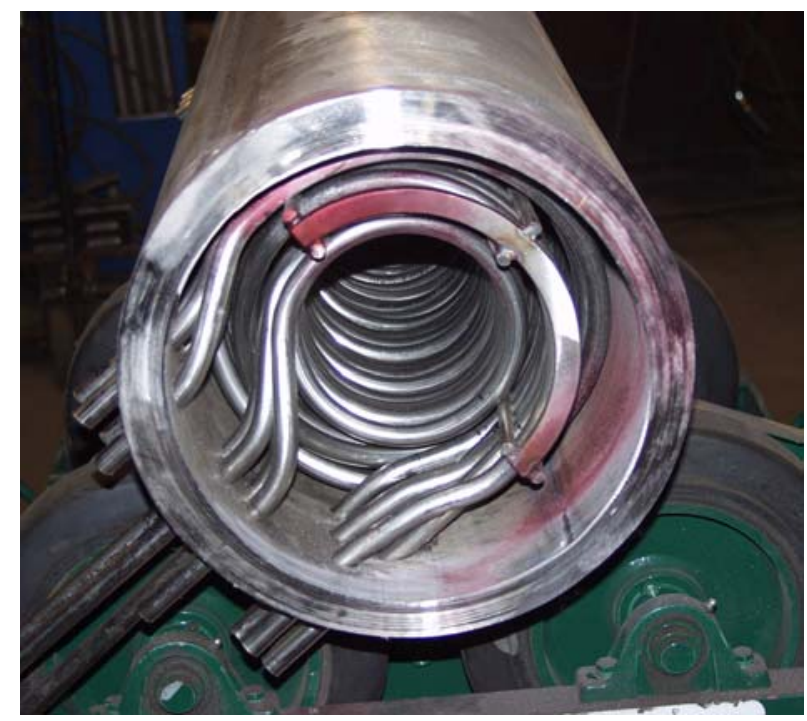

Figure 8-6 Three Sections of the Helical Tube Steam Generator

The main control parameters of the secondary side are the FW flow rate, steam pressure, the core exit fluid temperature, and the FW inlet temperature. The degree of steam superheat will be used in the design of an automated SG control system.

The FW is pumped from a FW storage tank into the SG by a "General Pump" Companies Inc. model WN 4215C positive displacement pump (3-plungers in line), shown in Figure 8-7. The FW pump is powered by an electric motor with a variable speed controller to 
allow precise control of the mass flow rate. FW pump data and information is presented below in Table 8-5.

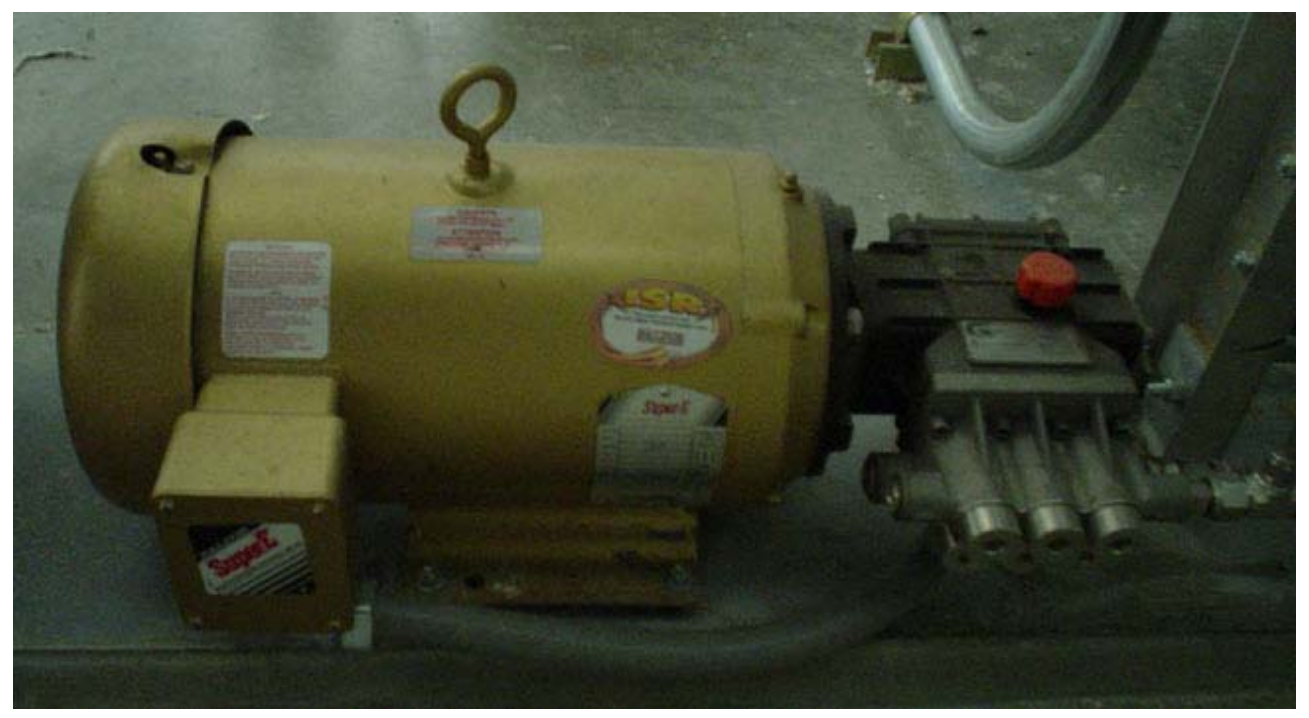

Figure 8-7 Feed Water Pump and Electric Motor

The components of the test facility RPV and SG were fabricated from SS 304 and are capable of prolonged operation at the nominal operating conditions:

- RPV pressure of 7.6 MPa (1102 psia)

- Core inlet temperature of $491.8 \mathrm{~K}(425.6 \mathrm{~F})$

- Core outlet temperature of $544.3 \mathrm{~K}(520 \mathrm{~F})$

- SG pressure of 1.5 MPa (217 psia) 


\subsubsection{Valves, Systems and Equipment}

The following tables provide the technical data for the valves.

Table 8-2 Motor Operated Valves

\begin{tabular}{|c|c|c|c|c|}
\hline $\begin{array}{l}\text { Name and } \\
\text { type: }\end{array}$ & $\begin{array}{c}\text { Fluid (media) and } \\
\text { parameters: }\end{array}$ & Operating Method & Location & $\begin{array}{l}\text { Normal } \\
\text { Operating } \\
\text { Position }\end{array}$ \\
\hline MF-508 & Main FW & Air through AS-508 & $\begin{array}{l}\text { First valve after MFP inline to } \\
\text { SG }\end{array}$ & Open \\
\hline PSC-103 & Primary Side coolant & Air though AS-103 & PRV bottom Lower plenum & Closed \\
\hline PSC-106A & Primary Side coolant & Air though AS-106A & PRV top - PZR & Closed \\
\hline PSC-106B & Primary Side coolant & Air though AS-106B & PRV top - PZR & Closed \\
\hline PSC-107A & Primary Side coolant & Air though AS-107A & PRV Mid shell Mid cold leg & Closed \\
\hline PSC-107B & Primary Side coolant & Air though AS-107B & PRV Mid shell Mid cold leg & Closed \\
\hline PSC-108A & Primary Side coolant & Air though AS-108A & PRV Lower plenum - Cold Leg & Closed \\
\hline PSC-108B & Primary Side coolant & Air though AS-108B & PRV Lower plenum - Cold Leg & Closed \\
\hline PCS-109 & Primary Side coolant & $\begin{array}{l}\text { Relive valve (spring) Setting } \\
\text { of } 1650 \text { psig }\end{array}$ & PRV top - PZR & Closed \\
\hline MF-543 & Drain water & Manual & $\begin{array}{l}\text { Main Steam Line Water Catch } \\
\text { Tank - bottom }\end{array}$ & Open \\
\hline MF-504 & $\begin{array}{l}\text { Purified water supply to FW } \\
\text { Storage Tank }\end{array}$ & Solenoid & FWST - top & Closed \\
\hline MF-506 & $\begin{array}{l}\text { Main FW } \\
\text { Temp }=291 \mathrm{~K}\end{array}$ & $\begin{array}{l}\text { Relive valve (spring) - } \\
\text { Setting of } 350 \text { psig }\end{array}$ & MFP - Exit & Closed \\
\hline MF-511 & $\begin{array}{l}\text { Main Steam } \\
\text { Temp }=481 \mathrm{~K} \\
\text { Pressure }=1.5 \mathrm{MPA}\end{array}$ & Relive valve (spring) & SG - Exit & Closed \\
\hline MS-503 & Main Steam & Solenoid & SG Drain Line & Closed \\
\hline PSC-800 & ADS Steam & Solenoid & Containment - Top & Open \\
\hline
\end{tabular}


Table 8-3 Manual Operated Valves

\begin{tabular}{|c|c|c|c|}
\hline Valve \# & Valve type & Fluid Path & $\begin{array}{c}\text { Normal } \\
\text { Operating } \\
\text { Position }\end{array}$ \\
\hline MF-500 & Globe valve & $\begin{array}{l}\text { Supply potable Water for purification } \\
\text { system }\end{array}$ & Open \\
\hline MF-501 & Globe valve & $\begin{array}{l}\text { Potable Water to FST } \\
\text { Purification system by-pass }\end{array}$ & Closed \\
\hline MF-502 & Globe valve & Purified water to filter & Open \\
\hline MF-512 & Globe valve & Supply purified water after to FST & Open \\
\hline MF-513 & Check-valve & Supply purified water after to FST & $\mathrm{N} / \mathrm{A}$ \\
\hline MF-514 & Globe valve & Fluid to resin tanks & Open \\
\hline MF-515 & Globe valve & Fluid from resin tanks & Open \\
\hline MF-503 & Check-valve & Chemical treatment supply & $\mathrm{N} / \mathrm{A}$ \\
\hline MF-505 & Globe-valve & $\begin{array}{l}\text { Supply FW from FWST and filter to FWP } \\
\text { inlet }\end{array}$ & Open \\
\hline MF-507 & Check-valve & FW Main flow & N/A \\
\hline MF-510 & Check-valve & FW to MF-511 coil 1 & N/A \\
\hline MF-520 & Check-valve & FW to MF-521 coil 2 & N/A \\
\hline MF-530 & Check-valve & FW to MF-531 coil 3 & N/A \\
\hline MF-511 & Globe-valve & FW SG Outer coil $1-5$ tubes & Open \\
\hline MF-521 & Globe-valve & FW SG Middle coil $1-5$ tubes & Open \\
\hline MF-531 & Globe-valve & FW SG Inner coil 3 - 4 tubes & Open \\
\hline MF-540 & Globe-valve & $\begin{array}{l}\text { Purified water supply to multiplication for } \\
\text { PRV hydrostatic test }\end{array}$ & Closed \\
\hline MF-541 & Globe-valve & FW supply to PRV feeling & Closed \\
\hline PSC-100 & Globe-valve & $\begin{array}{l}\text { High pressurized water supply to PRV from } \\
\text { multiplication }\end{array}$ & Closed \\
\hline PSC-101 & Check-valve & Purified water PRV filing line & N/A \\
\hline PSC-102 & Globe-valve & Purified water PRV filing line & Closed \\
\hline PSC-104 & Valve & $\begin{array}{l}\text { Primary side hot coolant drain line to the } \\
\text { Steam discharge pipe }\end{array}$ & $\begin{array}{c}\text { Partially Open }--\sim 3 \\
\text { turns }\end{array}$ \\
\hline PSC-105 & Globe-valve & Primary side coolant drain line & Closed \\
\hline PSC-110 & Globe-valve & Cold Primary side PRV venting line & Closed \\
\hline PSC-111 & Valve & Cold Primary side PRV venting line & Open \\
\hline
\end{tabular}


Table 8-4 Pressure Measurement Device Root Valves

\begin{tabular}{|c|c|c|c|}
\hline Name & Fluid Path & $\begin{array}{c}\text { Normal } \\
\text { Operating } \\
\text { Position }\end{array}$ & Information \\
\hline RV-500 & $\begin{array}{l}\text { Feed water. Level } \\
\text { in the FST }\end{array}$ & Open & $\begin{array}{l}\text { LDP-501 Level pressure device in the } \\
\text { FST. High pressure side. }\end{array}$ \\
\hline RV-501 & $\begin{array}{l}\text { Feed water. Level } \\
\text { in the FST }\end{array}$ & Open & $\begin{array}{l}\text { LDP-501 Level pressure device in the } \\
\text { FST. Low pressure side. }\end{array}$ \\
\hline RV-511 & $\begin{array}{l}\text { Feed water. } \\
\text { Pressure in the } \\
\text { Outer coil }\end{array}$ & Open & $\begin{array}{l}\text { PT-511 Pressure device in FW supply } \\
\text { line. }\end{array}$ \\
\hline RV-521 & $\begin{array}{l}\text { Feed water. } \\
\text { Pressure in the } \\
\text { Middle coil }\end{array}$ & Open & $\begin{array}{l}\text { PT-521 Pressure device in FW supply } \\
\text { line. }\end{array}$ \\
\hline RV-531 & $\begin{array}{l}\text { Feed water. } \\
\text { Pressure in the } \\
\text { Inner coil }\end{array}$ & Open & $\begin{array}{l}\text { PT-531 Pressure device in FW supply } \\
\text { line. }\end{array}$ \\
\hline RV-101 & $\begin{array}{l}\text { PC coolant. } \\
\text { Pressure in the } \\
\text { PVR (bottom- } \\
\text { Lower plenum) and } \\
\text { coolant level }\end{array}$ & Open & $\begin{array}{l}\text { DP-101 and LDP-106. Pressure loss and } \\
\text { Level devices }\end{array}$ \\
\hline RV-102 & $\begin{array}{l}\text { PC coolant. } \\
\text { Pressure in the } \\
\text { PVR (Core top } \\
\text { pressure) }\end{array}$ & Open & $\begin{array}{l}\text { DP-101 and DP-102. Pressure loss } \\
\text { device }\end{array}$ \\
\hline RV-103 & $\begin{array}{l}\text { PC coolant. } \\
\text { Pressure in the } \\
\text { PVR (Chimney top } \\
\text { pressure) }\end{array}$ & Open & $\begin{array}{l}\text { DP-102 and DP-103. Pressure loss } \\
\text { device }\end{array}$ \\
\hline RV-104 & $\begin{array}{l}\text { PC coolant. } \\
\text { Pressure in the } \\
\text { PVR (MC top } \\
\text { pressure) }\end{array}$ & Open & $\begin{array}{l}\text { DP-103 and DP-104. Pressure loss } \\
\text { device }\end{array}$ \\
\hline RV-105 & $\begin{array}{l}\text { PC coolant. } \\
\text { Pressure in the } \\
\text { PVR (Down Comer } \\
\text { after SG pressure) }\end{array}$ & Open & $\begin{array}{l}\text { DP-105 and DP-106. Pressure loss } \\
\text { device }\end{array}$ \\
\hline $\begin{array}{l}\text { RV-106 } \\
\text { and } \\
\text { RV-107 }\end{array}$ & $\begin{array}{l}\text { PC coolant. } \\
\text { Pressure-Mass flow } \\
\text { in the loop (Riser) }\end{array}$ & Open & FDP-131 Flow meter device \\
\hline RV-108 & $\begin{array}{l}\text { PC coolant. } \\
\text { Pressure in the } \\
\text { PVR (Pressurizer } \\
\text { bottom) }\end{array}$ & Open & $\begin{array}{l}\text { DP-105 and DP-106. Pressure loss } \\
\text { device }\end{array}$ \\
\hline RV-109 & $\begin{array}{l}\text { PC coolant. } \\
\text { Pressure in the } \\
\text { PVR (Pressurizer } \\
\text { bottom) }\end{array}$ & Open & $\begin{array}{l}\text { LDP-106 and LDP-301. Pressure loss } \\
\text { and Level device }\end{array}$ \\
\hline RV-110 & & Open & \\
\hline $\begin{array}{l}\text { RV-111 } \\
\text { and } \\
\text { RV-112 }\end{array}$ & $\begin{array}{l}\text { Main Steam } \\
\text { Collector top and } \\
\text { bottom }\end{array}$ & Open & LDP-601. Pressure loss and Level device \\
\hline RV-501 & $\begin{array}{l}\text { Main Steam pipe } \\
\text { Pressure }\end{array}$ & Open & PT-602. Main Steam Pressure device \\
\hline
\end{tabular}


Table 8-5 Balance of Plant Information

\begin{tabular}{|c|c|c|c|}
\hline Name & $\begin{array}{l}\text { General } \\
\text { Information }\end{array}$ & Working Fluid & Technical Information \\
\hline FW ST & & DI Water & \\
\hline FW Pump & $\begin{array}{l}\text { Model WM } \\
4215 \mathrm{C} \\
3 \text { in line plungers } \\
\text { Stainless Steel } \\
316 \mathrm{~L}\end{array}$ & DI Water & $\begin{array}{l}\text { Max. Flow Rate }=15.2 \\
\text { liter/min }(4.2 \mathrm{gpm}) \\
\text { Max. Rotation Speed }=1750 \\
\mathrm{rpm}(@ 100 \mathrm{bar}) \\
\mathrm{P}_{\max }=103 \mathrm{bar}(1500 \mathrm{psia}) \\
\text { Fluid }_{\max }=333.15 \mathrm{~K}\left(140^{\circ}\right. \\
\mathrm{F})\end{array}$ \\
\hline 325\# Pump & $\begin{array}{l}\text { Diaphragm type } \\
\text { metering pump by } \\
\text { LMI inc. }\end{array}$ & $\begin{array}{l}\text { 1-part Nalco } \\
\text { 1-part Amonium } \\
\text { hydroxide } \\
\text { 4-part DI Water }\end{array}$ & $\begin{array}{l}3.785 \text { litre } / \mathrm{hr}(1 \mathrm{gal} / \mathrm{hr}) \text { at } \\
0.069 \mathrm{bar}(1 \mathrm{psig})\end{array}$ \\
\hline Filter & Standard Paper & Potable Water & $\begin{array}{l}100 \text { micron previous to resin } \\
\text { beds, and } 20 \text { micron posterior } \\
\text { to resin beds }\end{array}$ \\
\hline Containment Pool & Open Top & Potable Water & N/A \\
\hline $\begin{array}{l}\text { Steam exhaust } \\
\text { system }\end{array}$ & $\begin{array}{l}\text { 8" diameter SS } \\
\text { pipe }\end{array}$ & $\begin{array}{l}\text { Steam or Heated } \\
\text { DI Water }\end{array}$ & $\mathrm{N} / \mathrm{A}$ \\
\hline PRZ Heaters & $\begin{array}{l}\text { Cartridge type by } \\
\text { Marathon inc. }\end{array}$ & $\begin{array}{l}\text { Submerged in } \\
\text { Water }\end{array}$ & $\begin{array}{l}0.610 \mathrm{~m} \text { (24 inch) Long } \\
0.016 \mathrm{~m}(0.625 \mathrm{inch}) \mathrm{Dia} . \\
\text { Power }_{\max }=12 \mathrm{~kW} \\
\mathrm{~T}_{\max }=\text { Not Monitored }\end{array}$ \\
\hline $\begin{array}{l}\text { Containment } \\
\text { HTR }\end{array}$ & $\begin{array}{l}\text { Flat strip type by } \\
\text { Chromalox inc. }\end{array}$ & $\begin{array}{l}\text { Contacted with } \\
\text { SS } 304 \text { vessel }\end{array}$ & $\begin{array}{l}\text { Multiple sizes used } \\
\text { Total } \text { Power }_{\max }=10.5 \mathrm{~kW} \\
\mathrm{~T}_{\max }=672 \mathrm{~K}(750 \mathrm{~F})\end{array}$ \\
\hline
\end{tabular}

\subsubsection{Water Purification System}

The water source of the primary system and feed water originates from the city potable water supply and is treated prior to use in the MASLWR facility. The demineralization system cleanses the incoming water of minerals, and then directs the flow through resin filled tanks (ion-exchange composition). Manually operated valves can be used to isolate the resin beds from the FW flow path. The DI water is next treated with NALCO and Ammonium for:

- $\quad$ Reducing the $\mathrm{pH}$ and minimize the corrosion effects on the system

- Prevention of any buildup of solids inside the system

- Providing enough capacitance for the magnetic flow meters to properly work.

The chemically treated DI water is directed into the FW Storage Tank (FWST) through a solenoid operated valve controlled by the CS computer. Using the FWST level measurement and the solenoid valve, the CS system maintains a set level in the FWST, and a supply of DI treated water for filling the RPV, containment vessel, and providing SG FW. 


\subsubsection{Data Acquisition System, Instrumentation and Controls}

The CS and Data Acquisition System (DAS) includes the equipment necessary to collect, transmit, process, record, and provide the output signals from individual sensors and devices. The CS and DAS system is comprised of:

- $\quad$ the sensors, thermocouple or pressure device

- control equipment (valves, power regulators, pump controllers)

- signal conditioners

- signal transmitters

- interconnecting wiring

- controllers (digital or analog)

- system control and data acquisition software

- control computer

The MASLWR test facility is instrumented for capturing the behavior of the system in either a steady state or transient condition. All of the instruments were calibrated to National Institute of Standards and Technology (NIST) standards on an annual basis, and checked for zero drift on a routine basis prior to tests. An instrument configuration file, identifying the range of each instrument is prepared for tests and is maintained with the raw data. A detailed list of all of the instruments and their locations is provided in Table 8-6. MASLWR includes the following type of instruments:

- $\quad$ Thermocouples (TF/TFM/TH/TW) are used to measure fluid, steam, heater and wall temperatures. Premium grade thermocouples were used and connected to the DAS through controlled purity thermocouple wire.

- $\quad$ Pressure Transducers (PT) are used to measure the static pressure within the tanks and piping.

- Differential Pressure (DP, LDP) transducers are used to measure liquid levels in tanks, vessels, and piping. They are also used to determinate pressure drop.

- Electric power measurement (KW) devices are used to monitor the core power, and provide feedback to allow core power to be controlled in a closed loop manner 
Table 8-6 MASLWR Instrumentation List

\begin{tabular}{|c|c|c|}
\hline Tag Number & Fluid (media): & Sensors Location: \\
\hline LDP-501 & Feed Water & FW Storage Tank \\
\hline FCM-501 & Feed Water main mass flow & FW pipe after operating valve MF-508 \\
\hline TF-501 & Feed Water temperature & FW pipe after operating valve MF-508 \\
\hline FCM-511 & $\begin{array}{l}\text { Feed Water supply in the SG Outer } \\
\text { coil mass flow }\end{array}$ & $\begin{array}{l}\text { FW pipe before MF-510 and MF-511 } \\
\text { valves }\end{array}$ \\
\hline PT-511 & $\begin{array}{l}\text { FW flow pressure in the SG Outer coil } \\
\text { supply pipe }\end{array}$ & Between MF-510 and MF-511 valves \\
\hline FCM-521 & $\begin{array}{l}\text { Feed Water supply in the SG Middle } \\
\text { coil mass flow }\end{array}$ & $\begin{array}{l}\text { FW pipe before MF-520 and MF-521 } \\
\text { valves }\end{array}$ \\
\hline PT-521 & $\begin{array}{l}\text { FW flow pressure in the Middle coil } \\
\text { supply pipe }\end{array}$ & Between MF-520 and MF-521 valves \\
\hline FCM-531 & $\begin{array}{l}\text { Feed Water supply in the SG Inner coil } \\
\text { Mass flow }\end{array}$ & $\begin{array}{l}\text { FW pipe before MF-530 and MF-531 } \\
\text { valves }\end{array}$ \\
\hline PT-531 & $\begin{array}{l}\text { FW flow pressure in the Inner coil } \\
\text { supply pipe }\end{array}$ & Between MF-530 and MF-531 valves \\
\hline LDP-601 & Level & FW supply collector on PRV \\
\hline PT-602 & Main Steam flow Pressure & Main Steam Pressure pipe after SG \\
\hline TF-602 & Bypass steam line temperature & $\begin{array}{l}\text { Main Steam Pressure pipe after MS-501 } \\
\text { and MS-502 valves }\end{array}$ \\
\hline FVM & Main Steam Volumetric flow rate & $\begin{array}{l}\text { Main Steam Pressure pipe between MS- } \\
502 \text { and MS-508 valves }\end{array}$ \\
\hline $\begin{array}{l}\text { TF-611,612, 613, } \\
614,615\end{array}$ & $\begin{array}{l}\text { Secondary side. Temperature in the } \\
\text { Outer coil Steam Exit T/Cs of the SG }\end{array}$ & $\begin{array}{l}\text { Thermo-couples inside the Outer coil pipe } \\
\text { of the SG }\end{array}$ \\
\hline $\begin{array}{l}\text { TF-621, 622, 623, } \\
624,625\end{array}$ & $\begin{array}{l}\text { Secondary side. Temperature in the } \\
\text { Middle coil Steam Exit T/Cs of the SG }\end{array}$ & $\begin{array}{l}\text { Thermo-couples inside the Middle coil } \\
\text { pipe of the SG }\end{array}$ \\
\hline $\begin{array}{l}\text { TF-631, 632, 633, } \\
634\end{array}$ & $\begin{array}{l}\text { Secondary side. Temperature in the } \\
\text { Inner coil Steam Exit T/Cs of the SG }\end{array}$ & $\begin{array}{l}\text { Thermo-couples inside the Inner coil pipe } \\
\text { of the SG }\end{array}$ \\
\hline $\begin{array}{l}\text { TF-101,102, } \\
103,104,105,106\end{array}$ & PC coolant temperature in the core & $\begin{array}{l}\text { Build-in in the core area thermo-couples } \\
\text { (core thermo-couple rod) spaced } 90^{\circ} \text { apart }\end{array}$ \\
\hline $\begin{array}{l}\text { TF-121, } \\
122,123,124\end{array}$ & PC coolant down flow temperature & Core inlet temperature PVR bottom \\
\hline TF-131,132,133,134 & PC coolant down flow temperature & SG coil PC T/Cs spaced $90^{\circ}$ apart \\
\hline TF-111 & & \\
\hline TF-301 & Steam media temperature in the PRZ & PRZ top of the PVR \\
\hline PT-301 & Steam media pressure in the PRZ & PRZ top of the PVR \\
\hline LDP-301 & PC coolant level in the PRZ & $\begin{array}{l}\text { 2" Below PZR heaters to upper steam } \\
\text { space }\end{array}$ \\
\hline DP-101 & Pressure loss in the core & Core flange to LP \\
\hline DP-102 & $\begin{array}{l}\text { Pressure loss between core top and } \\
\text { cone }\end{array}$ & Core flange to riser cone \\
\hline DP-103 & Pressure loss in the riser cone & Across riser cone \\
\hline DP-104 & Pressure loss in the chimney & Top of riser cone to upper chimney \\
\hline DP-105 & Pressure loss across SG & Below PZR heaters to below SG coils \\
\hline DP-106 & Pressure loss in the annulus below SG & Below SG coils to LP \\
\hline LDP-106 & PRV coolant level & Below PZR heaters to bottom of PRV \\
\hline
\end{tabular}




\subsubsection{Data Acquisition and Control Hardware Description}

The hardware of the CS completes two tasks. It processes the input signals from the system components and it generates the control signals determined by the system logic.

The processed signals consist of:

- Thermal couple inputs

(mV input)

- Pressure \& Flow meter inputs

(4-20 mA input)

- Valves \& Relays position

(discrete input)

The generated control signals consist of:

- Valves \& Relay Control signal

(discrete output)

- Heater \& Pump Control signal

(4-20 mA output)

A general schematic of the system is given in Figure 8-8.

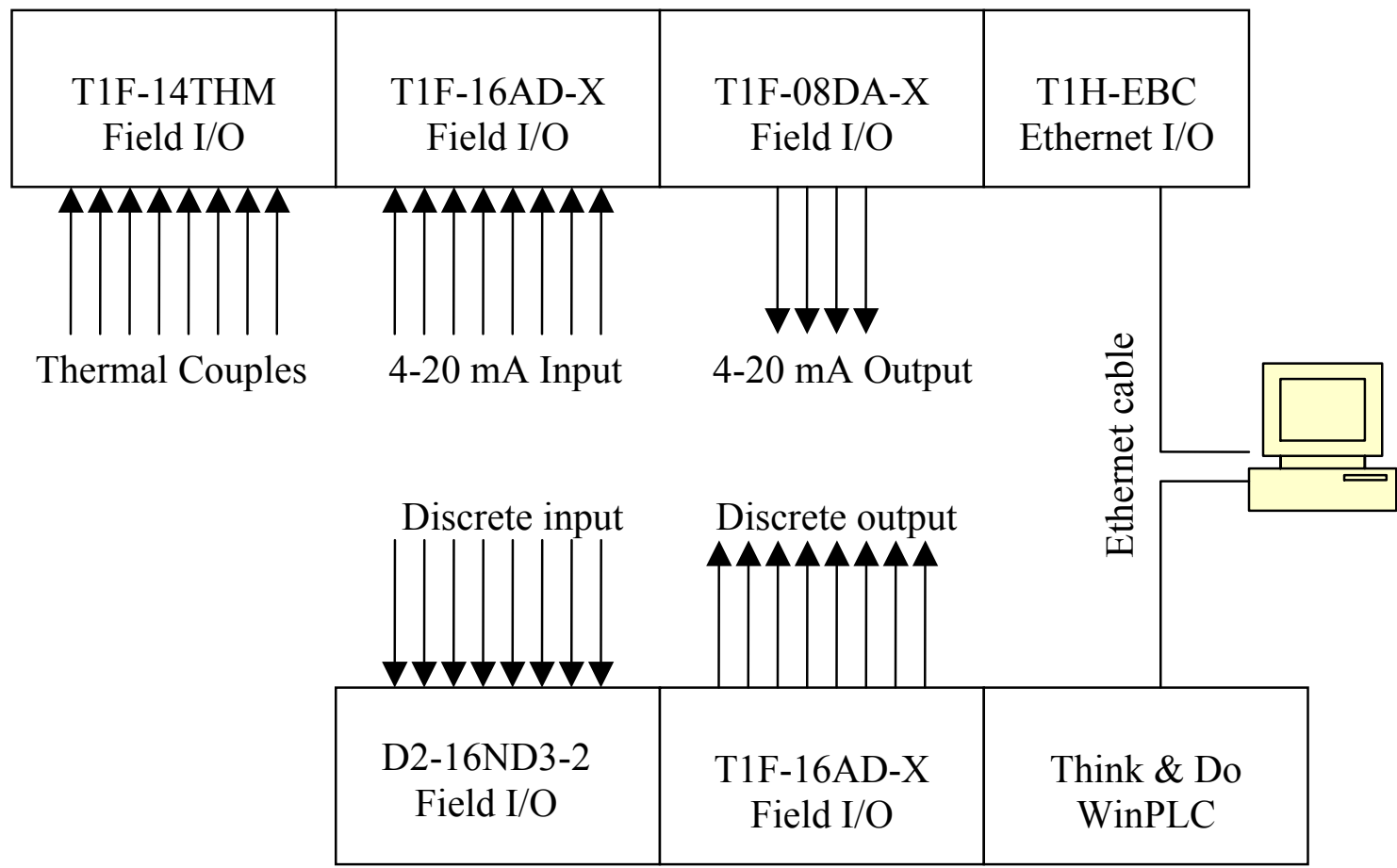

Figure 8-8 Control System Schematic

Since the system can generate either discrete or continuous data, different types of field I/O modules handle the different signals. The $\mathrm{I} / \mathrm{O}$ modules convert the analog input into digital signals so as to allow interfacing with the control computer. These digital signals are then transferred to the control computer via an Ethernet cable. In addition to the control that the CS computer provides, the discrete signal I/O system contains a (WinPLC) computer chip in module that can perform some minimal operations. These operations are limited to placing the system components into their determined "safe" positions (Rx power relays opened, Safety vent lines opened, etc.). 
The CS computer utilizes these parameters to determine the appropriate actions based on the safety logic of the system, or the operator can request an action from the CS computer. Any requested actions are implemented by the $\mathrm{I} / \mathrm{O}$ module upon receipt of the control signal from the CS computer.

\subsubsection{Control System Software Description}

The control system software was developed using Think \& Do Studio 6.51. This software program uses user defined flow charts to process system I/O. The logic for the MASLWR facility is described using 29 flow charts that are processed in order, once every scan cycle $(50 \mathrm{~ms})$. A description of each of the flow charts is given in Table 8-7. 
Table 8-7 Logic Chart Descriptions

\begin{tabular}{|l|l|}
\hline CHART NAME & CHART DESCRIPTION \\
\hline Calculate AllInput_1 & Convert 4-20 mA analog signal into engineering unit \\
\hline Calculate AllInput_2 & Convert thermal couple signal into engineering unit \\
\hline Calculate AllInput_3 & Convert thermal couple signal into engineering unit \\
\hline Calculate AllInput_4 & Convert thermal couple signal into engineering unit \\
\hline CalculateDerivedValue & Calculates required values not measured in system \\
\hline GetDateAndTime & Get current date and time \\
\hline Logging_Start & Prepare to start data logging \\
\hline Event_Display & Display the events strings in event screen \\
\hline Add_User_Event & Handle events inputted by user \\
\hline Test_OpenSubmergADS & $\begin{array}{l}\text { test logic for Inadvertent Opening of Submerged ADS Valve } \\
\text { Test }\end{array}$ \\
\hline StrageTankLeveControl & Monitor Storage tank level \\
\hline CoreHeaterPID & Control core heaters \\
\hline PressurizerPID & Control pressurizer heater \\
\hline PressurizerLevelControl & Automatic pressurizer level control \\
\hline Verifypassword & Password verification \\
\hline SG_PID & Feed water control \\
\hline SafetyCheck_All & Check safety limits \\
\hline Safety_Check_Shutdown & shutdown heater if necessary \\
\hline ContrainmentHeaterControl & Automatic containment heater algorithm \\
\hline RX\&PRZ Heater Action & Output real heater control signal \\
\hline Main Feed Pump Control & MFP safety check and ramping speed \\
\hline Enforce All Trips & Keep safety trip as it was if the alarm not cleared \\
\hline Valve \& Relay FinalAction & Output real valves and relays operation \\
\hline Event_Valve1 & Log the valves operation \\
\hline Event_Valve2 & Log the valves operation \\
\hline Event_Valve3 & Log the valves operation \\
\hline Event_Relay & Log the relays operation \\
\hline Event_Operation & Log other operation action \\
\hline ResetLogFile & Restart log if necessary \\
\hline
\end{tabular}

The CS software is interfaced by the user through the Graphical User Interface (GUI) also developed in Think \& Do Studio 6.51. The operator can monitor all the parameters and alarms in this GUI on the main control screen, see Figure 8-9. All the automatic valves, relays and pumps are controlled in by the software. 


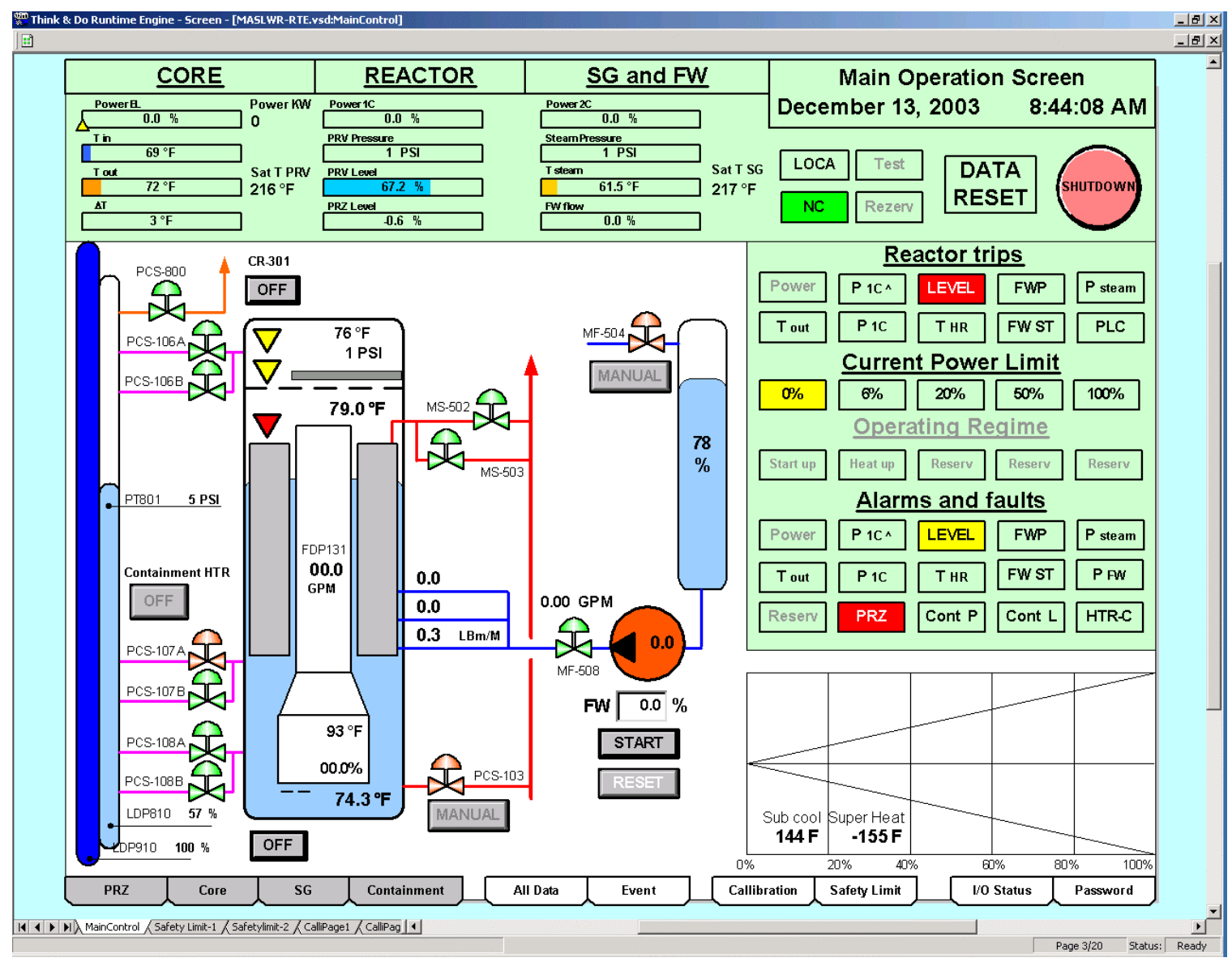

Figure 8-9 Computer Screen Image of Control System Software GUI

Data logging is performed automatically every time the CS software is started. The sample rate of the data logging is once a second for each data channel. The data, along with any input/output signals (analog or discrete), are logged into the text file "data.txt". In addition to the data channels, any alarms or operator actions are logged in a separate file titled "event.log".

\subsubsection{Individual System Component Operation Algorithms}

The Pressurizer heater can work in manual or automatic mode.

Manual mode: $\quad$ Operator specifies the heater controller electrical output. Auto mode: $\quad$ Operator sets the pressure set point, and the computer adjusts the heater controller to match the pressure using a Proportional Integral Differential (PID) method.

The Core heater can be operated in manual mode, automatic constant power, or automatic decay power modes.

Manual mode: Constant Power:
Operator specifies the heater controller electrical output. Operator specifies a constant core power, and the CS computer adjusts the heater controller to match the pressure using a Proportional method. 
Decay power:

The core power follows a decay power curve defined by the operator. The CS computer adjusts the heater controller to match the pressure using a Proportional Integral Differential (PID) method.

$$
P(t)=\frac{P_{0}}{\left(1+A\left(t-t_{0}\right)\right)^{B}} \quad \text { for } \mathrm{t}>\mathrm{t}_{0}
$$

A hard limit on the core power increase rate of change of $20 \%$ of full power per minute is enforced to help prevent heater element damage. The power decrease speed has no limit on the rate of change.

Containment heaters are used to keep an adiabatic boundary condition on all but the prescribed condensation wall of the containment. This insures that heat transfer only takes place between the containment pool and the containment vessel (required for scaling considerations). Four separate groups of strip heaters are attached to the outside of the containment vessel wall above the containment water level. Each group is controlled separately to maintain a constant wall temperature by measuring the containment wall temperature and the heater temperature, and adjusting the electric power cycle time. A flow chart description of the containment heater control algorithm is given by Figure 8-10.

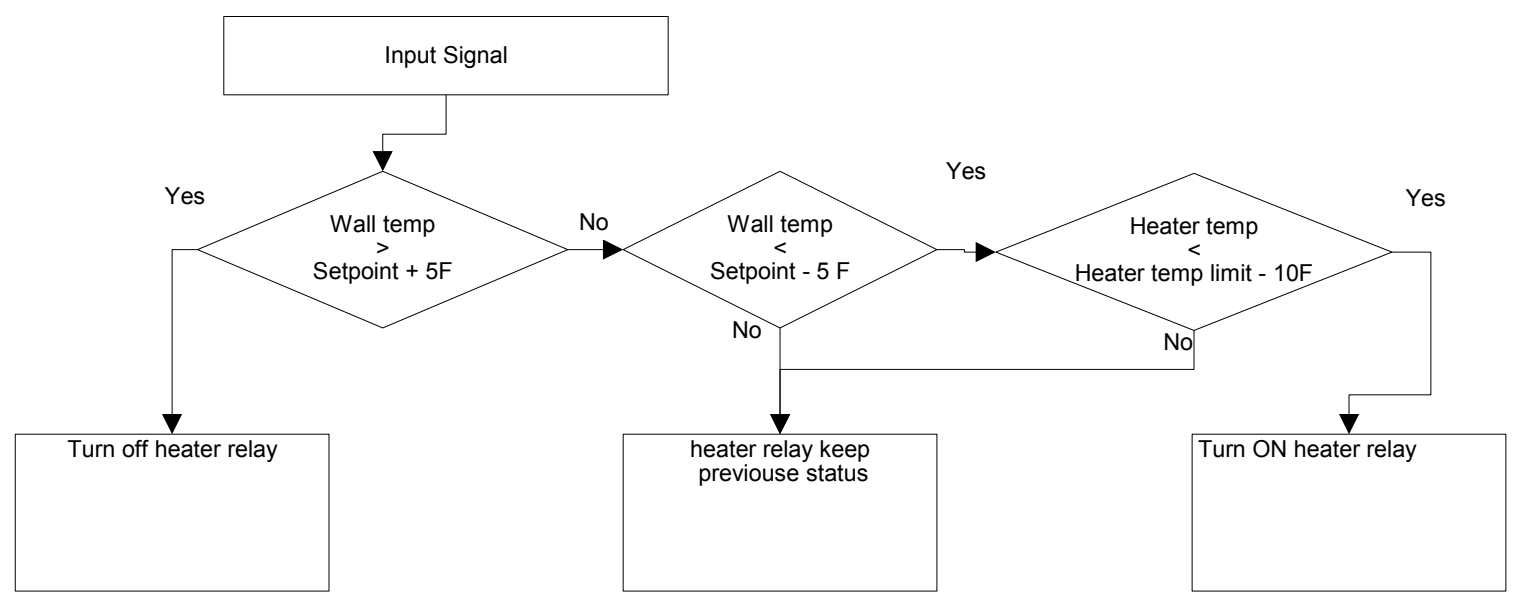

Figure 8-10 Containment Heater Control Algorithm Flow Chart

The Feed Water Storage Tank level is controlled by measuring the tank level, and cycling a solenoid valve to maintain the level within a band.

The Pressurizer water level is maintained in a similar manner. However, the facility is not capable of addition of coolant when the facility is at operational pressure. Since the system coolant only increases its volume during the heat up process, only a draining mechanism is required for PZR level management.

The MFP relay is programmed to not turn ON unless MF-508 (feed water supply line to the pump) is open. Additionally, only MS-503 (main steam line valve) or MS-502 (main steam drain valve) can be closed at a time. These two controls provide that at least one supply and exhaust path is provided to the pump in order for the pump to operate. 
The WinPLC I/O cabinet controls the heater relays. In the event of a loss of connection to the control computer, it will shutdown all heater relays to prevent overheating.

Any of the parameter measurements from the system can be used by the CS computer to determine appropriate actions. A main feature of the CS software is the application of the safety logic, either to protect system components or personal. The safety logic for the MALWR facility consists mainly of over-pressure and over-temperature protection. In order to prevent overpressure, the CS monitors fluid flow paths and RPV pressure to ensure that the positive displacement pumps are not dead headed, or that the RPV is at an excessively high pressure. The prevention of over-temperature in the system is related solely to sufficient heat removal from the core heaters. This is ensured by maintaining sufficient level to allow natural circulation, and sufficient FW to provide the heat sink necessary for natural circulation. All of the overpressure/over-temperature safety set-points and related actions are described in Table 8-8. 
Table 8-8 Listing of the System Safety Limits

\begin{tabular}{|c|c|c|c|c|c|}
\hline Signal & Limit type & Values & & ips & Other actions \\
\hline Electric power & $\mathrm{N} / \mathrm{A}$ & $\mathrm{N} / \mathrm{A}$ & & & (reserved expansion slot) \\
\hline \multirow[t]{7}{*}{ PRZ pressure } & HHHH & 113.76 bar (1650 PSIG) & & & $\begin{array}{l}\text { Relieve valve (PSC-109)open, } \\
\text { Alarm logged }\end{array}$ \\
\hline & $\mathrm{HHH}$ & 91.01 bar (1320 PSIG) & $\begin{array}{l}\text { Core } \\
\text { Trip }\end{array}$ & & PCS-106A \& PCS-800 open \\
\hline & $\mathrm{HH}$ & Setpoint $* 1.2$ & $\begin{array}{l}\text { PRZ } \\
\text { Trip }\end{array}$ & & Alarm logged \\
\hline & $\mathrm{H}$ & Setpoint $* 1.1$ & & & Alarm logged \\
\hline & Setpoint & 75.98 bar (1102 PSI) & & & None \\
\hline & $\mathrm{L}$ & Setpoint $* 0.9$ & & & Alarm logged \\
\hline & LL & Setpoint $* 0.8$ & & & Alarm logged \\
\hline \multirow[t]{2}{*}{$\begin{array}{l}\text { Core heater } \\
\text { temperature }\end{array}$} & $\mathrm{HH}$ & $727.59 \mathrm{~K}(850 \mathrm{~F})$ & $\begin{array}{l}\text { Core } \\
\text { Trip }\end{array}$ & & Alarm logged \\
\hline & $\mathrm{H}$ & $713.71 \mathrm{~K}(825 \mathrm{~F})$ & & & Alarm logged \\
\hline \multirow[t]{2}{*}{$\begin{array}{l}\text { Core outlet } \\
\text { temperature }\end{array}$} & $\mathrm{HH}$ & $553.87 \mathrm{~K}(537.3 \mathrm{~F})$ & $\begin{array}{l}\text { Core } \\
\text { Trip }\end{array}$ & & Alarm logged \\
\hline & $\mathrm{H}$ & $556.65 \mathrm{~K}(542.30 \mathrm{~F})$ & & & Alarm logged \\
\hline \multirow[t]{2}{*}{ PRV level } & $\mathrm{L}$ & $3.302 \mathrm{~m}$ (130 inch) & & & Alarm logged \\
\hline & LL & $3.175 \mathrm{~m}(125 \mathrm{inch})$ & $\begin{array}{l}\text { Core } \\
\text { Trip }\end{array}$ & & Alarm logged \\
\hline \multirow{3}{*}{$\begin{array}{l}\text { FW storage } \\
\text { tank level }\end{array}$} & $\mathrm{H}$ & $5.969 \mathrm{~m}(235 \mathrm{inch})$ & & & Alarm logged \\
\hline & $\mathrm{L}$ & $3.048 \mathrm{~m}$ (120 inch) & & & Alarm logged \\
\hline & LL & $2.540 \mathrm{~m}$ (100 inch) & $\begin{array}{l}\text { Core } \\
\text { Trip }\end{array}$ & $\begin{array}{l}\text { MFP } \\
\text { Trip }\end{array}$ & Alarm Logged \\
\hline \multirow[t]{3}{*}{$\begin{array}{l}\text { Max FW } \\
\text { pressure }\end{array}$} & $\mathrm{HHH}$ & 48.26 bar (700 PSIG) & & & $\begin{array}{l}\text { relieve valve (MF-506) open, } \\
\text { Alarm logged }\end{array}$ \\
\hline & $\mathrm{HH}$ & 20.68 bar (300 PSIG) & $\begin{array}{l}\text { Core } \\
\text { Trip }\end{array}$ & $\begin{array}{l}\text { MFP } \\
\text { Trip }\end{array}$ & Alarm logged \\
\hline & $\mathrm{H}$ & (280 PSIG) & & & Alarm logged \\
\hline \multirow[t]{3}{*}{ Steam pressure } & $\mathrm{HH}$ & 20.68 bar (300 PSIG) & $\begin{array}{l}\text { Core } \\
\text { Trip }\end{array}$ & $\begin{array}{l}\text { MFP } \\
\text { Trip }\end{array}$ & $\begin{array}{l}\text { MS-502 \& MS503 open, Alarm } \\
\text { logged }\end{array}$ \\
\hline & $\mathrm{H}$ & 19.99 bar (290 PSIG) & & & Alarm logged \\
\hline & Setpoint & 14.13 bar (205 PSIG) & & & Alarm logged \\
\hline \multirow{2}{*}{$\begin{array}{l}\text { Containment } \\
\text { pressure }\end{array}$} & $\mathrm{HH}$ & 20.68 bar (300 PSIG) & & & PCS-800 open, Alarm logged \\
\hline & $\mathrm{H}$ & 19.31 bar (280 PSIG) & & & Alarm logged \\
\hline \multirow{2}{*}{$\begin{array}{l}\text { Containment } \\
\text { level }\end{array}$} & $\mathrm{HH}$ & $5.08 \mathrm{~m}$ (200 inch) & & & Alarm logged \\
\hline & $\mathrm{H}$ & $1.270 \mathrm{~m}(50 \mathrm{inch})$ & & & Alarm logged \\
\hline $\begin{array}{l}\text { Containment } \\
\text { heater temp }\end{array}$ & $\mathrm{H}$ & $644.26 \mathrm{~K}(700 \mathrm{~F})$ & $\begin{array}{l}\text { Cont. } \\
\text { Trip }\end{array}$ & & Alarm logged \\
\hline \multirow[t]{2}{*}{ PZR Level } & $\bar{L}$ & $0.203 \mathrm{~m}(8 \mathrm{inch})$ & & & Alarm logged \\
\hline & LL & $0.140 \mathrm{~m}(5.5 \mathrm{inch})$ & $\begin{array}{l}\text { PZR } \\
\text { Trip }\end{array}$ & & Alarm logged \\
\hline
\end{tabular}

Note: Any Trip means the heater relays for on the respective component is OFF. Limit types H, HH, HHH means an alarm or action will be taken if signal value is higher than the limit value. Limit type L, LL means alarm or action will be taken if signal value is lower than the limit value. 


\subsubsection{Containment and Exterior Cooling Pool Models}

Assessing the operation of the MASLWR containment heat removal system behavior is one of the primary motivations for experimental testing of the MASLWR design. Therefore, the containment vessel and surrounding containment pool are modeled in the OSU MASLWR test facility with two separate vessels:

- One vessel to model the suppression pool volume, vapor bubble volume, and condensation surface inside the containment vessel

- One vessel to model the heat capacity of the water pool in which the containment vessel is held.

Separating these tanks is a plate of SS (thickness $0.04 \mathrm{~m}\left(1.5^{\prime \prime))}\right.$ ). This plate models the abovementioned heat transfer vessel wall between the containment vessel and the containment pool. A view of the containment vessel and containment pool tank, is shown in Figure 8-11. Both vessels are fabricated from SS 304. The containment and exterior cooling pool dimensions are presented in Table 8-9.

The containment vessel is connected to the RPV through 6 independent lines. Each line has an independent MOV for modeling the logic of a LOCA. The components of the test facility Containment vessels were fabricated from SS 304. The containment vessel is capable of prolonged operation at operating conditions [2.068 MPa (300 psia) and 477.59 K (400 F)]

Table 8-9 Containment Geometrical Data

\begin{tabular}{|c|l|c|c|c|c|l|}
\hline & \multicolumn{1}{|c|}{ Component } & $\begin{array}{c}\text { Length } \\
(\mathbf{m})\end{array}$ & $\begin{array}{c}\text { Diameter } \\
(\mathbf{m})\end{array}$ & Length (in) & $\begin{array}{c}\text { Diameter } \\
\text { (in) }\end{array}$ & \multicolumn{1}{|c|}{ Notes } \\
\hline 1 & Vessel & 5.75 & - & 226.50 & - & None \\
\hline 2 & Vessel (bottom part) & 3.87 & 0.27 & 152.5 & 10.63 & None \\
\hline 3 & Vessel (cone) & 0.51 & $0.27 / 0.51$ & 20.00 & $10.63 / 20.00$ & Eccentric cone \\
\hline 4 & Vessel 1 (top) & 1.21 & 0.51 & 47.75 & 20.00 & None \\
\hline 5 & Vessel 1 (cup) & 0.16 & 0.51 & 6.25 & 20.00 & None \\
\hline 6 & Vessel 2 & 7.37 & 0.76 & 290 & 30.00 & $\begin{array}{l}\text { Water level } ~ \\
2,23 \mathrm{~m} \\
(87,75 ")\end{array}$ \\
\hline 7 & & & & & & $\begin{array}{l}38.1 \mathrm{~mm}\left(1.5{ }^{\prime \prime}\right) \\
\text { thick x 171.7 } \\
\text { mm (6.76”) } \\
\text { wide }\end{array}$ \\
\hline
\end{tabular}




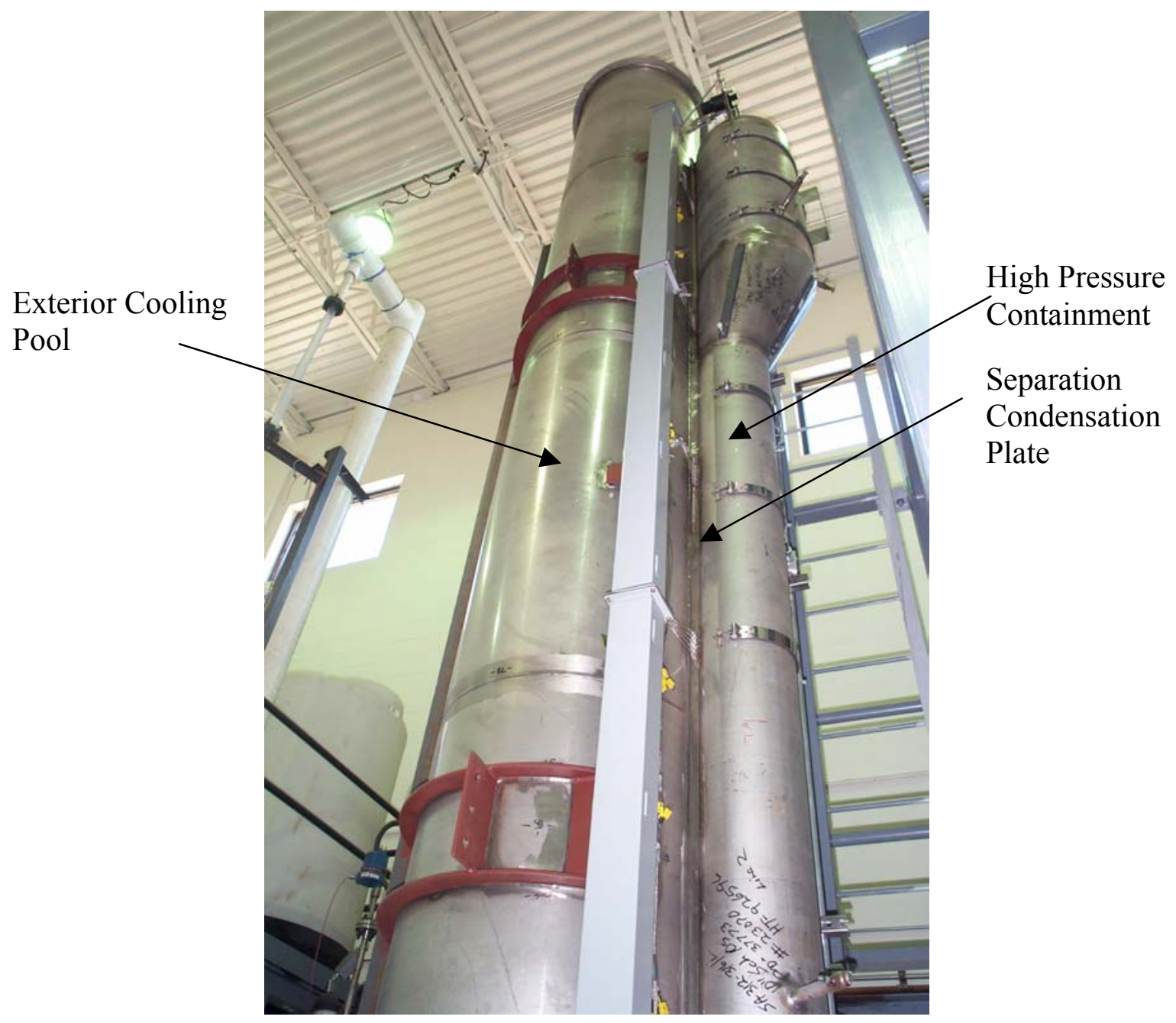

Figure 8-11 Containment and Exterior Pool Vessels of the MASLWR Test Facility

\subsection{Test Matrix}

The OSU test program is developed to attain data to assess the passive safety systems of the MASLWR facility. The testing program completed thus far includes 3 Design Basis Accidents and 1 Beyond Design Basis Accident tests. The data generated by the testing program is to be used to assess computer code calculations, and provide a better understanding of the thermal-hydraulic phenomena in this design of NSSS. Table 8-10 provides a summary of the four tests conducted at the OSU test facility. Table 8-10 includes the test number, a brief description of the test simulation, and the ADS/Sump re-circulation line configuration. 
Table 8-10 Summary of the OSU MASLWR Testing Program to Date

\begin{tabular}{|c|c|c|c|c|c|c|c|}
\hline Test \# & Simulation & $\begin{array}{c}\text { Low } \\
\text { ADS } 1 \\
(\%)\end{array}$ & $\begin{array}{c}\text { Low } \\
\text { ADS } 2 \\
(\%)\end{array}$ & $\begin{array}{l}\text { High } \\
\text { ADS } 1 \\
(\%)\end{array}$ & $\begin{array}{l}\text { High } \\
\text { ADS } 2 \\
(\%)\end{array}$ & $\begin{array}{c}\text { Sump } \\
\text { Recirc. } \\
1 \\
(\%) \\
\end{array}$ & $\begin{array}{c}\text { Sump } \\
\text { Recirc. } \\
2 \\
(\%) \\
\end{array}$ \\
\hline OSU-MASLWR-001 & $\begin{array}{l}\text { Inadvertent Actuation of } 1 \\
\text { Submerged ADS Valve }\end{array}$ & $\begin{array}{l}\text { Failed } \\
\text { Shut }\end{array}$ & 100 & 100 & 100 & 100 & 100 \\
\hline OSU-MASLWR-002 & $\begin{array}{l}\text { Natural Circulation at Core } \\
\text { Power up to } 210 \mathrm{~kW}\end{array}$ & $\mathrm{~N} / \mathrm{A}$ & $\mathrm{N} / \mathrm{A}$ & $\mathrm{N} / \mathrm{A}$ & $\mathrm{N} / \mathrm{A}$ & $\mathrm{N} / \mathrm{A}$ & $\mathrm{N} / \mathrm{A}$ \\
\hline OSU-MASLWR-003A & $\begin{array}{l}\text { Natural Circulation at Core } \\
\text { Power of } 210 \mathrm{~kW} \\
\text { (Continuation of test } 002 \text { ) }\end{array}$ & $\begin{array}{l}\text { Failed } \\
\text { Shut }\end{array}$ & $\mathrm{N} / \mathrm{A}$ & $\mathrm{N} / \mathrm{A}$ & $\mathrm{N} / \mathrm{A}$ & $\mathrm{N} / \mathrm{A}$ & $\mathrm{N} / \mathrm{A}$ \\
\hline OSU-MASLWR-003B & $\begin{array}{l}\text { Inadvertent Actuation of } 1 \\
\text { High Containment ADS } \\
\text { Valve }\end{array}$ & $\begin{array}{l}\text { Failed } \\
\text { Shut }\end{array}$ & 100 & $\begin{array}{l}\text { Failed } \\
\text { Shut }\end{array}$ & 100 & 100 & 100 \\
\hline
\end{tabular}

Note: The $210 \mathrm{~kW}$ data in OSU-MASLWR-002 was not used because of liquid carry over in the steam generator. Test OSU-MASLWR-003A determines this data point by using a reduced FW flow rate, while preceding OSUMASLWR-003B by achieving steady state operational conditions for the blowdown.

\subsubsection{OSU-MASLWR-001, Inadvertent Actuation of 1 Submerged ADS Valve}

The objective of this test is to acquire data on the pressure transients in the reactor vessel and containment vessel for an inadvertent ADS actuation.

Following the actuation of one of the submerged ADS line, the primary system enters into a blowdown period. The submerged ADS line is located below the water level in the containment vessel and the coolant level in the reactor vessel. The location of the submerged ADS line combined with the high system pressure leads to a period of sub-cooled blowdown. This period ends when the system pressure has decreased to a point where the Differential Pressure at the break location results in a flashing of the coolant, and a choked two-phase flow condition prevails. The marked decrease in the depressurization rate in combination with the paralleling of the primary system pressure and saturation pressure curves, define the two-phase blowdown period that exists between the points labeled "Sub-Cooled Blowdown Terminated" and "PZR Equals Saturation Pressure" (shown in Figure 8-12). Once the pressure in the reactor vessel equals the saturation pressure, a single phased blowdown begins and the depressurization rate increases. 10 seconds after the pressures equalize, the coolant level in the reactor vessel decreased below the open ADS line. This just continues the single-phase blowdown period.

Note: The pressures are considered equalized when the DP $<0.16 \mathrm{MPa}$. This value corresponds to the measured pressure difference during times $t>600$ seconds when the pressure is known to match; thus the measured difference is a constant offset. 


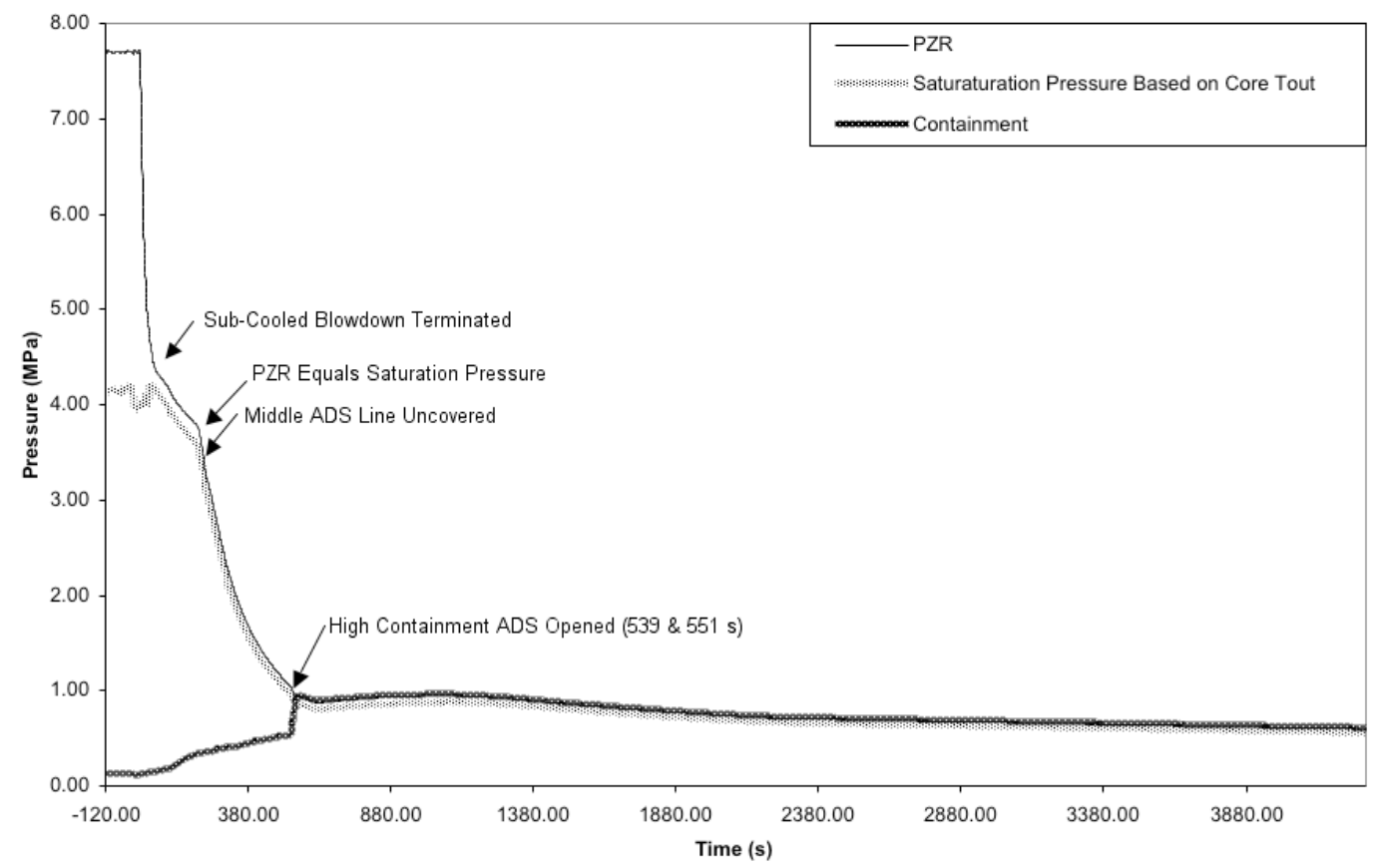

Figure 8-12 Primary and Containment Pressure for MASLWR-OSU-001

When the pressure difference between the reactor vessel and the containment reaches a value less than $0.517 \mathrm{MPa}$ (75 psig), one of the high containment valves is opened (at 539 seconds). Approximately 10 seconds later the second high containment valve is opened (at 551 seconds). The opening of these valves equalizes the pressure between the containment and the reactor vessel, shown in Figure 8-12 as the converged lines.

10 seconds after the second high containment valve is opened, the pressure difference between the reactor vessel and the containment reaches a value less than $0.034 \mathrm{MPa}(5 \mathrm{psig})$, and the first sump recirculation valve is opened (at 561 seconds). 10 seconds later the second sump recirculation valve is opened (571 seconds). The opening of these valves terminates the blowdown period and allows the reactor vessel to refill due to the higher relative coolant height in the containment compared to the reactor vessel, shown as the inflection point and consequent increasing level after 539 seconds in Figure 8-13. Note that the reactor coolant height never falls below the height of the top of the core, see Figure 8-13. 


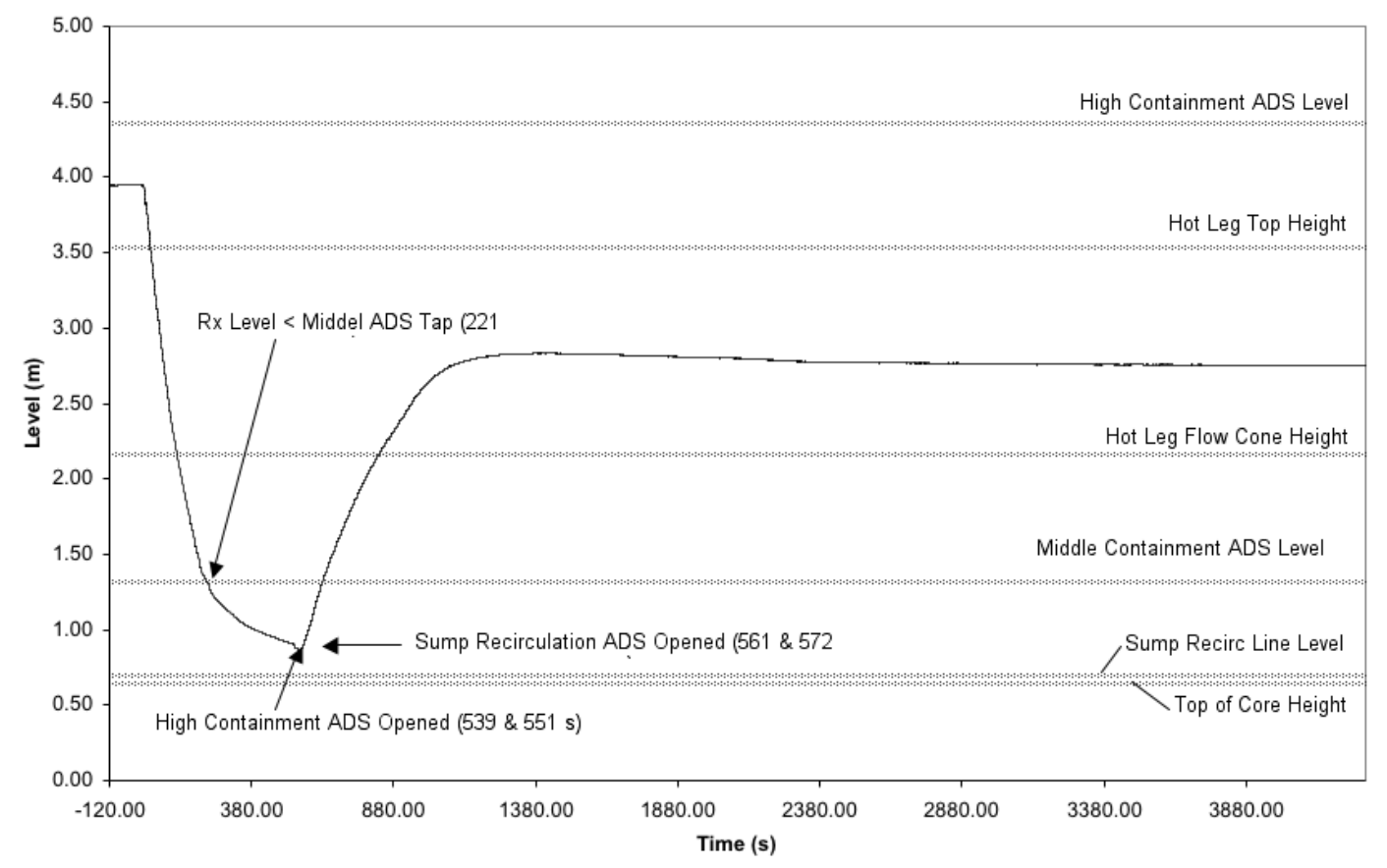

Figure 8-13 Relative values of the Location of the Reactor Vessel Penetrations, and the coolant level in MASLWR-OSU-001

As the reactor vessel refills, the coolant level reaches the location of the hot leg flow measurement devise (at 826 seconds). Approximately at this time, a large increase in the hot leg flow rate is seen. This large flow rate is solely due to the action of the refilling of the reactor vessel, see Figure 8-14.

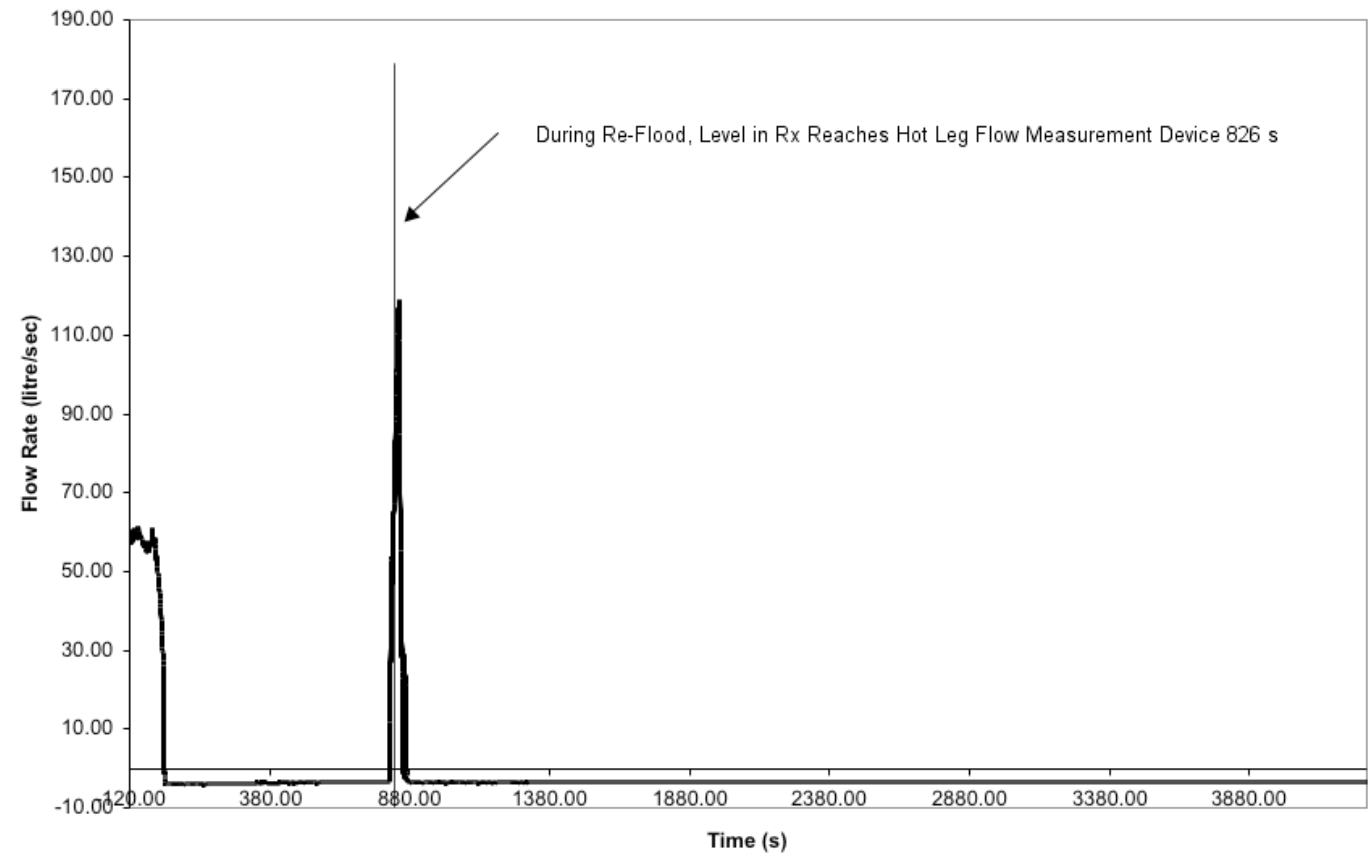

Figure 8-14 Hot Leg Flow Rate in MASLWR-OSU-001 
In the same manner as the pressures, the temperature of the inlet and outlet to the core follow the blowdown. Analyzing Figure 8-15, it is found that the saturation temperature based on the vessel pressure is the upper limit during the entire transient. During the times when the curve labeled "Top of Hot Leg" shows temperatures greater than the saturation temperature, the thermocouple whose data is used for this curve was not measuring a coolant temperature. It was uncovered during the beginning of the transient and the coolant level never regained the required height to submerge it, see Figure 8-13. The temperature at the top of the hot leg is equal to the saturation temperature between the times of 41 and 209 seconds. These times correspond to the end of the sub-cooled blowdown period and the time when the saturation pressure of the system reached that of the outlet of the core. After time $\sim 209$ seconds, the thermocouple sat in a steam bubble that was being heated by the stored energy in the metal mass of the system, hence its measurement of a greater than saturation temperature for the rest of the transient.

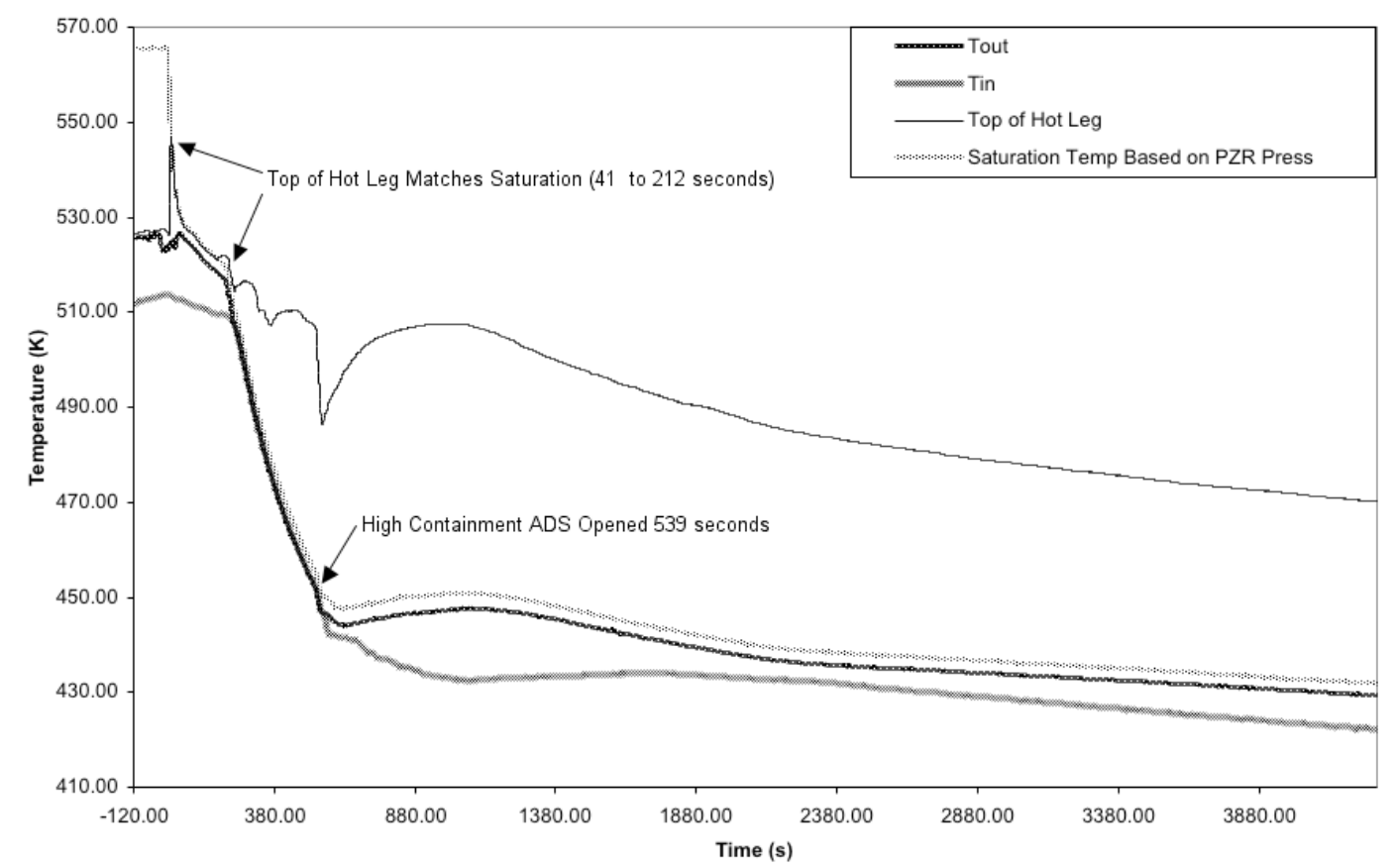

Figure 8-15 Reactor Vessel Temperatures in MASLWR-OSU-001

During the saturated blowdown period, the inlet and outlet of the core experience temperatures equal to each other and the saturation temperature. This is due to the vessel still draining during this period (reverse core flow), and the boiling off of the coolant in the core region at saturation. In other words, the maximum fluid temperature is limited by the pressure, and the reverse flow supplies the maximum temperature fluid to the outlet and inlet to the core. Once the containment and reactor vessel pressures are equalized, the draining of the primary terminates, and normal direction flow resumes during refilling. This results in a differential temperature across the core similar to that experienced during normal operation $\left(\mathrm{T}_{\text {out }}>\mathrm{T}_{\text {in }}\right)$, see Figure 8-15. The total Core $\mathrm{DT}_{\mathrm{DT}}$ is dependant on the core power at the time and the refill rate. 


\subsubsection{OSU-MASLWR-002 \& OSU-MASLWR-003A, Natural Circulation with Core Power up to $210 \mathrm{~kW}$}

The objective of these tests is to acquire primary system flow rates and secondary side steam superheat for different core power and feed water flow rates.

An exact method for determining the feed water flow rate based on measured system parameters is not available; due to the unknowns of flow regime development in the helical steam generator, which influences the amount of superheat achievable. This was addressed by developing a method to estimated feed water flow rates based on core electric power. The feed water flow rate was determined as the amount of mass flow required to remove the core energy, assuming a superheat of the steam of approximately $3 \mathrm{~K}\left(5^{\circ} \mathrm{F}\right)$ at approximately $13.79 \mathrm{bar}(200 \mathrm{psig})$ (see equation below).

$\dot{q}_{\text {core }}=\dot{m}_{\mathrm{FW}}\left(\left(h_{\text {feed,water }}-h_{\text {liquid,sat }}\right)+\left(h_{\text {steam,sat }}-h_{\text {liquid,sat }}\right)+\left(h_{\text {super }}-h_{\text {steam,sat }}\right)\right)$

The manner of control for the MASLWR facility is to vary the degree of superheat. This can be achieved by adjusting the power to be slightly greater than the amount needed to just boil all of the FW flow, or the amount of feed water can be reduced. Both methods produce the same result, an increase in superheat. Both are addressed in the tests, with 7 power levels and $10 \mathrm{FW}$ mass flow rates. Table 8-11 presents each of the steady state periods representing the combinations of power levels and FW flow rates. Table 8-12 presents average parameter values during each of the 10 periods: core inlet and outlet temperature, through core volumetric flow rate and velocity; SG inlet and outlet temperatures, SG pressure, SG FW volumetric flow rate (water at $\sim 291 \mathrm{~K}$ ). The data plots of the parameters of interest for the steady state periods, are presented in Figure 8-16 to Figure 8-23.

Table 8-11 Core Power and FW Flow Rates for MASLWR-OSU-002, MASLWR-OSU003A

\begin{tabular}{|c|c|c|c|c|c|}
\hline Test & Period \# & $\begin{array}{c}\text { Starting time } \\
(\mathrm{s})\end{array}$ & $\begin{array}{c}\text { Ending time } \\
(\mathrm{s})\end{array}$ & $\begin{array}{c}\text { Core Power } \\
(\mathrm{kW})\end{array}$ & $\begin{array}{c}\text { Feed Water } \\
(\mathrm{kg} / \mathrm{min})\end{array}$ \\
\hline \multirow{4}{*}{$\begin{array}{c}\text { MASLWR } \\
\text { OSU-002 }\end{array}$} & 1 & 0 & 127 & 80.0 & 1.13 \\
\cline { 2 - 6 } & 2 & 250 & 550 & 100.0 & 1.81 \\
\cline { 2 - 6 } & 3 & 750 & 1200 & 100.0 & 2.14 \\
\cline { 2 - 6 } & 5 & 1380 & 1570 & 100.0 & 2.50 \\
\cline { 2 - 6 } & 6 & 1670 & 1920 & 110.0 & 2.49 \\
\cline { 2 - 6 } & 8 & 2060 & 2250 & 125.0 & 2.50 \\
\hline MASLWR & 9 & 2450 & 2600 & 160.0 & 3.85 \\
\cline { 2 - 6 } OSU-003A & 10 & 0 & 2930 & 165.0 & 3.83 \\
\hline
\end{tabular}


Table 8-12 Inlet and Outlet Temperatures in the Primary and Secondary for MASLWROSU-002, MASLWR-OSU-003A

\begin{tabular}{|c|c|c|c|c|c|c|c|c|}
\hline \multirow{2}{*}{$\begin{array}{c}\text { Period } \\
\#\end{array}$} & \multicolumn{4}{|c|}{ Primary } & \multicolumn{4}{c|}{ Secondary } \\
\cline { 2 - 9 } & $\begin{array}{c}\text { T_in } \\
(\overline{\mathrm{K}})\end{array}$ & $\begin{array}{c}\mathrm{T} \text {-out } \\
(\mathrm{K})\end{array}$ & $\begin{array}{c}\text { Flow } \\
(\mathrm{L} / \mathrm{min})\end{array}$ & $\begin{array}{c}\text { Vel } \\
(\mathrm{m} / \mathrm{s})\end{array}$ & $\begin{array}{c}\mathrm{T} \text { in } \\
(\overline{\mathrm{K}})\end{array}$ & $\begin{array}{c}\text { T_out } \\
(\mathrm{K})\end{array}$ & $\begin{array}{c}\mathrm{P} \\
(\mathrm{MPa})\end{array}$ & $\begin{array}{c}\text { Flow } \\
(\mathrm{L} / \mathrm{min})\end{array}$ \\
\hline 1 & 489 & 506 & 65.6 & 0.13 & 292 & 482 & 1.41 & 1.13 \\
\hline 2 & 491 & 509 & 77.9 & 0.16 & 292 & 488 & 1.40 & 1.81 \\
\hline 3 & 490 & 508 & 80.0 & 0.16 & 292 & 494 & 1.38 & 2.14 \\
\hline 4 & 486 & 505 & 81.9 & 0.17 & 292 & 494 & 1.37 & 2.49 \\
\hline 5 & 483 & 503 & 84.9 & 0.17 & 292 & 493 & 1.36 & 2.49 \\
\hline 6 & 482 & 503 & 88.5 & 0.18 & 292 & 493 & 1.35 & 2.50 \\
\hline 7 & 481 & 505 & 104.1 & 0.21 & 292 & 488 & 1.36 & 3.85 \\
\hline 8 & 478 & 503 & 105.0 & 0.21 & 293 & 482 & 1.35 & 3.83 \\
\hline 9 & 501 & 528 & 118 & 0.24 & 293 & 507 & 1.581 & 4.14 \\
\hline 10 & 499 & 526 & 120 & 0.24 & 293 & 509 & 1.567 & 4.57 \\
\hline
\end{tabular}

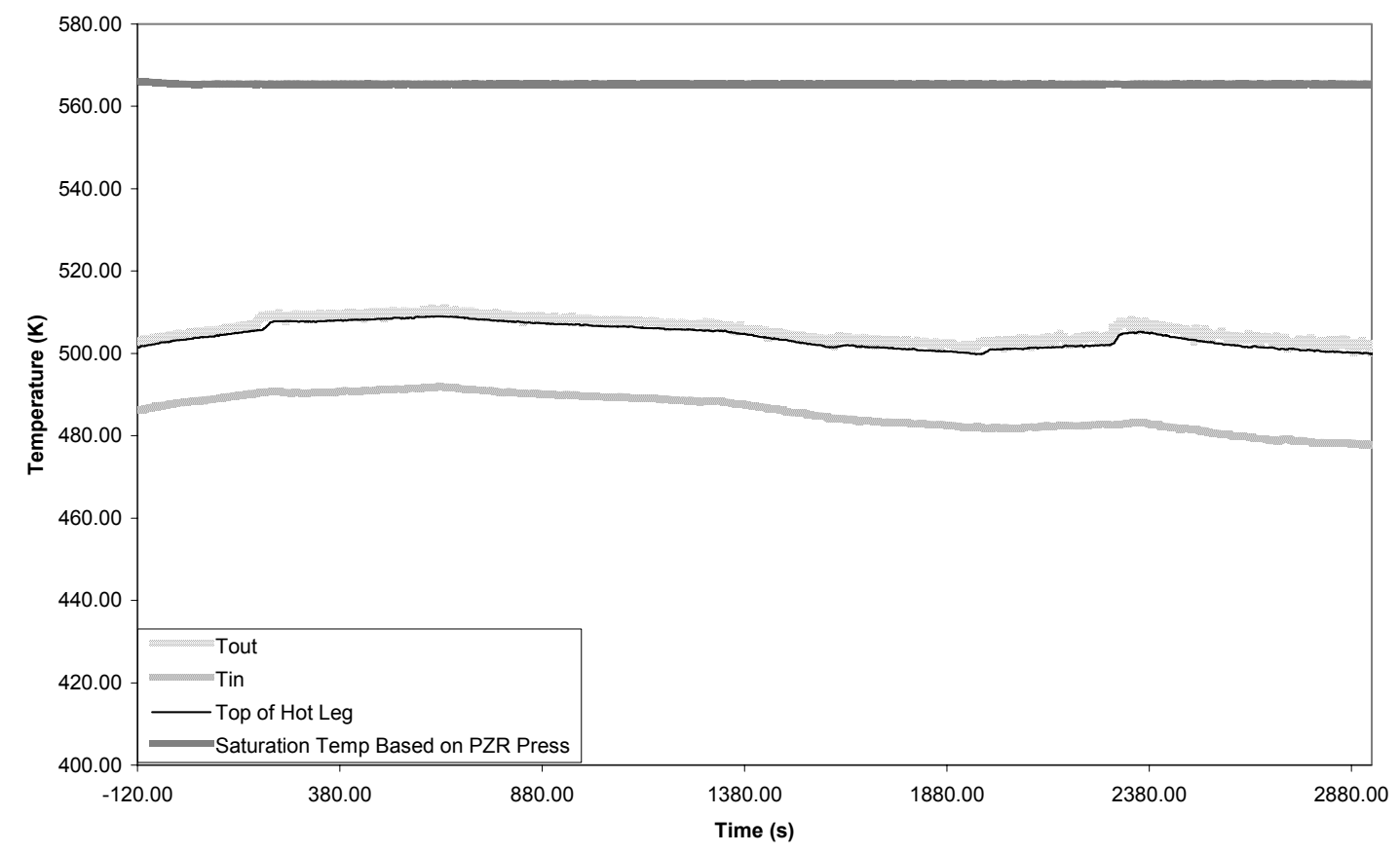

Figure 8-16 Core Temperatures for MASLWR-OSU-002 


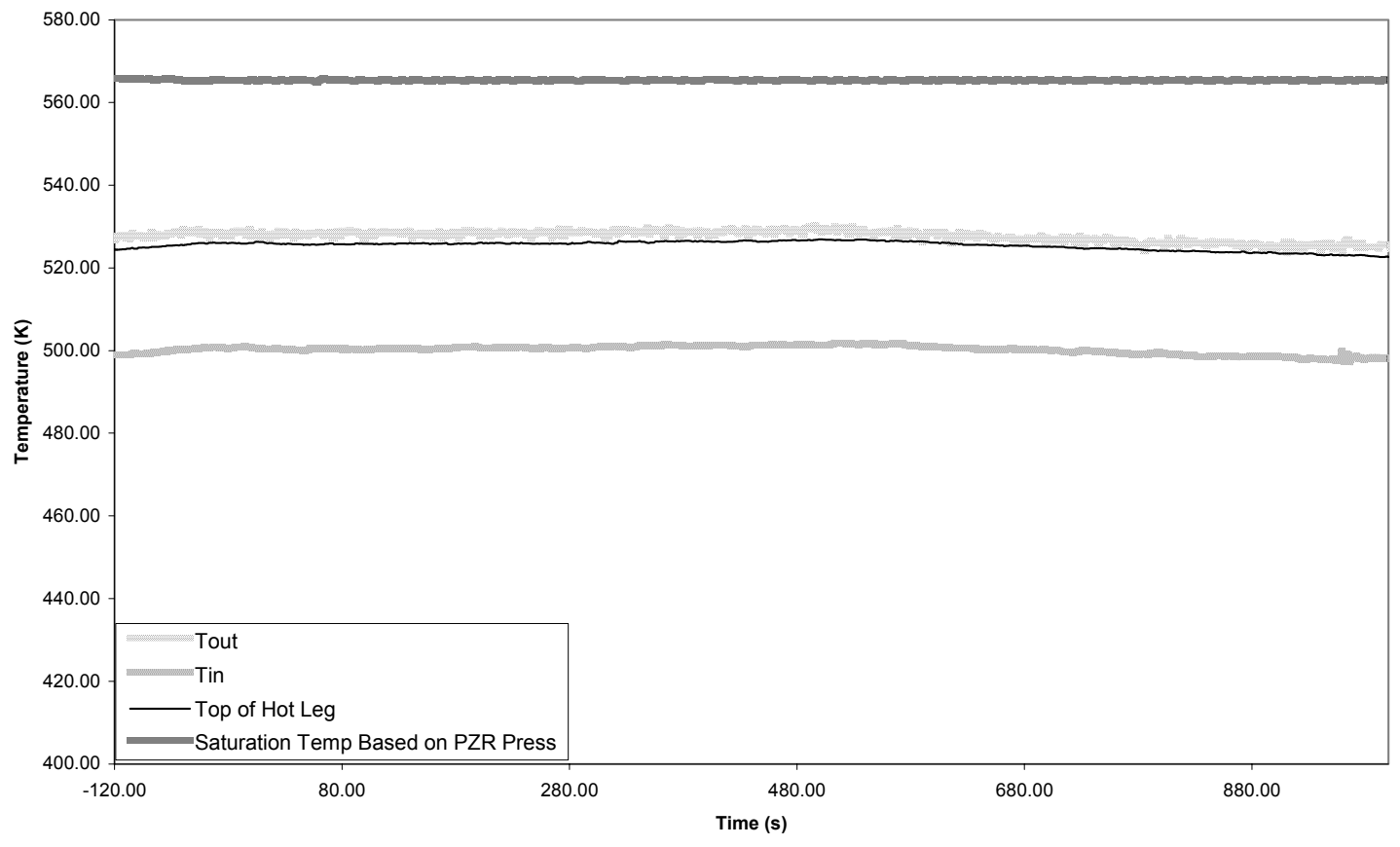

Figure 8-17 Core Temperatures for MASLWR-OSU-003A

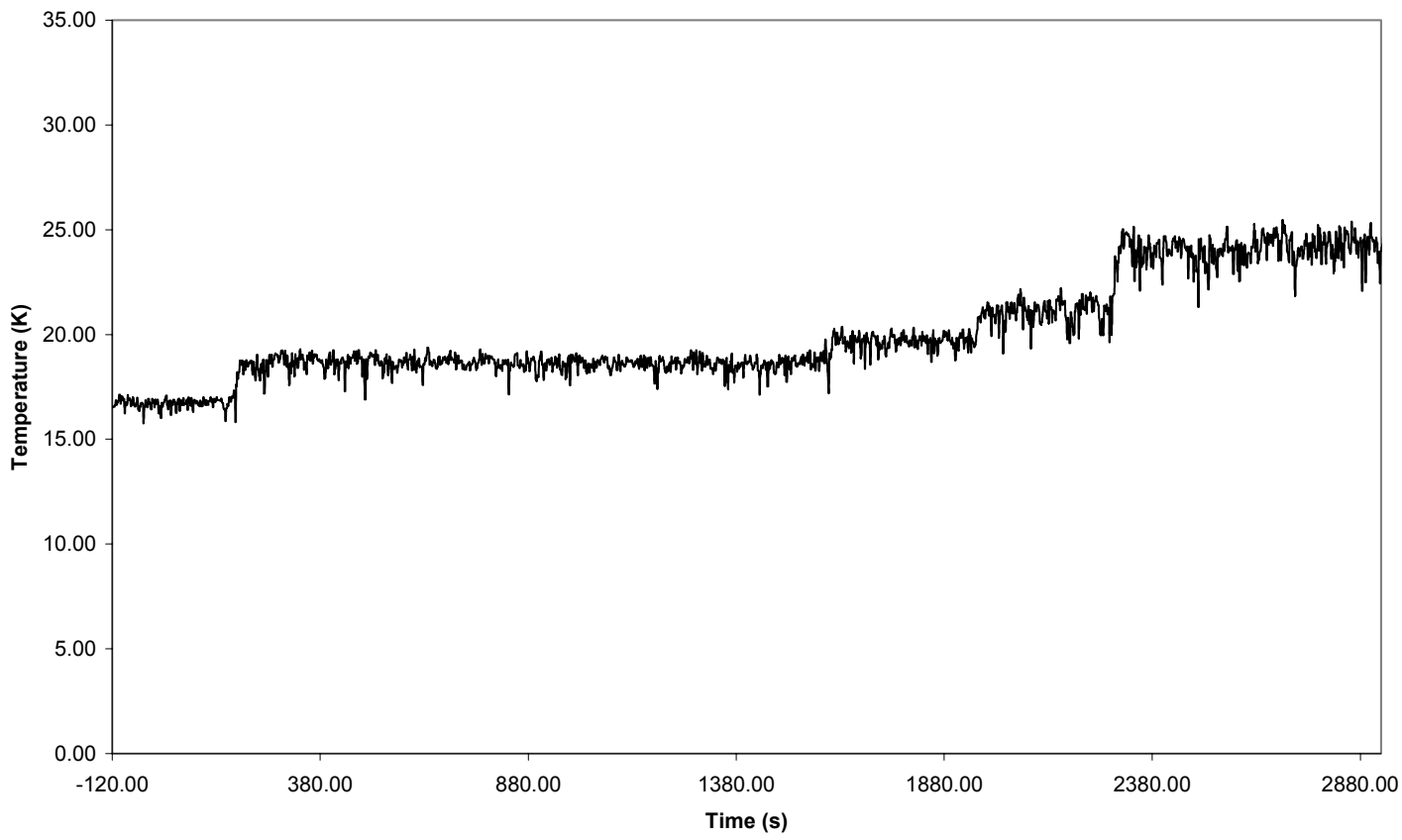

Figure 8-18 Differential Temperatures Across the Core for MASLWR-OSU-002 


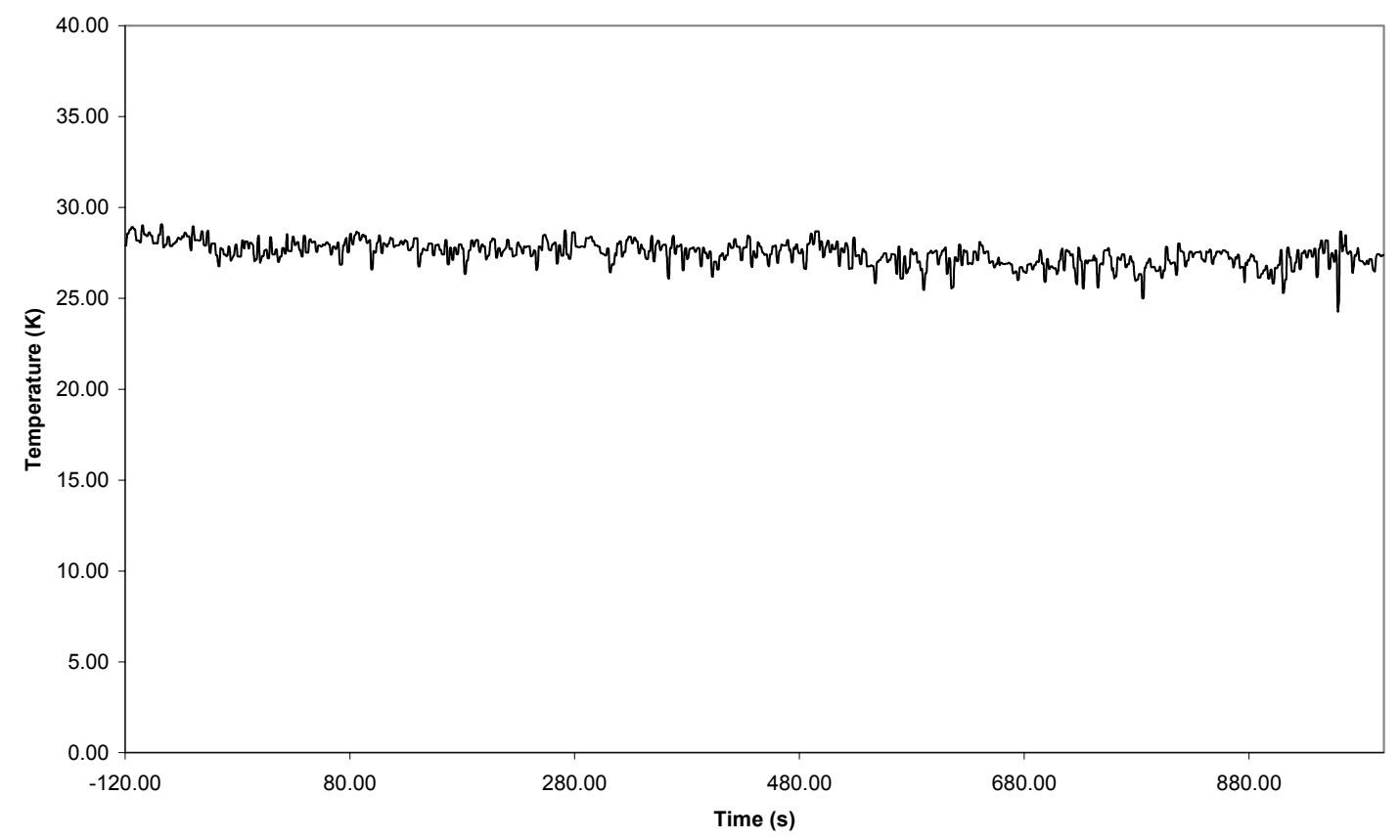

Figure 8-19 Differential Temperature Across the Core for MASLWR-OSU-003A

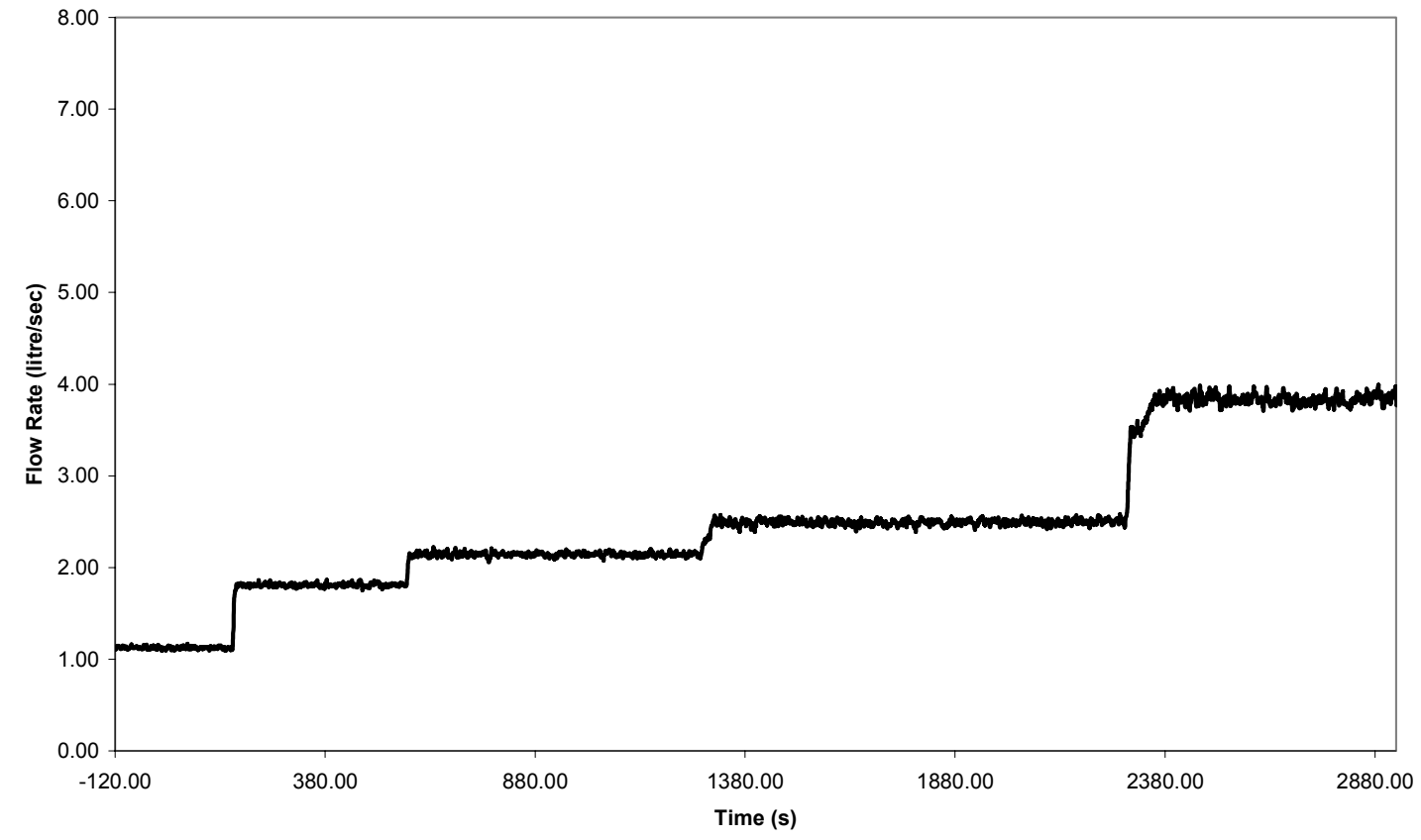

Figure 8-20 Steam Generator FW Flow Rate for MASLWR-OSU-002 


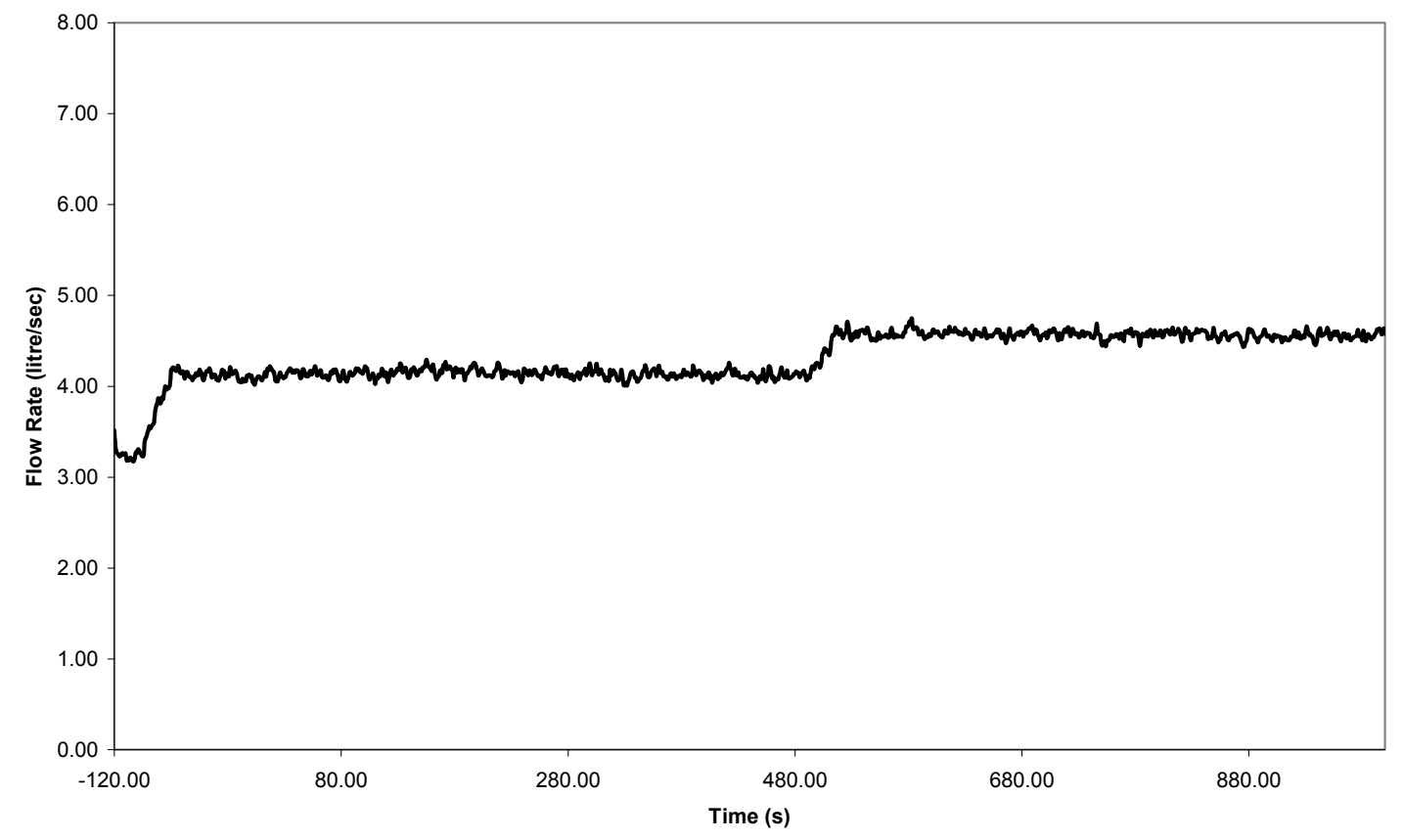

Figure 8-21 Steam Generator FW Flow Rate for MASLWR-OSU-003A

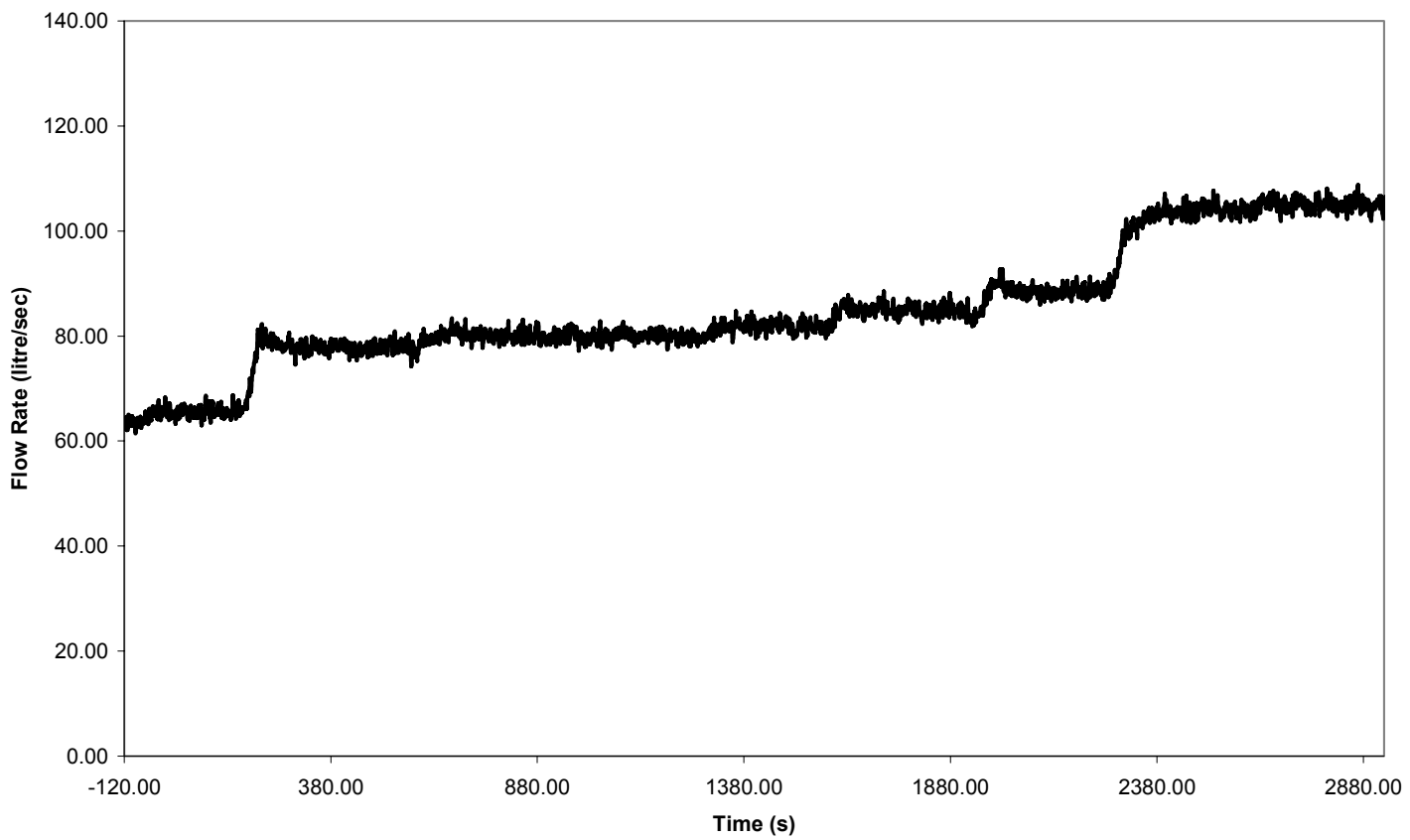

Figure 8-22 Core Volumetric Flow Rate for MASLWR-OSU-002 


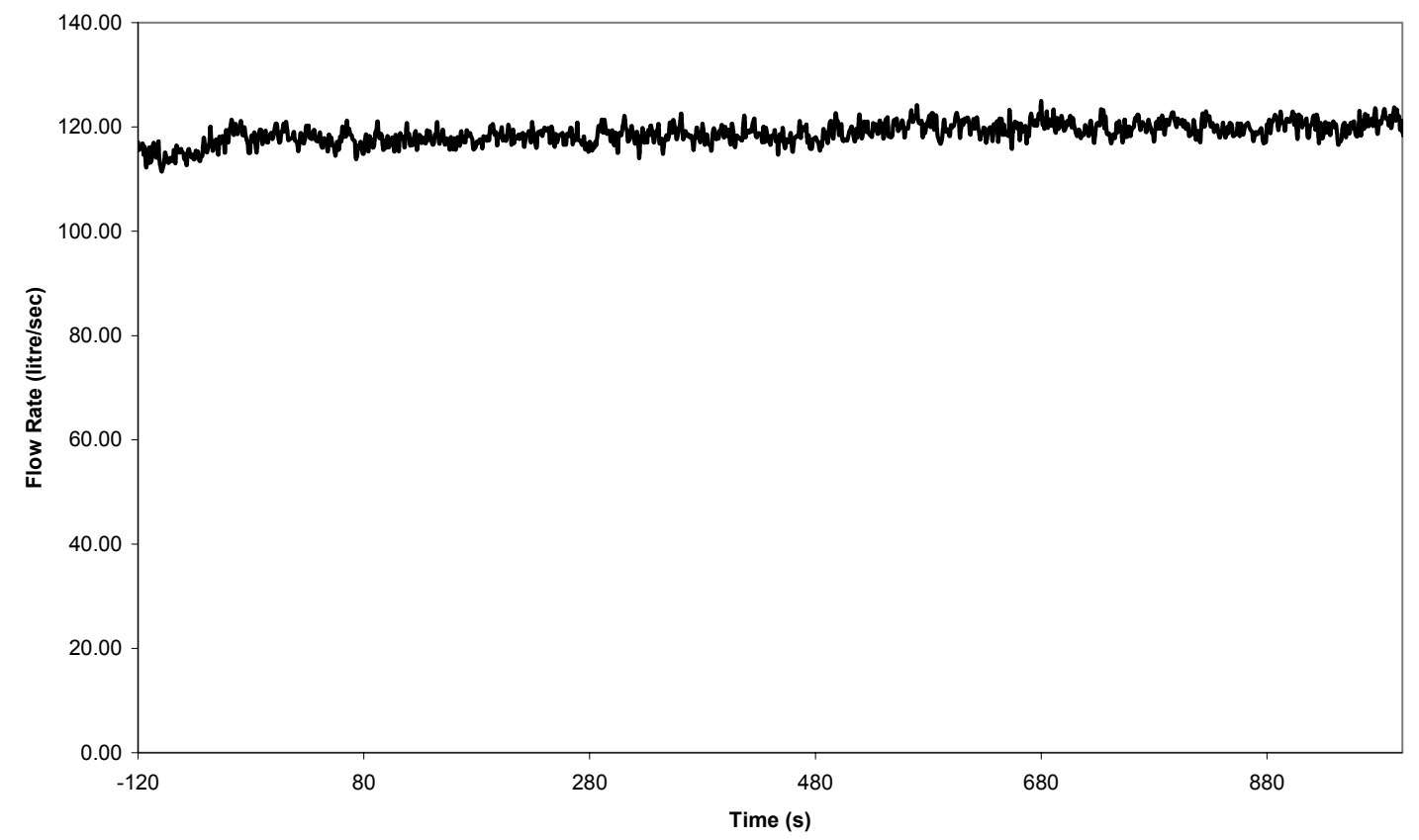

Figure 8-23 Core Volumetric Flow Rate for MASLWR-OSU-003A

\subsubsection{OSU-MASLWR-003B, Inadvertent High Containment ADS Vent Line Actuation}

The objective of this test is to acquire the pressure transient in the containment vessel, for the beyond design accident of the inadvertent high containment ADS actuation. No core power and no pre-heating of the containment non-condensation surface areas are employed.

The reason for this test being a beyond design accident scenario is due to the order of operation of the safety system components compared to the normal sequence. The normal sequence of actuation for the ADS system is:

- $\quad$ The submerged ADS lines

- The high containment ADS lines

- $\quad$ The sump recirculation lines

By operating the valves in this order, the containment pressure is minimized due to the high rate of energy transfer from the primary coolant to the subcooled containment coolant. This high rate of transfer is achieved by vigorous mixing of the fluids and the condensation of any steam produced when the primary coolant flashes in the submerged ADS line.

In contrast, when a high containment ADS line is opened first, the pressure in the two vessels begin to equalize. The choked condition at the ADS flow nozzle limits this equalization process (the nozzle simulates the prototypic ADS valve resistance). The vapor volume of the containment vessel begins to fill with steam, and a quantity of the steam is condensed on the containment walls while transferring energy to the containment pool. It is the relative rates of the steam influx through the ADS flow nozzle versus the condensation rate that will determine the pressurization of the containment vessel. 
The available energy storage in the containment vessel wall is small compared to the total energy transferred to the containment from the reactor vessel during a blowdown transient. Considering that the entire outer surface of the containment vessel is insulated with $0.0762 \mathrm{~m}$ ( 3 inches) of Calcium Silicate, any distortion due to the available energy storage in the containment vessel wall can be considered negligible for the majority of the transient. As part of the test, the containment wall heaters will not be employed to allow the wall to bring itself into equilibrium and provide an adiabatic wall boundary condition on the surfaces designated as non-condensation areas. This introduces a small distortion at the initiation of the transient, but provides a better adiabatic boundary condition once attained. This "better" boundary condition is due to the in-ability to exactly maintain the containment inside vessel wall area at the exact saturation temperature using cycled heaters while the pressure is constantly changing. In addition, another drawback of the containment pre-heat is that some degree of heating of the condensation plate will always occur when pre-heating the containment vessel wall.

The data shows that the outside of the containment vessel wall along the non-condensable surfaces, parallels the saturation temperature inside the containment, see Figure 8-24. After 117 seconds into the transient, all of the outside vessel wall temperatures are within a $5 \%$ difference to the saturation temperature, and remain within this tolerance for the duration of the transient, see Figure 8-25. This supports the original decision to complete the test while allowing the containment walls to self-equalize.

Note: One wall temperature maintains a percent difference between $20-30 \%$. The location of this thermocouple is located below the coolant level, hence matching the mixed temperature of the coolant rather than the steam space.

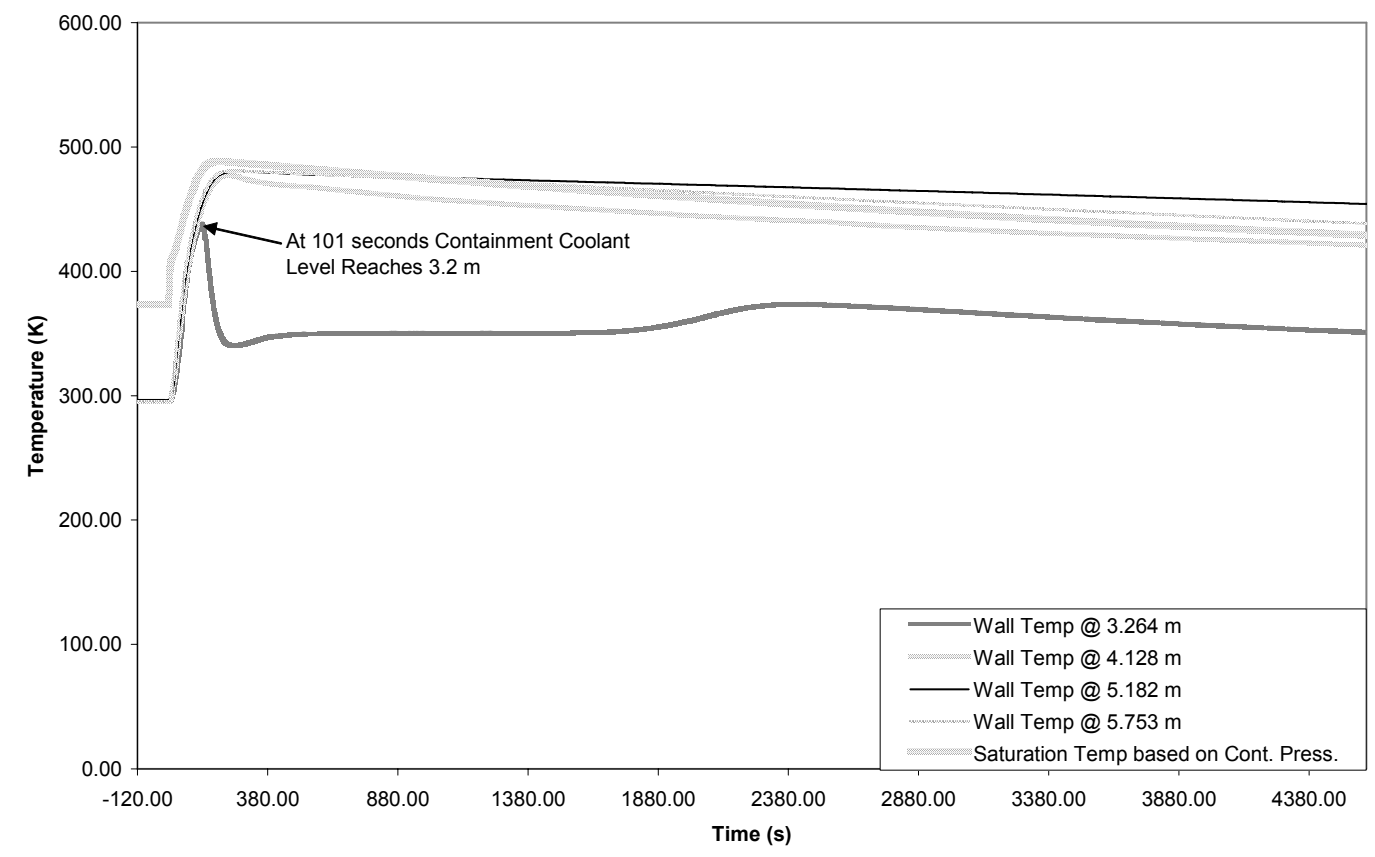

Figure 8-24 Containment "Non-Condensation" Wall Surface Temperatures for MASLWROSU-003B 


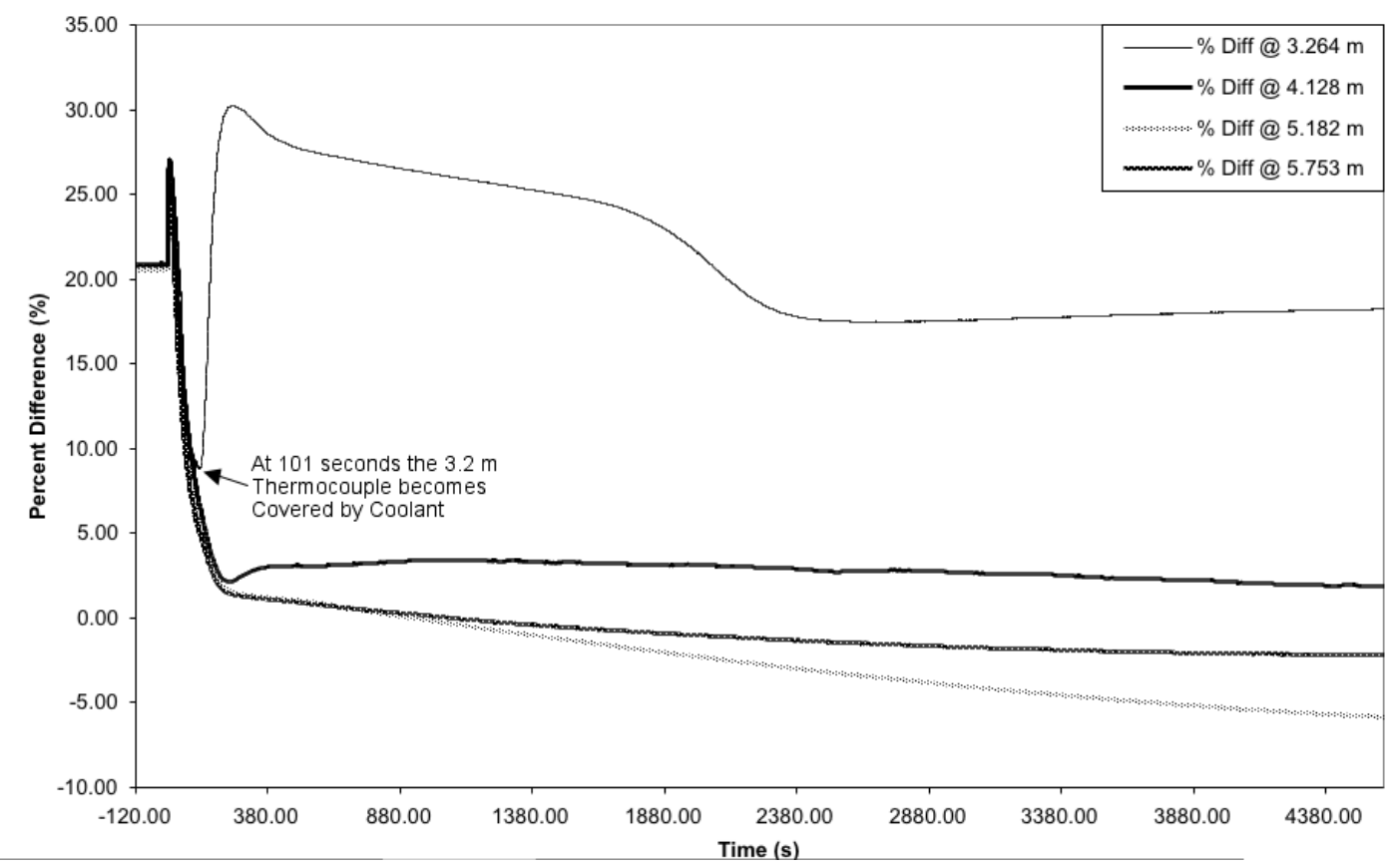

Figure 8-25 Containment "Non-Condensation" Wall Surface Temperatures Percent Difference with Containment Saturation Temperature for MASLWR-OSU-003B

The transient produced a maximum pressure of 21.15 bar at 185 seconds into the transient, see Figure 8-26.

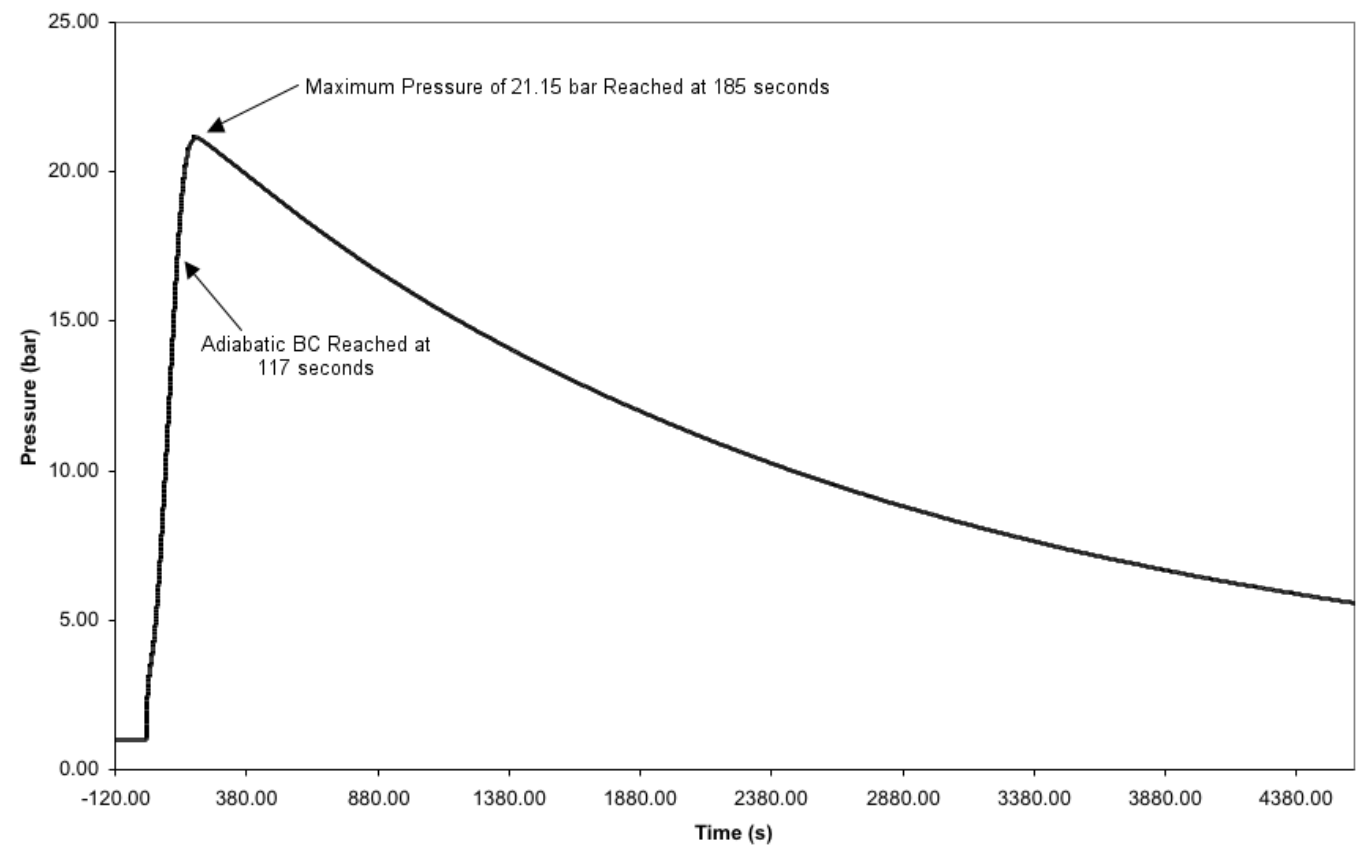

Figure 8-26 Containment Pressure for MASLWR-OSU-003B 
Thermocouples located a few millimeters off of the surface of the condensation plate showed similar trends to the saturation temperature. All of the temperatures quickly matched the saturation temperature, and as the thermocouple level was surpassed by the coolant surface level, the temperature measurements dropped to the liquid temperature, see Figure 8-27. The liquid level in the containment never reached a level greater than $3.77 \mathrm{~m}$ (this maximum was attained at 291 seconds, see Figure 8-28), so only the lower two thermocouples became submerged. The wall fluid temperature at the elevation of $5.61 \mathrm{~m}$ exceeded the saturation temperature at approximately 62 seconds, and elevation $5.11 \mathrm{~m}$ exceeded saturation at approximately 995 seconds. Both of these locations remained above saturation temperature once it was exceeded, see Figure 8-27.

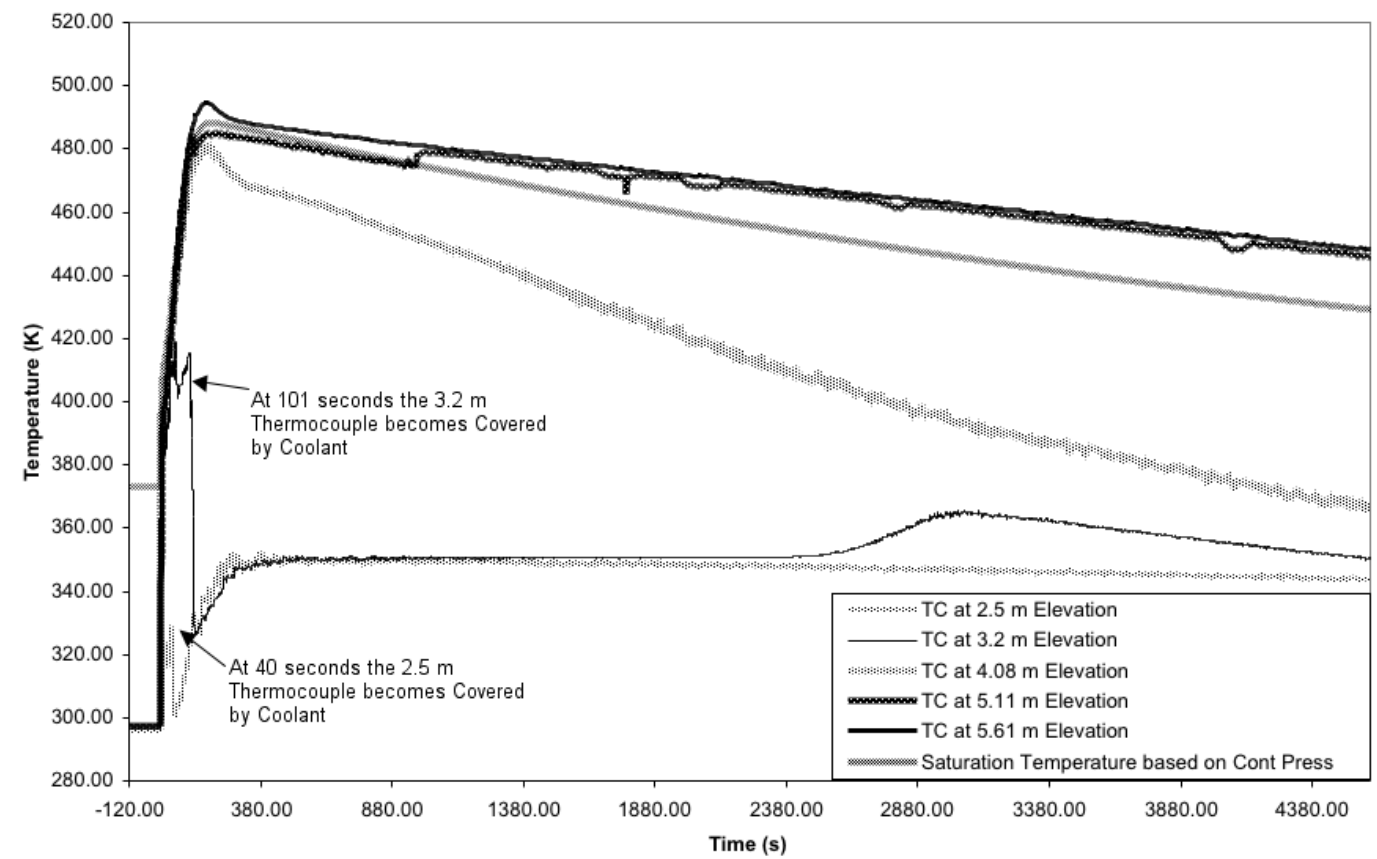

Figure 8-27 Containment Condensation Plate Wall Fluid Temperatures for MASLWROSU-003B 


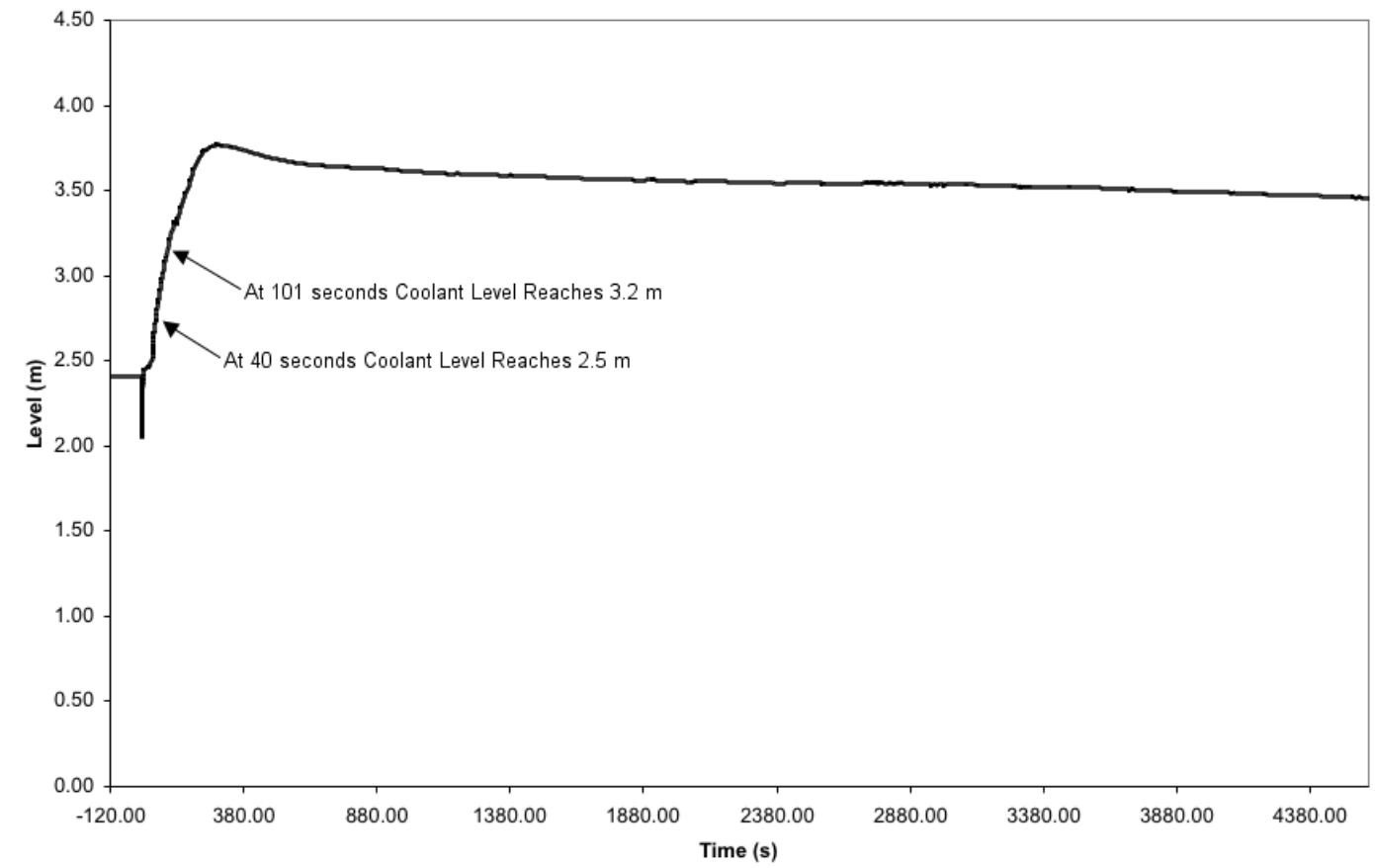

Figure 8-28 Containment Liquid Level for MASLWR-OSU-003B 


\section{Summary, Conclusions and Recommendations}

\subsection{Summary}

The conceptual design for a safe and economic multi-application LWR has been completed. The development of the MASLWR design described in this report has progressed sufficiently to conclude that the concept is very attractive from the standpoint of simplicity and economics. The more significant features of the baseline design concept developed include:

- Overall Plant

- Net Electrical Output

$1050 \mathrm{MWe}$

- Net Station Efficiency 23\%

- Number of Power Units 30

- Nominal Plant Capacity Factor $\quad 95 \%$

- Life-cycle

- Power Generation Unit

- Number of Reactors One

- Net Electrical Output $35 \mathrm{MWe}$

- Steam Generator Number One

- Steam Generator Type Vertical, once-through, helical tube,

- Reactor Core

- Thermal Power

$150 \mathrm{MWt}$

- Fuel

$\mathrm{UO} 2,8 \%$ enriched

- Refueling Intervals 5 years

- Estimated Cost

- Total Capital Cost

$\$ 1241 / \mathrm{kWe}$

- Total Busbar Cost

3.4 cents $/ \mathrm{kWh}$

\subsection{Conclusions}

The MASLWR conceptual design is simple, safe, and economical. The major aspects and features of the concept that makes it attractive are as follows:

- The NSSS is a self-contained assembly of reactor core and steam generator tube bundles within a single pressure vessel. The primary coolant is moved by natural circulation.

- The NSSS and all safety related systems and auxiliaries are contained in a compact steel containment, $4.3 \mathrm{~m}(14 \mathrm{ft})$ in diameter and $18 \mathrm{~m}(60 \mathrm{ft})$ long that can be easily transported by rail or truck.

- The reactor module, consisting of the containment and its contents, can be entirely factory fabricated. The factory can be completely automated using existing state-of-the-art manufacturing equipment. Construction can be done on a significantly reduced schedule.

- Compared to a typical PWR plant, the NSSS parameters are much lower. The thermal rating of the reactor is several times smaller, the coolant pressure is about 50\% lower, and the steam pressure is less than $25 \%$ of that of a typical PWR.

- The power generation system is much simplified. The turbine consists of a single stage (low pressure section only). There are no feedwater heaters, no moisture separators or reheaters, and the condensate/feedwater pump is a single stage. The entire turbine-generator is replaced with a spare unit for overhaul. 
- Refueling and maintenance is conducted by first replacing the entire module with a spare unit. The module is then transferred to the on-site refueling and maintenance facility, or a centralized location that incorporates a high level of proliferation resistance. The small module size allows automated refueling and maintenance activities, thereby eliminating the threat of diversion. While outside of the refueling and maintenance facility, the nuclear fuel is always inside a bottled-up containment.

- The safety of the plant is enhanced because of the simpler design, and the lower operating parameters and thermal rating.

- The current estimate of busbar cost is about 3.4 cents $/ \mathrm{kWh}$, and is therefore very competitive. The goal originally set was 4 cents/kWh.

- Design certification based on testing is economically feasible. A full-scale prototype plant using a full size reactor module and steam generator can be built for less than $\$ 100$ million, and a reduced scale integral test facility already exists for safety system assessment and design refinement.

- A reduced scale testing facility has provided proof of the proposed safety system design and operation.

The overall conclusion is that while the power generation concept has a much lower overall power generation efficiency ( $23 \%$ versus $30 \%$ ), the reduction in capital cost due to simplification of design more than makes up for the increased cost of nuclear fuel.

The baseline design concept complies with the safety requirements and criteria. It also satisfies the goals for modularity, standard plant design, certification before construction, construction schedule, refueling schedule, operation and maintenance, long plant life-cycle, and economics.

Use of small thermal capacity reactors, such as the MASLWR reactor with a capacity of $150 \mathrm{MWt}$, presents many advantages when compared to large reactors used in current nuclear power plants. They can be summarized, as follows:

- Simplicity of design, modularity, and automated factory fabrication makes a small reactor concept very competitive with other power generation concepts; and a busbar cost of less than 4 cents $/ \mathrm{kWh}$ is very realistic.

- Financial risks are significantly reduced because less capital is initially committed and revenues from sales of electricity are generated earlier. Also, unplanned shutdown of a reactor only affects a relatively small portion of the total plant capacity.

- Because the reactor is so simple and the design parameters much lower, the probability of a major accident is much more remote.

- Although very improbable, should an accident occur the environmental impact would be much less significant because of the low reactor power level and lower design parameters.

- MASLWR can be fabricated as a complete single module and the entire module can be easily transported on most roads and railways.

- Because of the design simplicity and novel approach to refueling and maintenance, a high degree of reliability/availability can be achieved.

- A small and simple design is very suitable for fully automated operation, both for normal and accident conditions including shutdown. This prevents operator errors. As a result, the main control room role is simplified and is limited to initiating reactor startup, reactor shutdown, and monitoring.

- A plant consisting of small reactors configured into independent power units allows for operation of power units at full load all the time. Operational transients are limited to startup and shutdown.

- The plant can be built in small increments to match the demand.

- A full-scale prototype facility can be built at a relatively low cost when compared to large reactors. This simplifies the development of a standard certified design based on testing. 
- The concept lies within the existing capabilities and experience of the industry, therefore it is possible that the concept could be deployed within 8 to 10 years.

\subsection{Recommendations}

Based on the attractiveness of the concept, as described in this report, it is recommended that the project moves to the next phase of development i.e. preliminary design. In parallel with the baseline design consisting of multi-modules, a design of a single module plant should be pursued. The single module plant is not only suitable for remote locations and developing countries, it will also provide the basis for the prototype plant to be tested in support of obtaining design certification and commercial plant deployment. 